\title{
Differences in learning styles and satisfaction between traditional face-to-face and online web-based sport management studies students
}

\author{
Ellen Jo West \\ West Virginia University
}

Follow this and additional works at: https://researchrepository.wvu.edu/etd

\section{Recommended Citation}

West, Ellen Jo, "Differences in learning styles and satisfaction between traditional face-to-face and online web-based sport management studies students" (2010). Graduate Theses, Dissertations, and Problem Reports. 2960.

https://researchrepository.wvu.edu/etd/2960

This Dissertation is protected by copyright and/or related rights. It has been brought to you by the The Research Repository @ WVU with permission from the rights-holder(s). You are free to use this Dissertation in any way that is permitted by the copyright and related rights legislation that applies to your use. For other uses you must obtain permission from the rights-holder(s) directly, unless additional rights are indicated by a Creative Commons license in the record and/ or on the work itself. This Dissertation has been accepted for inclusion in WVU Graduate Theses, Dissertations, and Problem Reports collection by an authorized administrator of The Research Repository @ WVU.

For more information, please contact researchrepository@mail.wvu.edu. 
Differences in Learning Styles and Satisfaction between Traditional Face-to-Face and Online Web-Based Sport Management Studies Students

Ellen Jo West

\author{
Dissertation submitted to the \\ College of Human Resources and Education \\ at West Virginia University \\ in partial fulfillment of the requirements \\ for the degree of \\ Doctor of Education \\ in \\ Education Leadership Studies
}

\author{
Elizabeth A. Jones, Ph.D., Chair \\ Ernest R. Goeres, Ph.D. \\ Richard T. Walls, Ph.D. \\ Susan L. Aloi, Ed.D. \\ Bruce D. Barnhart, Ed.D. \\ Department of Advanced Educational Studies
}

Morgantown, West Virginia

2010

Keywords: learning styles, Kolb LSI, distance education, online Copyright 2010 Ellen Jo West 


\begin{abstract}
Differences in Learning Styles and Satisfaction between Traditional Face-to-face and Online Web-based Sport Management Studies Students
\end{abstract}

\title{
Ellen Jo West
}

Each student has a unique learning style or individual way of perceiving, interacting, and responding to a learning environment. The purpose of this study was to identify and compare the prevalence of learning styles among undergraduate Sport Management Studies (SMS) students at California University of Pennsylvania ( $\mathrm{Cal} \mathrm{U}$ ). Learning style prevalence was determined for traditional face-to-face students and online web-based students and differences in learning style prevalence between these two groups were explored. Finally, differences in student satisfaction between program delivery methods were examined by using an online questionnaire designed by the researcher.

The population for this study included $247 \mathrm{Cal}$ U undergraduate SMS students enrolled in the fall 2009 semester. Through an online survey 101 face-to-face students and 146 on-line students were identified into one of four learning style groups (Accommodators, Divergers, Assimilators, and Convergers) utilizing Kolb's Learning Style Inventory 3.1 (2005).

The data from the study were analyzed and yielded a trend toward significance for learning style preference by delivery method. The comparison of the four learning styles for the face-to-face participants indicated a statistically significant difference. The comparison of the four learning styles for the on-line participants indicated a statistically significant difference. The follow-up analysis consisted of comparison of each of the four learning styles separately by delivery method (face-to-face and on-line) yielded no statistical significant difference.

Four satisfaction questions were found to have statistical significance in ratings between face-to-face and on-line students. On-line respondents were significantly more satisfied with the challenge and demand of Sport Management Studies courses, significantly more satisfied with the Sport Management Studies major setting high expectations for student performance, significantly more satisfied with the program finding connections between what students are learning in the classroom, relating it to their past experiences, and applying it to their daily lives, and significantly more satisfied with the quality of their academic experience within the program when compared to the face-to-face respondents.

The results of this study can help educators and academic administrators better understand the needs of their students and better develop or structure teaching methods in both on-campus and web-based instruction. Colleges and universities will need to implement changes to meet the advancement of the technological revolution at hand. As educators (virtual and live) are faced with an increasingly diverse population of learners with a wide range of expectations, there is a need to continually seek to understand what factors constitute excellent delivery to promote effective learning. By recognizing different learning styles, educators may better engage students, work in conjunction with their universities to meet demands of the growing distance education and on-line learning populations, increase levels of student satisfaction, ensure a greater program "fit" with students, individualize and capitalize learning opportunities in the classroom, and seek to employ different pedagogical approaches to better facilitate learning. 
Learning Styles Traditional and Online iii

\section{Acknowledgements}

I would like to thank my chair and advisor, Dr. Elizabeth Jones, for her guidance and support during my entire program of study. In addition, I would like to express appreciation to my committee members. Thank you, Dr. Ernest Goeres, for always making time for students and offering encouragement. To Dr. Richard Walls, thank you for your willingness to always help, especially over the rough statistical spots. To Dr. Susan Aloi, the grammar queen, thank you for always setting a wonderful classroom example. Thank you Dr. Bruce Barnhart. You have inspired me to be the athletic trainer and educator that I am today. My committee was outstanding and I am grateful for your guidance, support, and advice. Thank you to my fellow cohort members who always offered words of encouragement and some great laughs along the way. I am proud to have new members in my WVU family.

This dissertation is dedicated to my family whose love and support has made it possible. First, I want to thank my parents, Arlene and Joe, who have been incredible role models and have always believed in me - this graduation is for you. Second, to my husband and best friend, Tom, thank you for your never-ending love and support throughout these many years. I truly could not have accomplished this without your help. And finally, this is dedicated to my three children, Tucker, Sam, and Grace, the lights of my life and true reasons behind everything I do. Someday I hope you all realize that everything I do is for you. I am truly blessed to have such a wonderful, loving family. 


\section{Table of Contents}

Chapter One: Introduction and Problem Statement .......................................... 1

Introduction and Problem Statement ............................................................ 1

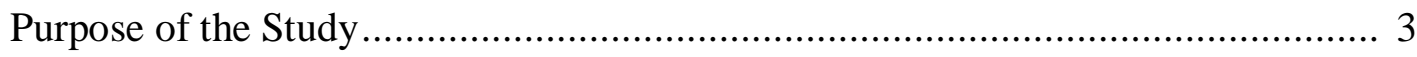

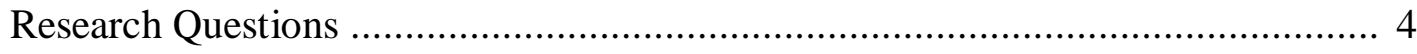

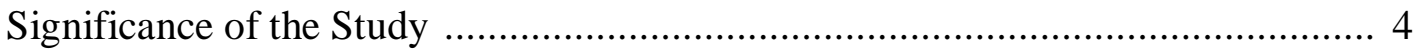

Chapter Two: Review of the Literature........................................................... 7

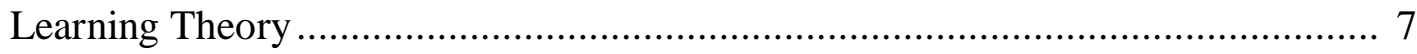

A paradigm shift in education ....................................................... 7

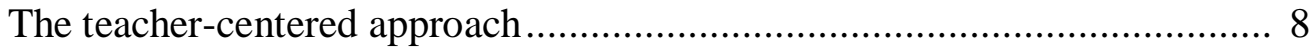

The learner-centered approach ................................................ 12

Synthesis of Chickering and Gamson's seven principles ....................... 16

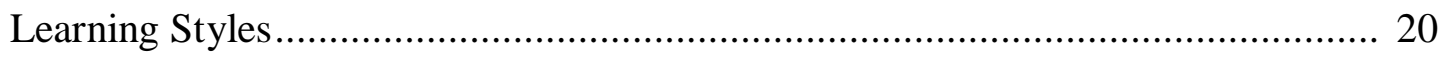

Learning Styles Defined ....................................................... 22

Relevant Learning Style Models and Inventories.................................... 25

Canfield Learning Style Inventory (CLSI) .............................. 26

Dunn and Dunn model and learning style inventories ................... 27

Grasha-Riechmann Student Learning Styles Scales (GRSLSS)......... 28

Gregorc Mind Styles Delineator (MSD) ................................. 29

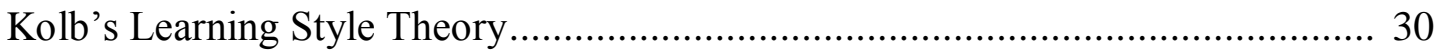

David Kolb: Experiential Learning Theory basis ............................... 30

Experiential Learning Model......................................................... 32 


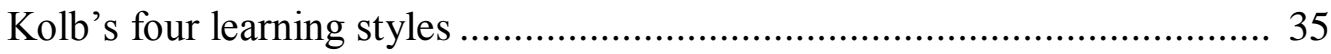

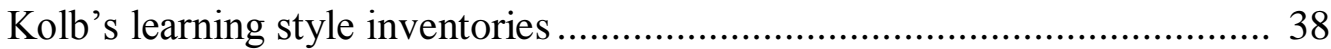

Previous Studies of Learning Styles in Traditional and Online Learning

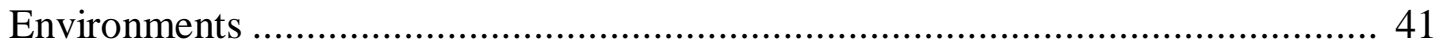

Distance Education v. Traditional Learning Environments..................................... 50

Distance education's development and definition ........................................ 50

Rationale for using distance education .................................................... 53

Various types of distance education ........................................................... 57

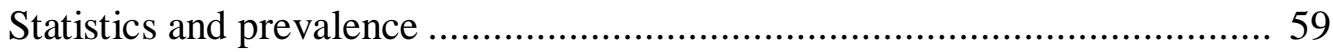

Impact and changes necessary in higher education ..................................... 61

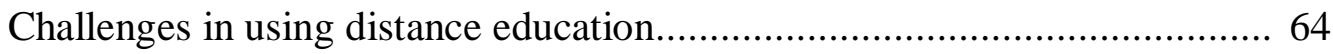

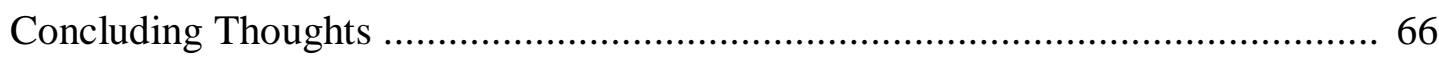

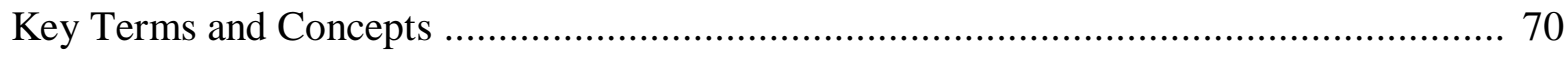

Chapter Three: Research Design and Methods ......................................................... 71

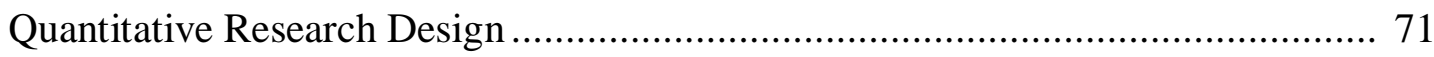

Questionnaire/Survey Research ....................................................................... 72

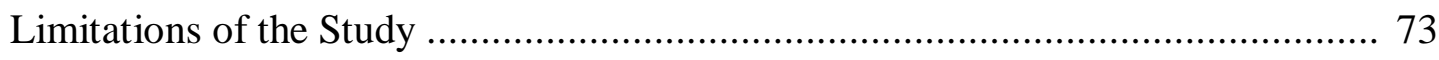

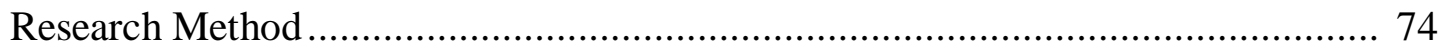

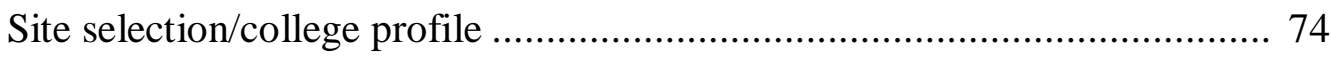

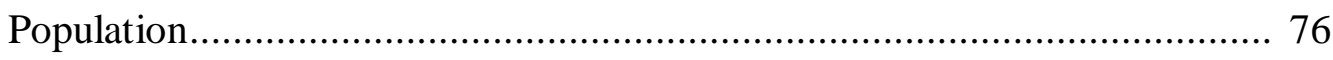

Strategy for attaining institutional and participant cooperation .................... 78

Data collection procedures/instrument.................................................... 80

Data coding and analysis of data ............................................................ 85 
Pilot study ........................................................................... 90

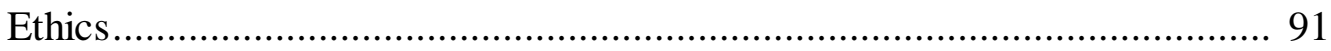

Researcher's Background ....................................................... 92

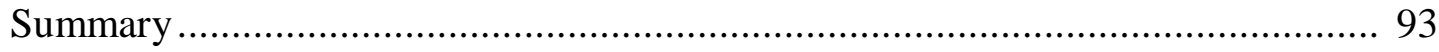

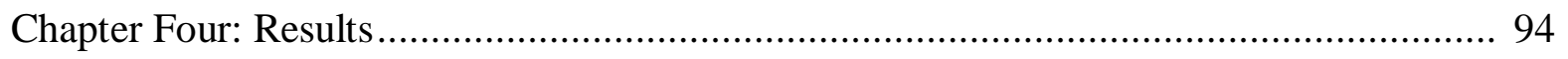

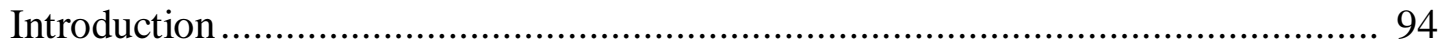

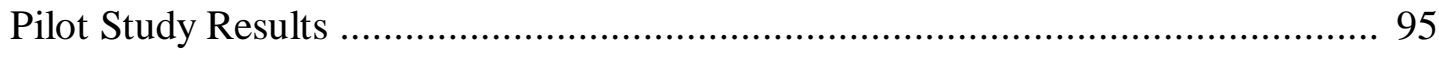

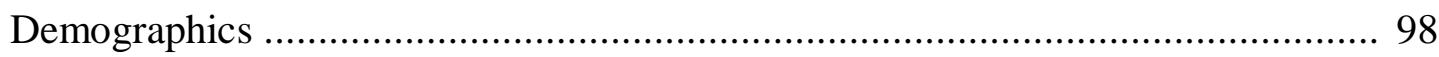

Prevalence of Learning Styles in Face-to-Face and On-Line Participants .............. 102

Differences in Learning Style Preference between Delivery Methods ................. 104

Differences in Student Satisfaction by Delivery Method ................................ 106

Summary of Key Findings ................................................................. 109

Chapter Five: Conclusion and Implications .................................................. 112

Introduction ................................................................................. 112

Findings Related to Literature................................................................ 113

Demographic implications .................................................... 113

Learning styles of face-to-face learners ........................................... 115

Learning styles of on-line learners............................................ 117

Comparing learning styles ...................................................... 120

Satisfaction with face-to-face and on-line programs ............................. 124

Recommendations for Practice............................................................ 127

Recommendations for Future Research ............................................... 142

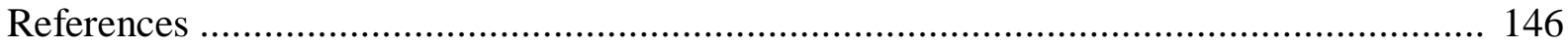


Appendix A: Demographic Questions.................................................... 163

Appendix B: Satisfaction Questions .................................................... 164

Appendix C: Letter to Request Institutional Site Approval ............................. 165

Appendix D: Letter from Institution Granting Permission for Pilot and Research .. 167

Appendix E: Pilot Invitation Letter.................................................... 168

Appendix F: Cover Letter for Program Directors Participating in Study .............. 169

Appendix G: Student Participation Letter ............................................ 170

Appendix H: Approval for LSI Use ................................................. 172

Appendix I: Cover Letter for SurveyMonkey …..................................... 173 


\section{List of Tables}

Table 1 California University of Pennsylvania - Carnegie Classification ....................... 75

Table 2 Sport Management Studies Learning Style Inventory - Page 3: KLSI-3.1 .......... 83

Table 3 Sport Management Studies Learning Style Inventory - Student Satisfaction ........ 85

Table 4 Learning Style Inventory Cal U SMS Survey Item Techniques .......................... 89

Table 5 Cal U Sport Management Studies Undergraduate Student Population and

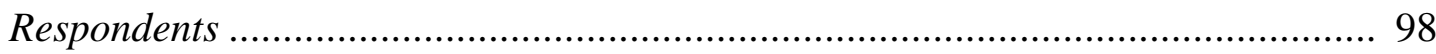

Table 6 Participating Students by Gender ............................................................ 99

Table 7 Participating Students by Age Group ........................................................ 99

Table 8 Participating Students by Residence Status ................................................ 100

Table 9 Ethnic Affiliation by Participant Delivery Method ........................................ 101

Table 10 Number of Respondents by Student Status .............................................. 102

Table 11 Number of Respondents by Academic Status ............................................ 102

Table 12 Learning Style Preference by Delivery Method ............................................. 103

Table 13 Pearson Chi Square for Learning Style Preference by Delivery Method ............ 104

Table 14 Pearson Chi Square for Learning Style Preference for Each Delivery Method ... 105

Table 15 Pearson Chi Square for Each Learning Style Preference .............................. 106

Table 16 Student's t-Test for Mean Satisfaction Score between Delivery Method ............ 107

Table 17 Means and Standard Deviations for Each Dependent Variable by Delivery

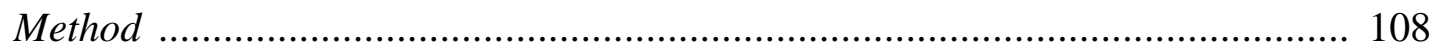


Learning Styles Traditional and Online 1

\section{Chapter One: Introduction and Problem Statement}

\section{Introduction}

American higher education is experiencing a paradigm shift. Traditionally, colleges and universities have been governed by the notion that they exist to provide instruction. The new paradigm advocates institutions of higher education exist to produce learning (Barr \& Tagg, 1995). It becomes a system of looking at learning as a process, not just a product. This noted paradigm shift has moved education from the teacher-centered model (otherwise, didactic, where teachers have the information and students receive) to a more learner-centered approach (teachers become guides rather than dispensers of knowledge, and instructional practice places more importance on the role of the student in constructing knowledge). Ackoff and Greenberg (2008) consider today's education system seriously flawed because of its focus on teaching rather than learning. As Barr and Tagg (1995) stated, "this shift changes everything. It is both needed and wanted" (p. 13).

According to Herrington and Standen (2000) regarding the "substantial" theoretical shift, "little credence is now given to learning theories that propose that learning is no more than the transmission of a body of knowledge from teacher to student" (p. 195). The shift is described by Barr and Tagg (1995) as moving from what the current theory-in-use is to what the espoused theory of most educators resembles. Tyler (1986) discusses the paradigm shift as one of the five most significant curriculum events in the twentieth century.

The growth of distance education courses via the Internet prompted educational research focused on learners' characteristics and learning differences during the past twenty years (Hills, 2003; Khan, 2005). Approaches to learning emphasized the importance of taking learners into consideration when designing instruction. Learners' characteristics have always been an 
important concern for educators, designers, and researchers (Khan, 2005; Laurillard, 2001; Moore \& Kearsley, 2005; Schwitzer, Ancis, \& Brown, 2001). Knowledge of learners’ characteristics is important when deciding on the type of media by which the content will be delivered and the structure of courses by which diverse students will be accommodated (Khan, 2005; Laulliard, 2001).

Distance education and web-based courses are mainstream in colleges and universities in the United States and growing (U.S. Department of Education, 2008). Sixty-six percent of the 4,160 2-year and 4-year Title IV degree granting postsecondary institutions in the nation offered college-level distance education course in the 2006-07 academic year. Overall, 97 percent of public 2-year institutions, 18 percent of private for-profit 2-year institutions, 89 percent of public 4-year institutions, 53 percent of private not-for-profit institutions, and 70 percent of private forprofit 4-year institutions offered distance education courses. Sixty-five percent of the institutions reported college-level credit-granting distance education courses while 23 percent reported noncredit distance education courses. In 2006-07, enrollments or registrations in college-level credit-granting distance education courses totaled an estimated 12.2 million (77 percent reported as online courses, 12 percent reported as hybrid/blended online courses, and 10 percent reported in other types of distance education courses). During this 2006-07 academic year, approximately 11,200 academic leaders designed college level programs to be completed totally through distance education (66 percent as degree programs and 34 percent as certificate programs) (U.S. Department of Education, 2008).

The 2007 Distance Education Survey concluded the distance education market outlook is "strong," and will continue to "be heavily utilized" and "grow for many years" (Distance Education and Training Council, 2007, p. 7). Additionally, as public acceptance of distance 
education is increasing and competition in distance education is growing, higher education will be turning to distance education as a mainstream delivery medium. This may encourage diversity of students and an expansion to more and various markets (Distance Education and Training Council, 2007). Beldarrain (2006) speculated student interaction will be "at the heart of learner-centered constructivist environments" (p. 139) as pedagogical perspectives and theoretical frameworks shift to accommodate current trends in distance education.

Current research focuses on learners' achievement and course evaluations as related to online learning (Moore \& Kearsley, 2005; Khan, 2005), but there is not much attention paid to the effects of online instruction on learners' psychological characteristics such as learning styles. Researchers believe that learning style is a good predictor of an individual's preferred learning behavior (Bostrom, Olfman, \& Sein, 1993).

The educational shift to the student-centered approach has led researchers to explore learning styles in greater depth in both traditional face-to-face and online web-based classroom settings. As people learn and process information in many different ways, it has long been supported by educators that individual differences play an important role in learning and instruction (Moallem, 2007). As unique as every student is, so are the learning styles and techniques they prefer. Educational researchers suggest there is a need to understand the distance learning student population (Vafa, 2004) and comparisons of variables which might impact distance learning effectiveness such as learning styles (Zhang, 2005). Diaz and Cartnal (1999) emphasized that very little research examines distance learning and learning styles.

\section{Purpose of the Study}

The purpose of this study is to identify and compare the prevalence of learning styles among undergraduate Sport Management Studies (SMS) students at California University of 
Pennsylvania (Cal U). Learning styles will be assessed utilizing Kolb’s Learning Style

Inventory, $3^{\text {rd }}$ Edition (LSI-3.1). Learning style prevalence will be determined for traditional face-to-face students and online web-based students. Differences in learning style prevalence between these two groups will be explored. Finally, differences in student satisfaction between program delivery methods will be examined by using an online questionnaire designed by the researcher.

\section{Research Questions}

This study will address the following questions:

1. What is the prevalence of the Diverging, Assimilating, Converging, and Accommodating learning styles of the traditional face-to-face Sport Management Studies undergraduate student based on the Kolb's Learning Style Inventory, $3^{\text {rd }}$ Edition (LSI-3.1)?

2. What is the prevalence of the Diverging, Assimilating, Converging, and Accommodating learning styles of the online web-based Sport Management Studies undergraduate student based on the Kolb's Learning Style Inventory, $3^{\text {rd }}$ Edition (LSI-3.1)?

3. Is there a statistically significant difference in prevalence of learning styles between the traditional face-to-face Sport Management Studies undergraduate students and the online web-based Sport Management Studies undergraduate students?

4. Is there a statistically significant difference in satisfaction between the traditional face-toface Sport Management Studies undergraduate students and the online web-based Sport Management Studies undergraduate students?

\section{Significance of the Study}

Learning style preferences play a role in student success in distance learning and in the educational process in general (Diaz \& Bontenbal, 2001). Learning styles can be used to create 
awareness and identify differences in how students take in and process information and can also help balance instruction. A research study revealed that students with different learning styles learned better in certain teaching environments than in others (Diaz \& Cartnal, 1999). The awareness gained by instructors of their students' learning styles could assist in choosing appropriate delivery methods.

The results of this study can help academic administrators better understand the needs of their students and better develop or structure teaching methods in both on-campus and webbased instruction. Colleges and universities will need to implement changes to meet the advancement of the technological revolution at hand. By recognizing differing student learning styles, faculty may seek to employ different pedagogical approaches. As educators (virtual and live) are faced with an increasingly diverse population of learners with a wide range of expectations, there is a need to continually seek to understand what factors constitute excellent delivery to promote effective learning. Faculty may not always utilize the best delivery method attuned to students' differing learning styles. By understanding different students' learning styles, faculty may seek to employ different pedagogical approaches to better facilitate learning.

In this chapter, the problem statement, key research questions, and purpose of the study were presented. In order to effectively address the above four research questions, the researcher first conducted a thorough literature review. In Chapter Two, a review of the literature is presented. The researcher examined learning theory and the paradigm shift in education from the teacher-centered approach to the learner-centered approach. Additionally, a synthesis of Chickering and Gamson's seven principles is included. Learning styles were examined including relevant models and inventories. Kolb's learning theory, model, four learning styles, and instrument are discussed in depth as the focus of this study. Previous studies of learning 
styles in the traditional and online learning environment are presented. Distance education and traditional learning environments are discussed including distance education development and definition, rationale for using distance education, various types of distance education, statistics and prevalence, impact and changes necessary in higher education, challenges in using distance education, and concluding thoughts. Finally in Chapter Two, key terms and concepts are presented. In Chapter Three, information pertaining to the research design, questionnaire/survey research, limitations of the study, research method, site selection/college profile, population, strategy for attaining institutional approval and participant cooperation, data collection procedures, and analysis is contained. In addition, an overview of the pilot study, ethics, and researcher's background are included. Chapter Four presents pilot study results and results related to the research study in the areas of prevalence of learning styles in face-to-face and online participants, differences in learning style preference between delivery methods, and differences in student satisfaction by delivery method. Additionally, demographic findings are presented. Chapter Five includes findings related to the literature, recommendations for practice, and recommendations for future research. 
Learning Styles Traditional and Online 7

\section{Chapter Two: Review of Literature}

\section{Learning Theory}

\section{A paradigm shift in education.}

American higher education is experiencing a paradigm shift. Traditionally, colleges and universities have been governed by the notion that they exist to provide instruction. Traditional education focuses on the ideal that education focuses on teaching, not learning (Ackoff \& Greenberg, 2008). The new paradigm advocates institutions of higher education exist to produce learning (Barr \& Tagg, 1995). It becomes a system of looking at learning as a process, not just a product. This noted paradigm shift has moved education from the teacher-centered model (otherwise, didactic, where teachers have the information and students receive) to a more learner-centered approach (teachers become guides rather than dispensers of knowledge, and instructional practice places more importance on the role of the student in constructing knowledge). Ackoff and Greenberg (2008) consider today's education system seriously flawed because of its focus on teaching rather than learning. As Barr and Tagg (1995) stated, "this shift changes everything. It is both needed and wanted" (p. 13).

According to Herrington and Standen (2000) regarding the "substantial" theoretical shift, "little credence is now given to learning theories that propose that learning is no more than the transmission of a body of knowledge from teacher to student" (p. 195). The shift is described by Barr and Tagg (1995) as moving from what the current theory-in-use is to what the espoused theory of most educators resembles. Tyler, (1986) discusses the paradigm shift as one of the five most significant curriculum events in the twentieth century.

Change is not instantaneous and is a process of gradual modification and experimentation. Barr and Tagg (1995) state, "changing paradigms is hard" (p. 24) and 
"paradigms change when the ruling paradigm loses its capacity to solve problems and generate a positive vision of the future" (p. 25). These authors suggested three ways to move to a new paradigm. The first recommendation is for educators to communicate the importance of producing quality learning and refer to the university's learning programs instead of speaking of quality of instruction and the instructional program. Second, higher education needs to focus on learning outcomes beginning in the conventional classroom and encompassing the program and institutional levels. Third, mechanisms that fund institutions based on hours of instruction should be addressed. To change funding formulas for institutions of higher education to give latitude and incentives to develop new structures for learning would greatly impact the progression of a new student-centered learning paradigm (Barr \& Tagg, 1995).

\section{The teacher-centered approach.}

The traditional model of learning has been described as the teacher-centered, instruction, or instructivist paradigm (Barr \& Tagg, 1995; Diaz, 2000; Diaz \& Bontenbal, 2000; Duffy \& Jonassen, 1991). Regarding a teacher-centered environment, Haycock (2003) stated "Teachers tend to follow the waves rather than charter courses" (p. 14) and covering material usually takes precedence. Barr and Tagg (1995) have noted that this paradigm relies on "conceptions of teaching that are increasingly recognized as ineffective" (p. 13). Guskin (1994) described the model as "contrary to almost every principle of optimal settings for student learning" (p. 20) whereby the format is fairly passive lecture-discussion having faculty mostly talking and students mostly listening. Brown (2003) stated, "the teacher-centered approach is associated chiefly with the transmission of knowledge" (p. 50). In an instuctivist approach, Reeves (1993) stated there is little emphasis placed on the learner "who is the passive recipient of instruction" (p. 4). Teaching is not just faculty talking and learning is not just students listening. 
Brown (2003) notes that in both approaches instructors demonstrate expertise in content knowledge and also acknowledge students have different needs. Brown (2003) states, Differences emerge in whether educators engage in reflective inquiry. Inquiry that focuses on culture and learners is at the crux of how to help learners make meaning of instruction. Thinking that helps learners to make connections to their past experience or prior knowledge is routine. Assessment is the balance that weighs how appropriately the teacher orchestrates learner characteristics and teaching practices. (p. 54)

Barr and Tagg (1995) thoroughly discussed the two paradigms (instruction and learning) and their marked differences. A specific methodology determines the boundary of what colleges can do in the instruction paradigm, while in the learning paradigm, student learning and success set the boundary. It must be noted that Barr and Tagg (1995) stated that in the learning paradigm lecturing is not prohibited and merely becomes "one of many possible methods, all evaluated on the basis of their ability to promote appropriate learning" (p. 15). The educational paradigms are examined by contrasting mission and purposes, criteria for success, teaching/learning structures, learning theory, productivity/funding, and nature of roles.

The mission and purpose of the teacher-centered instruction paradigm is "to teach - to provide and deliver instruction" (Barr \& Tagg, 1995, p. 15). The university and their faculty are to transfer knowledge to students, offer courses and programs, improve the quality of instruction, and achieve access for diverse students (Barr \& Tagg, 1995).

Criteria for success in the teacher-center paradigm focus on the quality of entering students, curriculum development and expansion, quantity and quality of resources, enrollment and revenue growth, and the quality of faculty and their instruction (Barr \& Tagg, 1995). 
Teaching and learning structures follow a very traditional means in the teacher-centered instructional paradigm. The structure as described by Barr and Tagg (1995) is "atomistic" emphasizing the parts prior to the whole (p. 19). The atom is considered the timed lecture and the molecule is the one classroom teacher. Traditionally, the higher education courses revolve around lecture courses where a time is held constant (for example a 50-minute lecture/course held three times per week). Learning typically varies and the instructor grades within the course via private assessment. There is usually one teacher and one classroom teaching independent disciplines for independent departments. In this approach degree equals accumulated credit hours (Barr \& Tagg, 1995). Huba and Freed (2000) discuss a focus on a single discipline in the teacher-centered paradigm that is not compatible with interdisciplinary investigation.

Learning theory according to this paradigm believes knowledge exists "out there" (Barr \& Tagg, p. 21). Knowledge comes in chunks and bits, it is delivered by instructors, and it is gotten by the students. In this paradigm any expert in knowledge and content can teach. Learning in the teacher-centered instructor paradigm is cumulative and linear. Learning theory is ....by the quality of existing students. The classroom and its students can be described as "competitive" and "individualistic" reflecting what Barr and Tagg (1995) describe as "reflecting a view that life is a win-lose proposition" (p. 23). Success for students of the instruction paradigm reflects the notion that success is an individual accomplishment.

In the teacher-centered instruction paradigm the definition of productivity is the cost per hour of instruction per student. Funding is based on hours of classroom time. Barr and Tagg (1995) considered this a serious design flaw of colleges as "they are structured in such a way that they cannot increase their productivity without diminishing the quality of their product" and 
these systems waste "not only institutional resources but the time and energy of students" (p. 23). In this paradigm efficient and effective learning is not espoused.

As for the nature and the roles within a teacher-centered instruction paradigm, faculty are the primary lecturers. A teacher-centered paradigm follows a lecture-based or one directional mode of instructional delivery whereby the learner is a passive recipient of the instruction. Kain (2003) stated:

...in teacher-centered approaches, judgments about appropriate areas and methods of inquiry, legitimacy of information, and what constitutes knowledge rest with the teacher. By contrast, student-centered approaches derive from constructivist views of education, in which the construction of knowledge is shared and learning is achieved through students' engagement with activities in which they are invested. (p. 104)

Barr and Tagg (1995) stated in the teacher-centered Instruction Paradigm students are merely "passive vessels, ingesting knowledge for recall on tests" (p. 21). Faculty and students act independently and in isolation in the teacher-centered model. The faculty member often functions as a sage on the stage, a disciplinary expert who imparts knowledge by lecturing (Barr \& Tagg, 1995). Huba and Freed (2000) echo the roles of faculty and students whereby professors transmit knowledge and students passively receive information. The professor's role is that of "primary information giver and primary evaluator" (Huba \& Freed, 2000, p. 5). Teaching is linked with the notion of "talking at" or "lecturing" (Ackoff \& Greenberg, 2008, p. 5). The teacher-centered paradigm is very traditional where “teachers 'pour in' knowledge, and students are expected to give it back as received...teachers with all the answers performing to passive students (Huba \& Freed, 2000, p. 35). This is very similar to the sage-on-the-stage role. 


\section{The learner-centered approach.}

National and state education reform movements are advocating for students to be actively engaged in learning, constructing understanding and meaning, not just receiving it. Learner and student centered approaches have been theoretically motivated by constructivist and sociocultural theories of learning. Brown (2003) asserts in a learner-centered approach stakeholders must support the ideology and a paradigm shift is required to incorporate reflective inquiry, thinking-centered learning, and assessing program quality. "Issues of societal change, alternative pathways to teaching, and the historical context of educational practices cannot be automatic. There must be a commitment to reflection, creating thinking-centered learning, and constantly assessing the quality of instructional programs" (Brown, 2003, p. 54). In a studentcentered approach the learner constructs new knowledge through a process of relating new information to prior knowledge and experience.

As the learning theory paradigm shifts from a teaching focus to a learning focus, it seems logical to take a constuctivist learning perspective. Olgren (1998) asserted through a constructivist approach the learner will construct new knowledge by relating and processing new information to prior knowledge and experience. Huba and Freed (2000) encouraged guiding students to seek out information on their own so they can understand and use it. Stroh and Sink (2002) stated students "must, to a great extent, be allowed to act on their environments and construct their own knowledge" (p. 101). As discussed by Brown (2003), students "must learn by doing and not by sitting passively and listening” (p. 101). Brown (2003) is also strong in his opinion that learner-centered classrooms "must avoid" (p. 101) using lecture as their primary means of teaching. 
Wilson (2001) viewed constructivism as a psychologically-oriented approach to learning that advocates individual and collaborative meaning construction. This method will give students meaningful experiences and direct encounters by employing complex and engaging products and tasks and by adding support from colleagues or a teacher/facilitator.

Barr and Tagg (1995) described the learning paradigm as envisioning the institution itself as a learner over time continuously learning "how to produce more learning with each graduating class, each entering student” (p. 14). Again, Barr and Tagg (1995) thoroughly discussed the student-centered learning paradigm by examining mission and purposes, criteria for success, teaching/learning structures, learning theory, productivity/funding, and nature of roles.

The mission and purpose of the learner-centered instruction paradigm is ultimately to produce learning. Barr and Tagg (1995) used the verb "produce" as it "strongly connotes that the college takes responsibility for learning...colleges are to produce learning - not provide, not support, not encourage" but unmistakably "they are responsible for the degree to which students learn” (Barr \& Tagg, 1995, p. 15). By eliciting students' discovery and construction of knowledge a powerful learning environment can be created. The students in turn will become members of communities of learners that make discoveries and solve problems. Additionally as a mission and purpose of the learning paradigm, instead of merely achieving access for diverse students, the paradigm strives to achieve success for diverse students (Barr \& Tagg, 1995). Most importantly, "a learning paradigm college is concerned with learning productivity, not teaching productivity" (Barr \& Tagg, 1995, p. 16). Cross (1993) stated, "the ultimate criterion of good teaching is effective learning" (p. 20). Similarly, Huba and Freed (2000) stated, "learning is the focus and ultimate goal of the learner-centered paradigm" (p. 8). 
Criteria for success in the learner-centered paradigm focuses on the quality of exiting students (not entering as in the teacher-centered model), learning technologies development, quantity and quality of outcomes (not of resources), aggregate learning growth and efficiency, and the quality of students and their learning (Barr \& Tagg, 1995).

Teaching and learning structures in the learning paradigm are holistic in nature and focus on the whole prior to the parts. Attention is given to the learning environment and learning is held constant with time varying. The environment is ready when the student is and utilizes whatever learning experience works. The structure often is cross discipline and department (unlike the focus of the single discipline in the teacher-centered approach). Specified learning results are considered while pre/during/post assessments and external evaluations of learning are encouraged. The degree does not equal accumulated credit hours but demonstrated knowledge and skills (Barr \& Tagg, 1995).

Learning theory in the learner-centered paradigm has some stark contrast to the teachercenter approach. In the learning paradigm, knowledge is constructed and created and knowledge exists in each person's mind being shaped by individual experience. Learning is student centered and controlled whereby learning is a nesting and interacting of frameworks (Barr \& Tagg, 1995). Huba and Freed (2000) emphasized the active involvement of students whereby "students construct knowledge through gathering and synthesizing information and integrating it with the general skills of inquiry, communication, critical thinking, problem solving, and so on" (p. 5). Students will actively search for meaning by "constructing knowledge rather than passively receiving it, shaping as well as being shaped by experiences" in a learning paradigm (Joint Task Force on Student Learning, 1998, p. 2). Talent and ability are abundant in the learning paradigm. Learning environments are cooperative, collaborative, and supportive, not 
competitive and individualistic (Barr \& Tagg, 1995). In a student-centered paradigm professors and students learn together; it is not a one way street (Huba \& Freed, 2000).

In the student-centered instruction paradigm the definition of productivity is the cost per unit of learning per student (as opposed to the cost per hour of instruction per student as represented by the teacher-centered paradigm). Funding is for learning outcomes and not based on hours of classroom time. Barr and Tagg (1995) stated "this new definition requires that colleges actually produce learning. Otherwise, there is no 'product' to count in the productivity ratio" (p. 23). As productivity is redefined, quality of teaching and learning is no longer threatened by an increase in the student-to-faculty ratio and it is possible to increase outcomes without increasing costs. As Barr and Tagg (1995) stated:

There is no more powerful feedback than revenue. Nothing could facilitate a shift to the Learning Paradigm more swiftly than funding learning and learning-related institutional outcomes rather than hours of instruction. The initial response to the idea of outcome-based funding is likely to be "That's not possible." But, of course, it is. As the new paradigm takes hold, forces and possibilities shift and the impossible becomes the rule. (p. 23)

Although Guskin (1994) agreed that some productivity gains can be produced by "faculty just teaching more," he doesn't "believe the volume of activity is the appropriate goal: the issue is not how many courses faculty teach, but how much students learn" (p. 18).

As for the nature and the roles within a student-centered instruction paradigm, faculty are primarily designers of learning methods and environments. They can lecture but are not primarily lecturers as in the teacher-centered paradigm. Faculty and students will work in teams with each other and staff, not work independently and in isolation. Ackoff and Greenberg 
described the instructor serving as a "guide and resource" (p. 4). In this paradigm, empowering learning is challenging and complex. Students' competencies and talents are developed by the teacher working towards producing learning and success through shared governance (Barr \& Tagg, 1995). As stated by Astin (1985), “students learn by becoming involved” (p. 133).

Chickering and Gamson (1987) discussed the importance of student involvement. Students should talk and write about learning and relate it to past experiences by applying it to their daily lives. This internalizes the learning and reinforces the notion that "learning is not a spectator sport" (Chickering \& Gamson, 1987, p. 3). Bonstingl (1996) described learner-centered professors as "supporters," "coaches," and "partners" who help each other improve and grow (Bonstingl, 1996, p. 5).

\section{Synthesis of Chickering and Gamson's seven principles.}

In 1987, researchers Chickering and Gamson produced an accessible, understandable, practical, and seminal paper titled "Seven Principles for Good Practice in Undergraduate Education." This article mapped out fundamental principles of effective teaching which have remained timeless even after decades of research. Originally published in the March 1987 AAHE Bulletin, good practice in undergraduate education focus on the following aspects: 1) encourages contact between students and faculty, 2) develops reciprocity and cooperation among students, 3) encourages active learning, 4) gives prompt feedback, 5) emphasizes time on task, 6) communicates high expectations, and 7) respects diverse talents and ways of learning (Chickering \& Gamson, 1987, p. 2).

These principles have served as a platform of educational reform. Chickering and Gamson (1987) believed the seven principles, while able to stand on their own, also could be very potent when combined. Collectively "they employ six powerful forces in education: 
activity, cooperation, diversity, expectations, interaction," and "responsibility" (Chickering \& Gamson, 1987, p. 3).

Later, Norman (1993) described the optimal environment for learning existing when a high intensity of interaction and feedback is provided, when specific goals and established procedures are established, when students are motivated, when a continual feeling of challenge is provided, when a sense of direct engagement is provided, when appropriate tools that fit the user and task (that aid not distract) are provided and when distraction and disruptions that might destroy the subjective experience are avoided.

Based on the research of cognitive psychologists and educational researchers, Huba and Freed (2000) discussed eight hallmarks of learner-centered teaching. The eight hallmarks of learner-centered teaching are the following:

1. Learners are actively involved and receive feedback.

2. Learners apply knowledge to enduring and emerging issues and problems.

3. Learners integrate discipline-based knowledge and general skill.

4. Learners understand the characteristics of excellent work.

5. Learners become increasingly sophisticated learners and knowers.

6. Professors coach and facilitate, intertwining teaching and assessing.

7. Professors reveal that they are learners, too.

8. Learning is interpersonal, and all learners - students and professors - are respected and valued.

(Huba \& Freed, 2000, p. 33)

Similar to the key points of Chickering and Gamson's (1987) Good Practice Principles, many of the main beliefs of the learner-centered paradigm mirror the eight hallmarks of learner-centered teaching.

According to the learning paradigm, the more students actively engage with subject matter, the better they master material and develop critical skills. By encouraging contact between students and faculty (Chickering and Gamson's first principle), a more holistic learning environment can be created. As stated by Chickering and Gamson (1987), "learning is enhanced 
when it is more like a team effort than a solo race" (p. 3). Good learning is described as "collaborative and social, not competitive and isolated" (Chickering \& Gamson, 1987, p. 3). Huba and Freed (1995) supported this notion while describing the nature of students' roles in the Instruction Paradigm as "shared governance" and "teamwork" (p. 17).

As in the seven principles, faculty encourage active learning in the learner-centered environment. Gardiner (1998) stated, "active involvement includes frequent student-faculty interaction" (p. 73). This could be achieved in and outside of the classroom whether traditional or online. The active learning process involves internalizing content by relating it to past experience and applying it to the students' daily lives. Many of the active learning class structures include discussions, team projects, peer critiques, and other out-of-classroom opportunities for the student to learn (Chickering \& Gamson, 1987). Classes, including online environments, can foster active learning and a learner-centered approach if properly structured. Guskin (1994) discussed that students "are treated as if they are expected to be passive recipients of information and knowledge, even though we know that the most effective learning occurs when students are active learners" (p. 24-25).

In his book, The Learning Paradigm College, Tagg (2003) identified five characteristics of the Learning Paradigm College. His characteristics "support students in pursuing their own goals, require frequent student performances, provide frequent and ongoing feedback, assure a long time horizon for learning, and provide for stable communities of practice" (p. 124). Tagg's characteristics are consistent with Chickering and Gamson's (1987) principles and support the learner-centered approach to learning.

Barr and Tagg (1995) stated, "in the Learning Paradigm, faculty find ways to develop every student's vast talents and clear the way for every student's success" (p. 23). Chickering 
and Gamson (1987) encouraged respect for diverse talents and ways of learning. Since there are many "roads to learning," Chickering and Gamson (1987) stated, "students need the opportunity to show their talents and learn in ways that work for them. Then they can be pushed to learning in new ways that do not come so easily" (p. 5).

Members of the higher education community should have an awareness of the diversity of learning styles, learning techniques, and learning environments which allow them to create optimal experiences to appeal to different kinds of learners. Students can maximize their learning experiences and challenges encouraged and created by instructors. Following the Learning Paradigm, a holistic learning approach will reach a greater portion of students with various learning styles. A traditional classroom of passive lecture would not embrace these principles. Baldwin and Baumann (2005) discussed education as being "in a time of rapid change" whereby academic programs must experiment and evolve in order to keep pace with advances in knowledge, changes in professional practice, and shifting conditions in society...education in every academic field must adapt to accommodate changing student interests, new approaches to teaching and learning, and new interpretations and applications of the discipline. Educational programs designed to prepare students for a dynamic future must be dynamic themselves, or they will become increasingly unpopular and irrelevant...In dynamic times, higher education must think "outside the box"...New options are needed to make educational programs more flexible and adaptive in a dynamic environment where change is a constant and rigid, one-size-fits-all programs and procedures are inefficient and impede needed reforms. Additional ways of fostering 
curriculum innovations and experimentations are needed if higher education is to serve a diverse society effectively. (p. 89-90)

Ritter and Lemke (2000) evaluated the use of the Internet to enhance learning and to promote good practice in undergraduate education according to Chickering and Gamson's principles. They found even though the principles may be addressed without technology, "the Internet offers a rich and efficient scaffolding for educators to address them" (p. 101). For learning (in its truest sense) to occur, many authors believe active learning is essential (Chickering \& Gamson, 1987; Barr \& Tagg, 1995; Huba \& Freed, 2000; McCombs, 2001; Brown, 2003). When discussing utilization of the Internet to enhance higher education, Ritter and Lemke (2000) state, "using the Internet to enhance higher education may promote studentinstructor communication, encourage student collaboration, encourage active learning, and respects diverse ways of learning" (p. 107). This champions the learning paradigm.

\section{Learning Styles}

The paradigm shift from teacher-centered (instructivism) to learner-centered (constructivism) becomes important when researching learning styles of students. Many instructors still teach as they have been taught and still use the traditional lecture as their teaching method of choice (Britzman, 2003). The teacher-centered paradigm presents multiple barriers to improving student learning and success. It will not provide appropriate opportunities for redesigned learning environments that could take in account student learning styles or alternative learning technologies.

While the instructivist viewpoint is still an approved mode of instruction (utilized by seventy to ninety percent of professors), Diaz (2000) pointed this might explain why many students exhibit the learning styles they do. 
Diaz (2000) stated,

The tide of learning theory has been shifting from instructivist to a constructivist perspective. This evolution has changed educational assumptions and has called into question the methods of traditional distance education research...The extent to which teachers see themselves as "instructivists" or "constructivists" may implicitly determine the extent to which classroom activities are based on teacher or student preferences, and may also influence the focus of research design. (p. 2)

Under this assumption, student learning styles may be pressured and in constant unrest by differing approaches to teaching and learning and differing instructional methods. By understanding and gauging students' preferred learning styles, educators can move toward a constructivist approach and act as a guide (rather than a dispenser of knowledge) to help the learner construct new knowledge based on their prior knowledge and experience. This educational shift to the student-centered approach has led to researchers exploring learning styles in greater depths in both traditional and web-based classroom settings. Villaverde, Godoy, and Amandi (2006) stated, "E-learning environments can take advantage of these different forms of learning by recognizing the style each individual student using the system and adapting the content of courses to match this style" (p. 197).

It has been concluded by many researchers that people learn and process information in many different ways (Villaverde, Godoy \& Amandi, 2006; Coffield et al., 2004; Lawrence, 1982; Diaz \& Cartnal, 1999; Diaz \& Bontenbal, 2001; Fizzell, 1984; Speth, Lee, \& Hain, 2006). Moallem (2007) suggested it has been long supported by educators "that individual differences play an important role in learning and instruction" (p. 217). As unique as every student is, so are the learning styles and techniques they prefer. Some students may have a dominant style of 
learning, while others will use an approach of combining styles. Given different sets of circumstances, students may also utilize different learning styles to adapt to a given situation. Ackoff and Greenberg (2008) encouraged faculty of offer students "a wide variety of ways to learn, among which they could choose or with which they could experiment. They do not have to learn different things the same way" (p. 5). Educators must remember that "the objective of education is learning, not teaching" (Ackoff \& Greenberg, 2008, p. 5).

Educational researchers stress the need to understand the distance learning student population (Vafa, 2002) and comparison of variables, such as learning styles, which might impact distance learning effectiveness such as learning styles (Zhang, 2005). Diaz and Cartnal (1999) emphasized research was sparse on the area of distance learning and learning styles. Guskin (1994) suggested "rethinking the role of faculty" and using new technologies to enhance student learning (p. 18).

\section{Learning styles defined.}

As numerous as the ways that people learn and process information, just as numerous are the ways which researchers have defined learning styles. As discussed by Blakemore, McCray, and Coker (1984), the definitions are usually broadly defined or defined to include a specific measurement instrument. Instead of a single, widely accepted definition of learning styles, research has shown there are many.

The term "learning style" refers to a student's consistent way of responding and using stimuli in the context of learning according to Claxton and Ralston (1978). Additionally, learning styles have been described as personally preferred ways of dealing with information and experience (Della-Dora \& Blanchard, 1979) and individual ways of perceiving, interacting, and responding to a learning environment (Kirby, 1979). Hunt (1979) discussed learning styles as 
educational conditions and believes a "learning style describes how a student learns, not what he has learned" (p. 27). Described by Kolb (1984) learning style is a sharing and interpretation through dialogue with one another as personal experience and as "how a person deals with ideas and day-to-day situations" (Smith \& Kolb, 1996, p. 1). Learning styles are "conceived not as fixed personality traits but as possibility-processing structures resulting from unique individual programming of the basic but flexible structure of human learning" (Kolb, 1984, p. 95, 97). McDermott and Beitman's (1984) definition included observable strategies for problem solving, decision making behavior, restrictions found in the learning situation and reaction under the expectations of others all express in the learning process in a unique way of learning. Both Gregorc (1979a) and Entwistle (1981) pointed learning styles focus on the learner's preference to employ specific learning strategies in a given learning situation and environment. Gregorc (1979a) stated learning styles “gives clues as to how a person's mind operates" and may be examined as a process or strategy (p. 234). Butler (1987) described learning style as a natural method, easiest and most effective, used by the learner to realize the relationship between self and environment. To Canfield and Canfield (1988) under learning conditions learning style is the peculiarity demonstrated by learners while accepting stimulation or solving problems. Keefe's (1982) definition of learning style included "characteristic cognitive, affective, and psychological behaviors that served as relatively stable indicators of how learners perceive, interact with, and respond to the learning environment" (p. 46). According to Keefe (1982), these three areas (physiology, cognition, and affect) are critical. Honey and Mumford's (1992) definition of learning styles and preferred way of learning includes attitudes and behaviors while James and Gardner (1995) suggested heredity, experience, and environment as core concepts in their definition. Jonassen and Grabowski (1993) proposed learning styles are self-reported 
accounts of an individual's preference for and perceptions of how they process information. Grasha's (1996) definition stated learning styles are "personal qualities that influence a student's ability to acquire information, to interact with peers and the teacher, and otherwise to participate in learning experiences" (p. 41). According to Dunn (2000), identical pedagogical methods may be effective for some students while ineffective for others because of learning styles determined by biological and developmental characteristics. As web-based learning is discussed in this research it is important to note Ford and Chen (2000) considered learning styles to be an important factor influencing e-learning. Price (2004) offered a broad definition encompassing the range of individual differences in learning. Learning style "is considered to include a range of constructs describing variations in the manner in which individuals learn" (Price, 2004, p. 681). Cooze and Barbour (2005) simplified the definition of learning styles by citing they are merely "different approaches to learning” (p. 4).

Educational researchers such as Blakemore, McCray, and Coker (1984) have suggested problems and issues in the application of learning styles such as in matching strategies, stability of learning styles, identifying learning styles, congruence of teaching/learning styles, and lack of technology for matching all possible styles. Matching strategies could include the inability to provide the specific instructional environment to a student based on his/her learning style (teaching according to the student's learning style). By "mismatching” (Blakemore, McCray, and Coker, 1984) students may be forced to learn by using nonpreferred instructional modes.

Is there stability of learning styles? Some researches such as Gregorc (1979b) argued that most learning styles are inherited rather than learned and that students can only minimally adapt to a nonpreferred instruction condition. Others have also found apparent changes in learning styles over time (Kolb, 1981; Geiger \& Pinto, 1991; Pinto, Marshall, \& Boyle, 1994) 
and possible changes in styles and strategies attuned to particular types of tasks and situations (Messick, 1987; Squires, 1981). Depending on task, stimuli, sensory modality, or environment the learning process may also vary. According to Price (2004) the "nature of the task and the context may have a bearing upon an individual's approach to learning” (p. 684).

Some researchers have questioned if students can accurately identify their own learning style (especially when students are young) (Davidman, 1981). The validity of learning style instruments is questionable if students cannot identify their own learning styles (Blakemore, McCray, and Coker, 1984)

Learning style preferences play a role in success in distance learning and in the educational process in general (Diaz \& Bontenbal, 2001). Learning styles can be used to create awareness and identify differences in how students take in and process information and can also help balance instruction. It has been recognized that students with different learning styles learned better in certain teaching environments than in others (Diaz \& Cartnal, 1999). The awareness gained by instructors of their students' learning styles could assist in choosing appropriate technologies and delivery methods.

\section{Relevant learning style models and inventories.}

There is a vast body of research in the area of learning styles (guided by the fields of psychology, sociology, and education). For example, a bibliography of research conducted in 2000 by David and Alice Kolb on the experiential learning theory (ELT) and Learning Style Inventory (LSI) conducted since 1971 showed 1,004 entries. A website bibliography for the Dunn and Dunn Learning Styles Questionnaire (LSQ) shows 1,140 entries, while the MyersBriggs Type Indicator (MBTI) between 1985 and 1995 show an estimated 2,000 articles written (Coffield et al., 2004). In one of the most comprehensive systematic and critical reviews of 
learning styles in pedagogy in post-16 learning, Coffield et al. (2004) identified 71 models of learning styles with thirteen of these categorized as "major models" (p. 1). Howles and Jeong (2009) reported by 2006 that over 650 books have been published in the U.S. and Canada on learning styles, over 4,500 articles have been written about learning styles in professional publications, and over 26,000 websites are available for measuring and addressing learning styles.

Due to the extensive nature of the number of learning styles and studies, this section will provide a brief overview of some of the more popular learning styles and inventories. Five main models will be identified and highlighted including the following: Canfield (1980), Dunn and Dunn (1979), Grasha-Reichman (1974), Gregorc (1977), and Kolb (1976). These models are associated in greater frequency in varied learning/teaching methodology such as traditional faceto-face and online web-based environments, with greater depth and information provided on Kolb's (1984) theory of experiential learning and Learning Style Inventory for the focus of this research study.

\section{Canfield Learning Style Inventory (CLSI).}

The Canfield inventory was primarily designed for adolescents through adults and concentrates on motivational and environmental factors present in formal instructional environments. According to Canfield (1992), the CLSI is a self-report inventory that measures learning preferences and divides learning styles into useful applications for distance/distributed learning. It consists of a 30-item assessment utilizing a four point rank order procedure for each item. These choices are ranked by students in the order that best describes their preferences. The CLSI has 20 subscale variables that are divided into the following four major categories: 
1) conditions for learning, 2) areas of interest, 3) modes of learning, and 4) expectation types (Canfield, 1992). Based on the validity indicators of the instrument, according to Canfield (1992), students taught using techniques congruent to their learning style preferences performed better in most learning tasks.

\section{Dunn and Dunn model and learning style inventories.}

Dunn and Dunn (1992a) defined style as "the way in which individuals begin to concentrate on, process, internalise and retain new and difficult academic information" (p. 8). Within their model, preferences, rather than strengths, are measured and a strong emphasis is placed on biological and developmentally imposed characteristics (Dunn \& Dunn, 1992a). Additionally, a Dunn and Dunn (1979) model premise was the thought that students' potential and achievement are heavily influenced by relatively fixed traits and characteristics (Dunn \& Griggs, 2000).

In 1979, Dunn and Dunn developed a model of learning style preferences which divides learning style into five major "strands" called "stimuli" (Dunn, 2003, p. 2). The five stimuli strands affecting learning are environmental, emotional, sociological, psychological, and physiological elements. From these strands, four variables (environmental, emotional, physical, sociological) which include different factors (such as sound, temperature, motivation, modality, learning groups, time of day, etc.) affect students' learning preferences. The design of the model is based on high or low preferences for 22 different factors (Dunn, 2003)

From the learning style model of Dunn and Dunn (1979), a number of self-report instruments have evolved including the Dunn and Dunn Learning Style Questionnaire (LSQ; 1979), the Dunn, Dunn, and Price Learning Style Inventory (LSI; 1992, 1996), the Dunn, Dunn, 
and Price Productivity Environmental Preference Survey (PEPS; 1996), the Building Excellence Survey (BES; 2002), and Our Wonderful Learning Styles (OWL; 2002) (Coffield et al., 2004).

Coffield et al. (2004) summarized several implications for pedagogy according to works regarding the Dunns' (1979) model including the following: 1) most people have learning style preferences and individuals' learning style preferences differ significantly from each other, 2) the stronger the preference, the more important it is to provide compatible instructional strategies, 3) accommodating individual learning style preferences results in increased academic achievement and improved student attitudes toward learning, 4) most students can learn to capitalize on their learning style strengths when concentrating on new or difficult academic material, and 5) the less academically successful the individual, the more important it is to accommodate learning style preferences (p. 30). Furthermore, strengths of the model affirm the belief that anyone can benefit from education if preferences are catered for, that teachers should be encouraged to respect differences, that a variety of teaching and assessment techniques (utilizing flexibility, imagination, and changing environmental conditions) are supported, and that behavior may be legitimized when teachers and students talk about learning (Coffield et al., 2004).

\section{Grasha-Riechmann Student Learning Style Scales (GRSLSS).}

The Grasha-Riechmann (1974) Student Learning Style Scales (GRSLSS) learning style inventory was primarily designed for four-year college students but has since been used with graduate students, two-year college students and high school students as well. It is a 90-item self-report scale that is group-administered (Ferrell, 1983). The GRSLSS utilizes learning styles in a broad context which spans six categories. The styles refer to a blend of characteristics that apply to all students and each person possesses some of each of the learning styles (Grasha, 
1996). Grasha (1996) suggested that particular teaching styles might encourage students to adopt certain learning styles.

The GRSLSS inventory is based on the student as a member of a social learning community and interaction of the student with course content, the instructor, and other students. A five-point Likert type scale assesses the following six styles: 1) Participant (who eagerly takes part in course content and asking questions), 2) Avoidant (who procrastinates or does as little work as possible), 3) Independent (who prefers independent work and rarely asks for help), 4) Dependent (who needs detailed instructions and requires a lot of help), 5) Collaborative (who enjoys group work and works well with others), and 6) Competitive (who wants to out-perform peers and receive recognition for academic accomplishments) (Fuhrmann \& Grasha, 1983). Grasha (1996) and Diaz and Cartnal (1999) proposed student learning styles are in continual and significant change. Online students, in addition to the constant flux of style change, demonstrate widely differing learning style profiles and characteristics (Diaz \& Cartnal, 1999).

\section{Gregorc Mind Styles Delineator (MSD).}

Learning style as defined by Gregorc (1979) consisted of "distinctive behaviors which serve as indicators of how a person learns from and adapts to his environment. It also gives clues as to how a person's mind operates" (p. 234). Gregorc's (1977) four-channel learning style model operated on two axes representing concrete versus abstract perception and sequential versus random ordering abilities. Gregorc's (1982) four learning style channels are as follows: 1) concrete sequential (CS) where the learner is ordered, perfection-oriented, practical, and thorough; 2) abstract sequential (AS) where the learner is logical, analytical, rational, and evaluative; 3) abstract random (AR) where the learner is sensitive, colorful, emotional, and 
spontaneous; and 4) concrete random learner (CR) where the learner is intuitive, independent, impulsive, and original.

The Gregorc (1982) Mind Style Delineator (MSD) was primarily designed for adults and concentrates on the Mind Styles Model (Gregorc, 1982) based on the premise that the mind interacts with the environment through four channels which mediate receiving and expressing information. The Gregorc's Style Delineator (GSD), published in 1982, is a 10-item self-report questionnaire whereby respondents rank order four words in each item from the most descriptive of themselves, to the least descriptive of themselves. Gregorc (2002) suggested all four channels can be used by everyone; however, there are inborn inclinations towards one or two of them. The researcher suggested his mission is to prompt self-knowledge, promote depth-awareness of others, foster harmonious relationships, reduce negative harm and encourage rightful actions (Gregorc, 2009). Gregorc (2009) believed if there is a lack of alignment of learners' styles and the demands placed on them by teaching methodology, the student will suffer. According to Gregorc (2002), teachers and students should not be forced to change their natural styles. He contended straightforward Mind Style dispositions are linked with preferences for certain instructional media and teaching strategies, but concedes that most people prefer variety in their instructional methodology (Gregorc, 2009).

\section{Kolb's Learning Style Theory}

\section{David Kolb: Experiential Learning Theory basis.}

David Kolb, along with Roger Fry (1975), developed one of the most influential learning models by introducing the learning styles movement in the early nineteen seventies. Kolb (1976; 1981 ; 1984) explored the processes associated with making sense of concrete experiences and provided a foundation for the growing literature in experiential learning and in the area of higher 
education. As proclaimed by Kolb (1984), his work is building on the framework of John Dewey, Kurt Lewin, and Jean Piaget. John Dewey was influential in his work with experiential learning in higher education and the process that links education, work, and personal development. He believed there was an "intimate and necessary relation between the processes of actual experience and education" (Dewey, 1938, p. 20 in Kolb 1984). Kurt Lewin contributed to Kolb by discussing experiential learning in training and organizational development. He focused on influences on social psychology and on organizational behavior (Kolb, 1984). Jean Piaget was influential with his theories of cognitive development and tradition of experiential learning. He believed action is the key. Simply stated, "Piaget's theory describes how intelligence is shaped by experience... [and] arises as a product of the interaction between the person and his/her environment" (Kolb, 1984, p. 12). Kolb's model of underlying structure of the learning process is based on research in psychology, philosophy, and physiology. It stems from work of the Russian cognitive theorist, L.S. Vygotsky, who supported the notion that human development occurs from the process of learning from experience (Kolb, 1984).

Learning, according to Kolb (1984), is the process "whereby knowledge is created through the transformation of experience. Knowledge results from the combination of grasping experience and transforming it... learning, and therefore knowing, requires both a grasp or figurative representation of experience and some transformation of that representation" (p. 4142). Kolb (1984) summarized his definition of learning by highlighting the following critical aspects of the learning process when viewed from the experiential perspective:

First, is the emphasis on the process of adaptation and learning as opposed to content or outcomes. Second is that knowledge is a transformation process, being continuously created and recreated, not an independent entity to be acquired or transmitted. Third, 
learning transforms experience in both its objective and subjective forms. Finally, to understand learning, we must understand the nature of knowledge and vice versa. (p. 38)

Kolb's (1984) Experiential Learning Theory (ELT) stresses the role experience plays in learning and emphasizes the link with Dewey, Lewin, and Piaget while distancing itself from other cognitive theories of the learning process. Kolb (1984) outlined six main characteristics of experiential learning. First, learning is best conceived as a process, not in terms of outcomes. Ideas can be formed and re-formed through experience, therefore making two thoughts never the same. Ideas are not fixed and immutable elements of thought. Second, learning is a continuous process grounded in experience. This implies that all learning is relearning so a responsibility of an educator is not only to impart new ideas but also to alter or dispose of old ones. Third, learning requires the resolution of conflicts between dialectically opposed modes of adaptation to the world (learning is by its very nature full of tension). Fourth, learning is a holistic process of adaptation to the world that could be considered a "molar concept" describing the central process of human adaptation to the social and physical environment instead of a "molecular educational concept" (Kolb, 1984, p. 31). This could be likened to Jungian theory of psychological types. Fifth, learning involves transactions between the person and the environment (including application to everyday life as an active, self-directed process). Sixth, learning is the process of creating knowledge that is the result of the transaction between social knowledge and personal knowledge (Kolb, 1984).

\section{Experiential Learning Model.}

Kolb's (1984) Experiential Learning Model (ELM) proposed that people learn in a twostep process of inputting information and processing information. These two continuums, a theoretical vertical continuum showing a person's preference for inputting information 
(perception) and a theoretical horizontal continuum showing a person's preference for processing information, form a quadrant (Little, 2004). The perception continuum shows our emotional response to a task and whether learning is preferred by thinking or feeling. The processing continuum shows our approach to a task and whether learning is preferred by doing or watching. Kolb's (1984) dimensions of inputting, comprehending, and perceiving have a preference for concrete examples (CE) at the top and a preference for abstract concepts (AC) at the bottom. The dimensions of transforming and processing have a preference for active experimentation (AE) at the far left and the preference for reflective observation (RO) at the far right. Little (2004) pointed that individuals use a sliding scale between concrete (specific) examples and abstract (holistic) concepts for inputting information while they use a sliding scale between active (hands-on) experimentation and reflective (passive) observation for their preferences. Through this ELM, learning is conceived as a four stage cycle and is translated into concepts that guide the choice of further experiences (Loo, 2004).

Kolb (1984) discussed the differences of the four modes of the learning process CE, AC, $\mathrm{RO}$, and $\mathrm{AE}$ and also used a combination to indicate extent to which a person emphasizes abstractness over concreteness (AC-CE) and the extent to which a person emphasizes action over reflection (AE-RO). Concrete experience, as described by Kolb (1984), "focuses on being involved in experiences and dealing with immediate human situations in a personal way" (p. 68). Concrete experience is feeling (instead of thinking), uniqueness and complexity (instead of theories and generalizations), and intuitiveness/artistic (instead of systematic and scientific). People exhibiting CE orientation usually relate well to others, are intuitive decision makers, and adapt well to unstructured environments. Individuals in the CE orientation value relating to people and having an open-minded approach (Kolb, 1984). Those individuals with an AC 
orientation focus on logic, ideas, and concepts according to Kolb (1984). A person with an AC orientation emphasizes thinking (instead of feeling), building general theories (instead of focusing on specific areas), and likes systematic planning and quantitative analysis. They value precision, rigor, and the discipline of analyzing ideas (Kolb, 1984). A person with an RO orientation carefully observes and impartially describes situations while focusing on understanding the meanings of ideas. People exhibiting RO orientation emphasize understanding (instead of practical application), a concern with the truth (instead of what will work), and an emphasis on reflection (instead of action). Those who favor RO excel at viewing things from different perspectives and enjoying different points of view. While relying "on their own thoughts and feelings to form opinions", individuals with RO orientation "value patience, impartiality, and considered, thoughtful judgment" (Kolb, 1984, p. 68-69). Those with AE preference like to focus on actively influencing people and changing situations. Individuals with AE orientation emphasize practical applications (instead of reflective understanding), exhibit a pragmatic concern with what works (instead of the absolute truth), and prefer doing (instead of observing). Risk-taking to achieve objectives typifies this orientation. Those exhibiting AE orientation are good at accomplishing things, value influencing the environment around them, and enjoy seeing results (Kolb, 1984).

Within Kolb's learning cycle, a learner may enter at any point depending on the situation or environment. The new task will be best learned if the individual practices in all four modes. The learning process, according to Kolb (1999), is a context of people moving between the modes of concrete experience, abstract conceptualization, reflective observation, and active experimentation. The effectiveness of learning therefore will rely on the ability to balance these modes through opposing activities that best promote learning (Kolb, 1999). Also, according to 
Kolb (1999) concrete experience and abstract conceptualization reflect right-brain and left-brain thinking respectively. Baker, Jensen, and Kolb (2002) stated individuals, according to Experiential Learning Theory must continually choose which set of learning abilities will be used in a specific learning situation while resolving abilities that are polar opposites.

\section{Kolb's four learning styles.}

By using this four-stage learning cycle model and based on the premise that people learn in different manners depending on how they input/process information, Kolb (1984) placed learners into four learning style groups: Accommodators, Divergers, Assimilators, and Convergers. Each learning style is located in a different quadrant of the learning cycle and is a conceived combination of perceiving and processing of how people prefer to learn. Kolb (1984) referred to these as preferences as styles, believing these are not fixed personality traits, but relatively stable patterns of behavior based on background and experiences. While dependant on our hereditary equipment, particular life experience, and demands of our present environment, Kolb (1984) stated most people "develop learning styles that emphasize some learning abilities over others" (p. 76). De Jesus, Almeida, Teixeira-Dias, and Watts (2007) portrayed the styles in a learning cycle or spiral where the learner "touches all bases - experiencing, reflecting, thinking, and acting - in a recursive process that is responsive to both the learning situation and what is being learned" (p. 3). The four learning styles involve the two bi-polar dimensions of information gathering (a combination of $\mathrm{CE}$ versus $\mathrm{AC}$ ) and information processing (a combination of RO versus AE).

The Diverger, or divergent learning style, emphasizes concrete experience and reflective observation and falls into the upper right-hand quadrant of the graph. Kolb (1984) stated the greatest strength of this orientation "lies in the imaginative ability and awareness of meaning and 
values" (p. 77). The Diverger emphasizes an innovative and imaginative approach to doing things. Little (2004) stated these individuals like to ask "why?" of a situation and reason from concrete, specific information exploring what the system has to offer (p. 8). Those with this style view concrete situations from many perspectives and adapt by observation rather than by action. They relate to "brainstorming" idea sessions and focus on people, imagination, and feeling oriented (Kolb, 1984, p. 78). Along with the use of cooperative groups and brainstorming, Little (2004) identified instructional methods aligning with the Diverger to include the lecture method. Lectures should focus on specifics like strengths, weaknesses, and uses of a system. Instructors should use examples, questioning, and reflective time for students to answer (Little, 2004).

The Assimilator, or assimilating learning style, emphasizes abstract conceptualization and reflective observation and falls into the lower right-hand quadrant of the graph. Kolb (1984) stated the greatest strength of this orientation "lies in inductive reasoning and the ability to create theoretical models, in assimilating disparate observations into an integrated explanation" (p. 78). This orientation focuses more on ideas and abstract concepts rather than people and theory must be logically sound and precise. Little (2004) stated these individuals like to ask "what is there to know?" (p. 8) and like accurate, organized delivery of information. Little (2004) identified instructional methods aligning with the Assimilator to include the lecture method, followed by a demonstration and laboratory exploration of a subject (following a prepared tutorial with answers provided).

The Converger, or convergent learning style, emphasizes abstract conceptualization and active experimentation and falls into the lower left-hand quadrant of the graph. Kolb (1984) stated the greatest strength of this orientation "lies in problem solving, decision making, and the 
practical application of ideas" (p. 77). Conventional intelligence tests seem to fit the person with this style best. Knowledge, for the Converger, is organized that through hypothetical-deductive reasoning there can be a focus on specific problem. Some basic characteristics of the Converger, or convergent learning style, include a preference with technical tasks and problems rather than social and interpersonal issues, decision-making, and problem-solving (Kolb, 1984). Little (2004) stated these individuals like to ask "how" of a situation and have a strength in deductive reasoning abilities (p. 8). Because of Converger's comfort level in designing experiments and testing theories, Little (2004) identified instructional methods aligning with the Assimilator to include interactive instruction, computer assisted instruction, problem-sets, or work-book usage.

The Accommodator, or accommodative learning style, emphasizes concrete experience and active experimentation and falls into the upper left-hand quadrant of the graph. Kolb (1984) stated the greatest strength of this orientation "lies in doing things, carrying out plans and tasks and getting involved in new experiences" (p. 78). Individuals in this grouping focus on opportunity seeking, risk taking, and action (Kolb, 1984). Kolb (1984) described this style as "accommodation" because it is "best suited for those situations where one must adapt oneself to changing immediate circumstances" (p. 78). Little (2004) stated these individuals like to ask "What would happen if I did this?” (p. 8) because they learn by doing and feeling through handson experience. Those within the accommodative learning style solve problems in an intuitive trial-and-error manner and rely on other people for information. Accommodators tend to be at ease with people, yet they can be seen as impatient or pushy with others (Kolb, 1984). Little (2004) identified instructional methods aligning with the Accommodator as anything encouraging independent discovery and active learning. 
Learning Styles Traditional and Online 38

\section{Kolb learning style inventories.}

This dissertation research study will utilize the survey instrument known as the Learning Style Inventory (LSI) developed by Kolb (1976, revised in 1984, 1999, and 2005). The researcher selected this particular instrument for its strong theoretical base in experiential learning theory (ELT). According to ELT, learning occurs when students participate in some activity, reflect upon the observations, use their conceptualization skills form their understandings from the experience, and then use their understandings to create new activities or incorporate them into new situations. Kayes (2005) stated Kolb's Learning Style Inventory (LSI) "remains one of the most influential and widely distributed instruments used to measure individual learning preference" (p. 249).

The LSI has been used primarily in educational, management training, and medical settings for many purposes including to gain a better understanding of the unique learning needs of specific, specialized, professional groups and being able to design and organize activities to meet those needs. Educationally, the LSI has helped learners and teachers alike. While learners gain an understanding of the learning process and preferences for differing educational experiences, teachers gain the exploration of their preferences in designing educational experiences (HayGroup/FAQ, n.d.). The HayGroup (n.d.) stated "the LSI has been especially useful when used by teachers and learners to develop a shared understanding of the educational venture and the contributions to it of both parties" (p. 2). Addressing applications and implications, Dunn, DeBello, Brennan, Kriminsky, and Murrain (1981) stated by focusing on hereditary equipment, past experience, and the environment, Kolb placed emphasis on individual awareness of learning styles and available alternate modes. Individual strengths and 
development of non-dominant orientation should be encouraged through knowledge of learning style differences and the design of instructional experiences (Dunn, 2003).

Since its original development as the Learning Style Inventory - Version 1 (Kolb, 1971; Kolb, 1976) in 1969, the instrument has seen five versions. Through the development of the first instrument, "the term learning style was coined to describe these individual differences in how people learn" (Kolb \& Kolb, 2005, p. 9). The LSI was originally developed as a short, nine-item questionnaire, but was expanded to twelve-items for all subsequent versions (Kolb \& Kolb, 2005). Learning Style Inventory - Version 2 (Kolb, 1985) was published in 1985 with the changed twelve scored items and wording simplified to a seventh grade reading level. For this version, a "new more diverse normative reference group of 1,446 men and women was created" (Kolb \& Kolb, 2005, p. 9). The next version, Learning Style Inventory - Version 2a, was published in 1993 producing a research version of the random format inventory (Kolb \& Kolb, 2005). Developed in 1999, Kolb Learning Style Inventory - Version 3 (Kolb, 1999) was a randomized format adopted with a revised self-scoring and interpretation booklet and also colorcoding for simplification. The most current version, Kolb Learning Style Inventory - Version 3.1 (Kolb, 2005), included new norms based on a larger and more diverse sample of 6,977 LSI users. The norm charts used to convert raw LSI scores is the only change in the KLSI 3.1 from the KLSI 3 (Kolb \& Kolb, 2005).

Kolb and Kolb (2005) conceived the Learning Style Inventory (LSI) for two main purposes. First, it serves as an educational tool for increasing individuals' understanding of the process of learning from experience and each individual's unique individual approach to learning. Kolbs' goal was to increase learners' capacity for meta-cognitive control of their learning process by increasing the awareness of how they learn. It would also enable learners to 
select and monitor learning approaches that would work best in each differing learning situation. Conversation could be fostered between educators and learners to discuss how to best accommodate and develop the most effective learning environment. The scores of the LSI could serve as a beginning for exploring how individuals learn best. Second, the LSI was created to supply a research tool for exploring and investigating characteristics of individual learning styles and for construct validation of the ELT (Kolb \& Kolb, 2005).

As discussed by Kolb and Kolb (2005), the intent of the LSI was not to predict behavior for purposes such as selection, placement, job assignment, or selective treatment. It is not a criterion-referenced test. By emphasizing individual uniqueness, Kolb (1981) intended to remain true to the philosophy of ELT. Kolb (1981) intended it to be used in a simple, straightforward, and open manner so the LSI could provide

a valuable self-examination and discussion that recognizes the uniqueness, complexity, and variability in individual approaches to learning. The danger lies in the reification of learning styles into fixed traits, such that learning styles become stereotypes used to pigeonhole individuals and their behavior. (pp. 290-291)

Derived from the ELT, the LSI was designed to be brief and straightforward, constructed for individuals to respond as they would to a learning situation, and hoped to predict behavior consistent with ELT (Kolb \& Kolb, 2005). In its design, Kolb (1984) intended the LSI to measure the degree to which individuals display the different learning styles by rank-ordering preferences for the abstract, concrete, active, and reflective orientations. Format, as described by Kolb and Kolb (2005), is a twelve-item short questionnaire format where respondents are asked to rank four sentence endings which correspond to the four learning modes $(\mathrm{CE}, \mathrm{RO}, \mathrm{AC}$, and AE). Unlike using a Likert scale, this is a forced-choice format instead of a free-choice format. 
The four modes ( $\mathrm{CE}$ - experiencing, $\mathrm{RO}$ - reflecting, $\mathrm{AC}$ - thinking, $\mathrm{AE}$ - doing) are conceived as interdependent and the crux of learning is based on the tension amongst the modes in response to a specific learning situation (Kolb \& Kolb, 2005). Kolb and Kolb (2005) stated the technical specifications of the KLSI 3.1 "are designed to adhere to the standards for educational and psychological testing developed by the American Educational Research Association, the American Psychological Association, and the National Council on Measurement in Education" (p. 1). The LSI 3.1 is available from Hay Resources Direct and is published in English, French, and Spanish. Approximate time for completion is 20 to 30 minutes and administration is said to be offered self-scored, paper-based, and online (HayGroup/Kolb LSI, 2009).

\section{Previous Studies of Learning Styles in Traditional and Online Learning Environment}

Neuhauser (2002) utilized learning styles in her research but focused primarily on effectiveness. The researcher compared two sections of a course. One was asynchronous and online while the other was face-to-face. The two sections of this same course were taught by the same instructor using the same instructional materials. The enrolled students self-selected the section in which to enroll (online or face-to-face). Learning style was assessed by using two instruments: the Learning Modality Preference Inventory and the Keirsey Temperament Inventory. Her study examined learning styles to see if those differences, if any, impacted outcomes in the courses. Neuhauser (2002) concluded there were no significant differences between learning preferences and styles and also no correlation between final grades in either group. Results showed most students (greater than 60 percent in each) were visual learners whereas only three students (of the total population) chose auditory as their preferred style. The most successful students, identified by Neuhauser (2002) as "A" students, had preferred learning 
styles of kinesthetic (66 percent) and visual (40 percent) for the online learner and had preferred learning styles of kinesthetic (43 percent) and visual (43 percent) for the face-to-face learner.

Utilizing the Canfield Learning Style inventory (CLSI) Tucker (2001) examined the effectiveness and learning styles in online versus tradition face-to-face instruction. The population of the study consisted of business communications undergraduates. Results indicated no significant difference in final course grade between the two groups. Several findings were concluded regarding learning styles. In both groups there was a similar preference for "Organization" and "B-Expectation" for course grade while "Numeric" was least preferred. "People" and "Direct Experience" were preferred by online students and "Inanimate and "Iconic" were preferred by traditional students. Additionally, online students indicated their least preferred style was "Authority" and "Listening" while traditions students indicated their least preferred style was "Independence" and "Reading" (Tucker, 2001).

Liu (2007) replicated Tucker's (2001) study but used two sections of a graduate course (one online and one traditional face-to-face) instead of an undergraduate course. The CLSI was used in this comparative study which investigated how online and traditional face-to-face students used different learning styles in a graduate education course. No significant statistical differences were found in learning styles at pretest, but significant statistical differences were found in many learning style subscales at posttest. Online students seemed to have a higher preference in the learning style subscales of 1) peer interaction, 2) competition, 3) interaction with instructor, 4) details of the course materials, 5) independence, 6) authority, 7) reading, 8) direct experiences, 9) and clear goal setting. In both groups, no significant difference was found in learning performance (Liu, 2007). The changes occurring between pretest and posttest 
indicated online students' preferred learning styles were apt to change from the beginning of a semester to the end of the semester.

Canfield's Learning Style Inventory was also used by Keri (2002-2003) who investigated learning style differences between traditional and nontraditional students. Subjects were community college and university undergraduates. Results indicated learning styles between the two groups of students could not be differentiated using the CLSI (Keri, 2002-2003).

A study of online students' needs by Butler and Pinto-Zipp (2006) looked for a dominant learning style, a preferred method of online instruction, and a relationship between learning styles and the preferred method of online instruction. The Gregorc Learning Styles Delineator (GSD) along with a demographic and Likert scale questionnaire were utilized. Varied learning styles with dual learning styles (56.2 percent) represented the greatest number of students. The students preferred asynchronous log-ons and high course interaction and also noted a high degree of satisfaction within their online programs (Butler \& Pinto-Zipp, 2006).

In a study by Downing and Chim (2004), students enrolled in two online courses were compared with students enrolled in equivalent classroom-based courses. The relationship between learning style and mode of delivery was investigated as well as student satisfaction measures. It was found that students of a Reflector learning style demonstrated higher satisfaction with online instructional delivery than those in the classroom-based courses. Students classified with the Reflector learning style exhibited Extrovert behavior while in the online courses while in the traditional setting they might be considered Introverts (Downing \& Chim, 2004).

Wang, Wang, Wang, and Huang (2006) conducted a study which investigated the effects of formative assessment and learning style on student achievement in a web-based learning 
environment. Subjects were 455 seventh-grade students from twelve classes of six junior high schools. Students were tested using Kolb's Learning Style Inventory. Online students were found to perform best when they had a Divergent learning style (Wang et al., 2006). Wang et al. (2006) concluded two main points from their findings: 1) awareness of student learning styles may increase student performance when considered in e-learning design, and 2) because of the great diversity in students, utilizing various teaching strategies may be more effective than utilizing a single teaching strategy.

Mahoney (2006) utilized the Sensory Modality Checklist and assessed strengths in nineteen graduate nursing students in the auditory, visual, and kinesthetic domains. No significant differences were found between visual or kinesthetic learners in the online versus traditional students. Auditory and visual learners were strongest between groups and both used mixed sensory modality styles. It was suggested that faculty need to be aware of their own learning styles and the varying needs of students to incorporate various learning modalities (Mahoney, 2006).

Buerck, Malmstrom, and Peppers (2003) conducted a study directed at determining if there was a relationship between students' preferred learning environment (face-to-face or online) and also if there was a difference in the academic success of the students in the two learning environments. Subjects (29 participants successfully completed the course) included nontraditional students in a computer science course at Saint Louis University. Kolb's (1985) Learning Style Inventory and a brief demographic questionnaire were used to measure styles of learning and demographic information. Between the two learning environments a significant difference was found in learning styles. Online students were found to more likely have a Converger learning style while face-to-face students were more likely to have the Assimilator 
learning-style. These findings supported the hypothesis that there is a relationship between students' preferred learning style and their learning environment. Academic success of the students did not differ due to the learning environment selection (Buerck et al., 2003).

Aragon, Johnson, and Shaik's (2002) study design questioned whether there were distinguishable differences between the learning style preferences of students enrolled in an online course and those enrolled in an equivalent face-to-face course (they also investigated if learning style preferences influenced student success). Two sections of a graduate-level instructional design course for human resource development professionals taught at a large midwestern university were used for the study. Motivation maintenance was assessed using Riechmann and Grasha’s (1974) Student Learning Style Scale (SLSS), task engagement was assessed by the Weinstein, Palmer, and Schulte (1987) Learning and Study Strategies Inventory (LASSI), and cognitive control functions were assessed through the Kolb (1985) Learning Style Inventory (LSI). It was found there were significant differences between the learning style preferences of the students enrolled in different learning environments (but these differences were not significant when success factors were controlled). No significant differences in the social and environmental preferences between the students of the two delivery formats were found and both the face-to-face and online students were found to have similar learning and study strategies. The two groups showed significant differences in the area of cognitive processing habits (cognitive controls). Online students were found to be more reflective and have a higher reported preference for abstract conceptualization in comparison to face-to-face students. Face-to-face learners were found to report a greater use of learning by doing, or active experimentation, scale (Aragon et al., 2002). 
The Grasha-Reichmann Student Learning Style Scale (GRSLSS) was used in a study by Diaz and Cartnal (1999) comparing students' learning styles in online distance and an equivalent on-campus health education class. Results indicated on-campus students were more dependent in their styles as learners while online students were more independent. The online students with independent learning styles tended to be less collaborative and dependent and appeared more driven by intrinsic motives and not by the reward structure of the class. Significant positive correlations were also found between the collaborative learning style and the competitive and participant learning styles. The collaborative on-campus students tended to be competitive and participatory in the classroom. The on-campus students preferred structure and guidance (Diaz \& Cartnal, 1999).

In a study designed to determine the learning styles, expectations, and needs of online industrial education undergraduate college students, Mupinga, Nora, and Yaw (2006) utilized the online Myers-Briggs Cognitive Style Inventory personality test. A predominant learning style was not identified among the online students; however, about half of the survey population were categorized as introverts, sensors, and judgers. Because there was not a predominant style, Mupinga et al. (2006) reported "the design of online learning activities should strive to accommodate multiple learning styles" (p. 188). Web-based environments were identified as not addressing student diversity. Instructors need to understand the online learning environment, and be able to meet the learners' diverse learning styles, need, and expectations to maximize the learning experiences (Mupinga et al., 2006).

A study examining the influence of learning styles on student satisfaction in conventional and web-based environment was conducted by Manochehri and Young (2006). The population for this study was university students enrolled in the college algebra course (both an on-campus 
instructor-led course and a web-based course) having the same instructor. Based on a student's learning styles, a series of two-way analysis of variance (ANOVA) techniques and independent variable tests were used for the dependent variable - satisfaction. Results of this study concluded the following: 1) there was no significant difference in student satisfaction based on their learning styles, but there was a significant difference in satisfaction, based on teaching methodology, 2) there is a significant difference in student satisfaction between learning on the web versus instructor-based learning, with the instructor-led methodology being more satisfying, 3) there was a slight trend in an increase of satisfaction among the learning styles of Assimilator and Converger compared to Diverger and Accommodator, and 4) there was greater satisfaction of the instructor-based students, regardless of their learning styles, compared to the web-based students (Manochehri \& Young, 2006).

Manochehri and Young (2006) conducted a study which compared the effects student learning styles (web-based learning and traditional instructor-based learning) had on student knowledge and satisfaction. The population for this study was university students enrolled in the Math 1100 (college algebra) course. The independent variables were learning methods and learning styles (based on Kolb's four learning styles) and the dependent variables were student knowledge and satisfaction. The following results were found: 1) There was no significant difference in student satisfaction based on their learning styles, but there was a significant difference in satisfaction based on teaching methodology (instructor-led were more satisfied than web-based); 2) Students' learning styles were statistically significant for knowledge performance (Assimilator and Converger did better with web-based methodology, while Diverger and Accommodator received better results with instructor-based learning); 3) There was not a significant difference in performance between instructor-based and web-based subjects 
(Manochehri \& Young, 2006). Allen, Bourhis, Burrell, and Mabry (2002) conducted a metaanalysis summarizing and evaluating empirical literature comparing student satisfaction with distance education to traditional classrooms in higher education. Overall, analysis indicated students have a slightly higher level of satisfaction with live course settings than distance education formats; however, after removal of three outliers and reanalysis, the results indicated there is homogeneity. In general, there was little decline in student satisfaction with the quality of the educational experience between the two methodologies.

Additionally, the researchers found that learning style may impact as a form of individual difference on the issues of distance education whereby the need for diagnosis or providing a course in multiple formats may be indicated (Allen et al., 2002).

Moallem (2007-2008) examined what effects students' learning styles and the design of instruction have on attitude and satisfaction. The course used in the study was a foundation course for all students in a graduate instructional technology program using the Vista platform and was a blend of asynchronous and synchronous instruction. For this study, Felder and Soloman's (n.d.) index of learning styles instrument was used to assess students' learning styles while a separate open-ended survey assessed students' satisfaction (of units). Results of the student learning styles showed the majority of the students were equally divided in different categories of learning styles with visual learners being the highest in frequency. Additionally, all active learners were also visual learners while only half of reflective learners were visual. Reflective and active learners were equally divided between sequential and global learning styles. Eighty percent of active learners were intuitive and 80 percent of reflective learners were sensing learners. No significant differences in satisfaction were shown (Moallem, 2007-2008). Regarding online learning, Moallem (2007-2008) offered several conclusions of his study: 1) 
Students' perceptions of their positive learning experience influence their motivation and willingness to adjust their preferred learning styles (in online environments where social interaction, collaboration, and problem solving were highly emphasized). 2) Learning styles can be integrated into online learning environments instruction without compromising the appropriateness of instructional strategies for specific content and learning outcomes. 3) Integrating learning styles in the design of instructional materials seemed to encourage learners to spend more time interaction with content and exploring various instructional materials to achieve learning outcomes. 4) Higher learning outcomes may result if multiple learning styles are addressed in a variety of instructional strategies (Moallem, 2007-2008).

Sahin (2008) investigated satisfaction in web-based courses in higher education and established a connection for satisfaction and learning styles. Kolb’s (1984) Learning Style Inventory, along with Walker's (2005) distance education learning environment instrument, and demographic questions were used in the study of students in five web-based undergraduate university courses. Results found web-based courses appear more appropriate for AC learners (in perception of authentic and active learning) (Moallem, 2007-2008). Moallem (2007-2008) suggested web-based courses could better accommodate learners with the preferences for CE and AE if the courses include more collaborative and real life activities. Moallem (2007-2008) recommended "course activities be designed to address a range of learning styles with instructional activities" (p. 134). When considering the high emphasis social interaction, collaboration, and problem solving have in the online environment, Moallem (2007-2008) stated, “it is likely that students' perceptions of their positive learning experience influence their motivation and willingness to adjust their preferred learning styles" (p. 238). 
Satisfaction was investigated by Allen et al. (2002) in meta-analysis comparing distance learning and traditional classroom environments. Findings indicated a 22 percent drop in the level of satisfaction in distance education compared to traditional instruction format (on average, the students in the distance education course demonstrated a lower level of satisfaction with the process) (Allen et al., 2002).

Wang, Hinn, and Kanfer (2001) investigated links between students’ learning styles and computer-supported collaborative learning environments. It was found that learning style does not affect student satisfaction with online students and Convergers who combined active experimentation and abstract conceptualization preformed better in the online learning environment than students with other learning styles (Wang et al., 2001).

Student satisfaction with e-learning was investigated in a study by Levy (2007) which compared dropouts and persistence in e-learning courses. Results indicated students' lack of satisfaction with e-learning was a key indicator in students' decision to dropout from e-learning courses (Levy, 2007). Studies such as Chyung, Winiecki, and Fenner (1998) reported satisfaction as a major factor in a student's decision to dropout of a distance education course. Sachs and Hale (2003) proposed major emphasis should be placed on students' satisfaction in measuring success of college and university e-learning courses and also retention. Keeping students' satisfaction levels with e-learning high should be goal of college distance education programs (Sachs \& Hale, 2003).

\section{Distance Education v. Traditional Learning Environments Distance education's development and definition.}

In basic terms, many researchers believe distance education is where the teacher and student are separated by space and/or time (Moore \& Kearsley, 2005; Kearsley 2000; Perraton, 
1988). Similarly, King, Young, Drivere-Richmond, and Schrader (2001) defined distance learning by including the time and geographic separations and not having "in-person contact" between the teacher and student (p. 8). King et al. (2001) also defined distance learning as "improved capabilities in knowledge and/or behaviors as a result of mediated experiences which are constrained by time and/or distance such that the learner does not share the same situation with what is being learned" (p. 7). Additionally, Stella and Gnanam's (2004) definition of distance education includes the time and space separation from students and their instructors and shows it as a subset of distributed learning. Sherry (1996) asserted "the terms 'distance education' or 'distance learning' have been applied interchangeably by many different researchers to a great variety of programs, providers, audiences, and media" (p. 338).

Bower (2004) stated the US Distance Learning Association incorporated different facets of the learning environment by defining distance education as the "acquisition of knowledge and skills through mediated information and instruction, encompassing all technologies and other forms of learning at a distance" (n.p.). Taking the definition of distance education a step further, Dabbagh (2004) revised the definition to include "the deliberate organization and coordination of distributed forms of interaction and learning activities to achieve a shared goal"' (p. 41). Additionally, the following traits are applied to the definition: globalization and learning as a social process (inherent and enabled through technology), a learning group is essential for learning, distance is somewhat unimportant and isn't always a long-distance separations between teacher and student, teaching and learning experiences can occur synchronously and/or asynchronously and are distributed over time and place, and learners are engaged in multiple forms of interaction (with each other, the content, and the instructor) (Dabbagh, 2004). 
The mainstream delivery mode for higher education is no longer traditional campusbased education. The last two decades has witnessed a significant increase in alternative education formatting and delivery and also new globally impacting providers due to the technological developments (Stella \& Gnanam, 2004). The birth of university-level distance education (DE) has been dated back to the 1800's when the University of Chicago, the University of Wisconsin, and the Pennsylvania State University launched their first correspondence study programs (Miller, 2001). Parker (2003) states that DE as an alternative to face-to-face instruction has witnessed steady growth since that time. Miller (2001) couples general education and DE as catalysts that "have been affected by, and help effect, higher education's response to the shifting currents of American society" (Miller, 2001, p. 314). Miller (2001) believes three factors have brought DE into a new prominence in higher education: 1) the change in standards for professional education, 2) the emergence of the adult learner as a significant percentage of the student population, and 3) the rise of computer-based technologies that offer new instructional tools.

Five generations of distance education, each largely defined by available media and range of instructional options available at the time, have been characterized by Taylor (2001). The progression is described as a rough continuum of increased flexibility, interactivity, delivery of materials, and access beginning with correspondence education and progressing through radio, television, multimedia, Internet, web-based resources, computer-mediated communication, and finally to campus portals (Taylor, 2001). Bernard, Abrami, Lou, Borokhovski, Wade, Wozney, Wallet, Fiset, and Huang (2004) stated distance education was once "regarded simply as a reasonable alternative to campus-based education, primarily for students who had restricted access to campuses because of geography, time constraints, disabilities or other circumstances," 
(p. 382) but has since "set traditional educational institutions into intense competition for the worldwide market of online learners" (p. 383). Bernard et al. (2004) included the following three criteria into their definition of distance education: 1) semipermanent separation (place and/or time) of learner and instructor during planned learning events, 2) presence of planning and preparation of learning materials, student support services, and final recognition of course completion by an educational organization, and 3) provision of two-way media to facilitate dialogue and interaction between students and the instructor and among students.

\section{Rationale for using distance education.}

The reasons that faculty members typically use distance education seem congruent with what Hillstock (2005) stated as the fundamental premise of distance learning - "to create and widen access to education and to improve its quality, using distance education techniques and associated technologies to meet the particular requirements of individuals who were unable to participate in the traditional classroom environment" (p. 139). Hillstock (2005) discussed there "seems to be a drive towards the need for distance learning" due to the new technologies emerging daily and growing need for more flexibility (p. 139). PBS Campus reports $67 \%$ of colleges and universities agree that online education is a critical, long-term strategy for their institution and in response $49 \%$ of public colleges and universities and $34 \%$ of all higher education institutions offer complete online degree programs (Hillstock, 2005). As distance education programs have been increasing in the United States, Internet-based distance education now could be described as mainstream education (Scagnoli, 2001).

The 2007 Distance Education Survey concluded the distance education market outlook is "strong," and will continue to "be heavily utilized" and "grow for many years" (Distance Education and Training Council, 2007, p. 7). Additionally, as public acceptance of distance 
education is growing and competition in distance education is growing, higher education will be turning to distance education as a mainstream delivery medium. This will encourage diversity of students and an expansion to more and various markets (Distance Education and Training Council, 2007). Beldarrain (2006) speculated student interaction will be "at the heart of learnercentered constructivist environments" as pedagogical perspectives and theoretical frameworks shift to accommodate current trends in distance education (p. 139).

Baldwin and Baumann (2005) described education "in a time of rapid change" contending academic fields "must adapt to accommodate changing student interest, new approaches to teaching and learning" and also be "dynamic" (p. 89). Higher education is encouraged to "think outside the box" and apply new options to encourage programs to become more flexible and adaptive to serve a diverse society effectively (Baldwin \& Baumann, 2005, p. 90). Utilizing learning styles and creative pedagogical approaches can help academic programs to achieve these goals.

As Stella and Gnanam (2004) posit "the borderless and boundaryless distributed learning has already become a reality" (p. 156). Moller, Foshay, and Huett (2008) discussed the evolution of distance education and describe the growth of distance learning as "explosive in almost all sectors, and in many developed and developing countries” (p. 70). Miller and King (2003) described distance education as "the burgeoning learner-centered paradigm that offers the opportunity to provide access to students seeking higher education in the $21^{\text {st }}$ century" (p. 294). Liu (2007) described online education as growing "exponentially every year all over the world" (p. 41). Damoense (2003) believed "E-learning is increasingly forming an integral part of course delivery and instruction, and is reshaping traditional learning world wide" (p. 25). Even though research studies recommended considering online students' learning styles in both course 
design and online course delivery (Grasha \& Yangarber-Hicks, 2000; Kirkwood \& Price, 2005; Mupinga, Nora, \& Yaw, 2006), there seems to be paucity in the research supporting distance learners' unique needs and learning styles. Harris, Dwyer, and Leeming (2003) also found the relationship between individual learning styles and Web-based instruction has received very little attention. Concerning online instruction on learner's psychological characteristics such as learning styles, Liu (2007) stated "there is not much attention paid to the effects" (p. 42). Liu (2007) asserted there is a need to investigate the similarities and differences in learning styles between online and traditional students to "make the online option more attractive and viable for different groups of learners" (p. 44).

Liegle and Janicki (2006) described the tremendously fast-growing rate of web-based training as a "one-size-fits-all approach" to the material delivery (p. 885). It is also proposed that a more effective system to adapt to the relationship of the material presentation mode and learning style of the users could be implemented (Liegle \& Janicki, 2006). The general one-sizefits-all approach does not take in account the needs of all the different learners (Janicki \& Liegle, 2001).

The growth of online education (eLearning) has grown exponentially (Li \& Irby, 2008; Moller 2008) in almost all sectors and in developed and developing countries. However, the value of transformational potential and high instructional quality may not be recognized and valued (Moller, 2008). Distance education creates added opportunities for non-traditional education and provides easy access to course materials for instructors and students (Karber, 2003).

Distance education has open to students many portals to learning where universities have failed to provide the seats. The growing access to networking capabilities also helps to promote 
this learning venue. Carvin (2008) stated 96 percent of universities offered campus WiFi, three out of four campuses utilized distance learning, and six out of ten offered off-campus networking to their students. The number of students is being impacted by the growing number of college courses delivered over the web (Chen 2001).

Within the rationale for the use of distance education, it is also important to note that it was found that the underrepresented groups were represented in a greater numbers in the online course compared to their face-to-face counterparts. Innovated strategies can be developed by education providers to reach out to these individuals (Swindell \& Thompson, 2000).

Additionally, there may be more opportunities for more privacy and safety by utilizing an online medium (Githens, 2007).

While focusing on the online student, Ackoff and Greenberg (2008) pointed how equitable and fair education can be in online learning. Age, gender, religion, race, ethnic origin and almost any other factor that has played a major role in determining a person's relationship with those around them is irrelevant. In cyberspace, "everyone is a person" and "treated in the same manner as the communication of any other person" (Ackoff \& Greenberg, 2008, p. 15). Students can be linked directly to the most up-to-date sources of information on virtually any topic through the Internet, CDs, DVDs, and storage media making an infinite diversity of activities and interests accessible. Ackoff and Greenberg (2008) stated these endless possibilities as a "stark contrast to the narrowly limited field of view presented by the handful of subjects selected by anonymous pedagogues as the proper focus for all students" while the world of traditional education seems "hopelessly sterile, arcane, and irrelevant" (p. 15). Ackoff and Greenberg (2008) suggested online education and computers have enabled students to learn from each other and become "facilitators of learning" (p. 17). Through technology, what Ackoff and 
Greenberg (2008) called a global mind can be created. Global mind, as defined by Ackoff and Greenberg (2008), is the following:

a universal repository in which all events are recorded as they occur; everything that has been recorded is stored in an appropriate fashion in a global memory; and everything stored is accessible in whatever form the accessors wish to have and can be manipulated in any way they want. The present and the past, on a cosmic scale, are all integrated into a great reservoir of experience that can be analyzed and studied at will. (p. 58)

\section{Various types of distance education.}

In the past, institutions of higher education mainly provided distance education by using

face-to-face sessions, live satellite, or closed-circuit television. More recently, a broad use of the Internet has become popular in academia (Fuller, Rena, Pearce, \& Strand, 2000). Horton (2000) stated three environments are usually used for online instruction: 1) completely online without face-to-face interaction, 2) as a hybrid course where the class frequently meets face-to-face in addition to the online component, and 3) as a face-to-face course with integrated web-based support materials and activities.

Learning Management Systems (LMS), also known as Virtual Learning Environments (VLE) or learning platforms, are now being utilized for instruction. These systems provide an interface that automates the administration and facilitation of online interactions and distribution of learning materials. Instructors are able to provide learning activities and materials and track participation and progress through data systems and assessments (Falvo \& Johnson, 2007).

Falvo and Johnson (2007) reported the most popular LMS used at colleges and universities in the United States was Blackboard (1997) and WebCT. It is reported that the interface is "easy to use" and "efficient for students" (Falvo \& Johnson, 2007, p. 44). Although 
Falvo and Johnson (2007) found these two commercial systems to dominate the higher education market, systems such as eCollege, Moodle, SharePointLMS, Dokeos, ILIAS, and many others are being utilized.

Lovelace (1999) described two types of web-based learning: asynchronous, or self-paced, and synchronous, or instructor-led. Synchronous is described as communication without extended time delay (with activities such as chat sessions and discussions), while asynchronous is described as two-way communication involving a time delay between transmission and receipt (Bower \& Hardy, 2004). Synchronous distance education as described by Bernard et al. (2004) is not very different from the early closed-circuit television distributed education on campuses (similar to the beginning courses at the Pennsylvania State University that began in the late 1940's). Bernard et al. (2004) contrasts this to asynchronous distance education described as "group-based" and "individually based" whereby students in remote locations work independently (p. 387). Asynchronous learning networks allow students to create a virtual learning community by allowing students to participate at their own time and location. It also permits collaborative projects between students because of the wide range of information and learning resources available. Emphasis on inquiry, independent use of information resources, case studies, and individual and small-group problem solving and decision making are encouraged through this active, collaborative, and resource-rich learning environment (Miller, 2001). In an online, asynchronous environment, students are able to read comments and reflect before offering their own comments. The "amount and sometimes depth of interaction can be quite impressive" (Carriuolo, 2002, p. 58) without pressure from a professor. The notion of utilizing learning styles in the online classroom can be very important since learning styles of most students "are not accommodated by lectures, but by engaging students in active learning 
accompanied by continuous feedback and review" (Carriuolo, 2002, p. 60). Within asynchronous studies there is usually an element of "within-group synchronicity" (Bernard et al., 2004, p. 387). This can mean distance education students are communicating with each other synchronously, among themselves. In distance education, asynchronous environments are experiencing the most explosive growth (Miller \& King, 2003).

As described by Jackson (2005), the web-based classroom "is a special social environment that is very different from the on-ground classroom" (p. 4). The success of the ecourses and web-based instruction "depends not only upon the schools and universities, but also the faculty and adjunct instructors who teach these courses" (Cook, Ley, Crawford, \& Warner 2009 , p. 149). It is also suggested that money is becoming a powerful and influential factor in distance learning. This can be evidenced by the growth of proprietary, for-profit online institutions of higher learning such as Walden University, Capella University, and the University of Phoenix (Cook et al., 2009).

\section{Statistics and prevalence.}

Distance education and web-based courses have been shown to be mainstream in colleges and universities in the United States and growing (U.S. Department of Education, 2008). The magnitude and impact of distance education in higher education can be easily shown through the current distance education statistics. Sixty-six percent of the 4,160 2-year and 4-year Title IV degree granting postsecondary institutions in the nation offered college-level distance education course in the 2006-07 academic year. This included and overall percentage of 97 percent of public 2-year institutions, 18 percent of private for-profit 2-year institutions, 89 percent of public 4-year institutions, 53 percent of private not-for-profit institutions, and 70 percent of private f0rprofit 4-year institutions. Sixty-five percent of the institutions reported college-level credit- 
granting distance education courses while 23 percent reported noncredit distance education courses. In 2006-07, enrollments or registrations in college-level credit-granting distance education courses totaled an estimated 12.2 million (77 percent reported as online courses, 12 percent reported as hybrid/blended online courses, and 10 percent reported in other types of distance education courses). During this 2006-07 academic year, approximately 11,200 collegelevel programs were designed to be completed totally through distance education (66 percent as degree programs and 34 percent as certificate programs) (U.S. Department of Education, 2008).

There is a growing interest in distance learning students shown by the numbers enrolled. Between 2002 and 2014 total enrollment in degree-granting institutions is projected to increase 17 to 20 percent (Hussar, 2005). If distance learning students follow the projected trend in growth of total enrollment, there will be demand on institutions of higher education to meet the challenge of growth by expanding class size and by developing new courses and programs. Capitalizing on designing courses using learning styles could better meet the needs of this growing population. Stella and Gnanam (2004) reported in the US, many large public universities (like the University of Maryland University College, UMUC) are very active providing distance learning and online course opportunities to their students. For example, in 1999-2000, UMUC had more than 40,000 online students (Eaton, 2001). Enrollments and online course offerings are rapidly expanding in other universities as well. Salmi (2000) showed the portion of US universities with distance education courses went from 34\% in 1997-1998.

Karber (2003) suggested many opportunities for non-traditional education are accessible and available through the Internet and World Wide Web. Li (2008) contended similar thoughts adding that the flexibility of online education has helped working self-motivated and mature students to complete their education while still supporting themselves or their families. Online 
education is "a catalyst to enable the paradigm shift to take place in education, making educators/academics think about and study how such programs are best delivered" (Li, 2008, n.p.) Online education and e-learning has become an essential part of teaching in higher education.

\section{Impact and changes necessary in higher education.}

There is a rapid increase in delivery of courses at a distance, especially online courses, in higher education (Shieh, Gummer, \& Niess, 2008). Because of the growth in DE and e-learning courses both the academic and public communities have been entreating for more (Cook, et al, 2009). Kanuka (2002) stated "the last decade has witnessed an unprecedented popularity of the use of the Web in all levels of education" (p. 163). Miller (2001) considered DE to be a "lifeline" between higher education and lifelong learners (p. 321). Learning communities can now be created at a scale not previously practical by bringing together students outside of the traditional campus classroom (Miller, 2001). Miller (2001) concluded, "the scalability offered by distance education technology may prove, ultimately, to be its most practical benefit to general education" (p. 322). The most common factors cited as affecting distance education decisions to a major extent were meeting student demand for flexible schedules (68 percent), providing access to college for students who would otherwise not have access (67 percent), making more courses available (46 percent), and seeking to increase student enrollment (45 percent) (U.S. Department of Education, 2008).

Wickersham, Espinoza, and Davis (2007) concluded "Online courses are growing in popularity, providing opportunities for individuals to complete their education while overcoming time and distance constraints. Innovations in distance education allow for the design and development of online courses that adapt to meet the specific needs and/or learning styles of the 
students enrolled, and reflect the unique learning style and personality of the instructor” (p. 197). For effective learning to occur, the context must be meaningful to the learner. According to Damoense (2003), "the key to effective online learning is to increasingly engage learners" (p. 45). Knowing students' learning styles may foster their engagement and therefore meaningfulness to the learner.

According to Davis (2001), the world is starting a new age of learning where technology is the driving force to reaching an "increasingly diverse audience with a variety of flexible, compelling, and more effective learning opportunities" (I[2). Davis (2001) suggested the key to delivering effective instruction that meets the needs of the diverse population of learners is recognizing DE learning requires different pedagogical approaches from classroom learning. Zhao (2003) agreed that teaching online is not the same as teaching in a traditional classroom in terms of pedagogical approaches and use of technology.

Because higher education is beginning to change in response to providing education and increasing student diversity, opportunities to restructure the educational system utilizing technology and e-learning will initiate new pedagogical change (Desai, Hart, \& Richards, 2008). Raised in a world of instant access to knowledge and information, distance education and elearning can provide "strong interaction between the learner, learner/instructor, and the content as well as other learners" in a low-cost, flexible format (Desai et al., 2008, p. 328). Desai et al. (2008) concluded e-learning will provide more benefits versus traditional learning including the following: 1) compared to traditional learning, e-learning requires great maturity and discipline, 2) learning opportunities through e-learning are provided 24-hours per day, 3) cost effective high quality educational choices are available, 4) geographical location is not an issue due to worldwide accessibility. Pedagogical approaches, once appropriate, will have to be revisited and 
revised to accommodate the rapid growth of online distance education worldwide (Beldarrain, 2006). Carriuolo (2002) stated "distance learning is providing a portal not just to academic degrees, but also to upward social and economic mobility" (p. 57).

Distance education, according to Lyons (2004) can be important in higher education and attractive to students such as the following: 1) those with family or work constraints, 2) those who frequently travel, 3) those who need to advance their career but can pause current responsibilities to do so, 4) those who physically find it difficult to attend college, and 4) those who need/want to be home with children. The flexibility of staying home or traveling while engaged in education is appealing. According to $\mathrm{Li}$ (2008) DE is attractive because it offers accessibility to many universities. Students are no longer limited to educational opportunities only near them. Students can garner a broader perspective on various topics and experiences because they are able to interact with other students from all over the world. This global outreach can enrich students' experience and perception (Li, 2008).

"Expansion" is the defining trend in the worldwide development of higher education according to Daniel, Kanwar, and Uvalić-Trumbić (2009) "where age participation rates (APRs) in higher education of 40 to 50 percent are perceived as necessary for sustained and sustainable development" (p. 30). By supporting a trend to educate people to higher levels, Daniel et al. (2009) believed poorer countries will become increasingly prosperous and stable politically and economically. Working adults and those in rural areas, who are normally harder to reach, can participate in higher education through open and distance learning and e-learning methods (Daniel et al., 2009). 


\section{Challenges in using distance education.}

According to Bower and Hardy (2004), faculty, staff, and student expectations and fears will need to be addressed due to the technical, pedagogical, and organizational challenges distance education pose for the institutions. In some colleges stakeholders will argue that distance education is a passing phase while many more will recognize that this method of learning has irrevocably revolutionized education.

Changes in the classroom will also challenge distance education. Bower and Hardy (2004) discussed distance education and web-based instruction has changed course content, teaching roles and methods, assessment strategies, interaction, and communication aspects of teaching. Bower and Hardy (2004) outlined some of the distance education challenges to include requiring innovations in student support (library services, financial aid, registration, advising all from a distance), gaining technology expertise for faculty, establishing a marketable presence in this rapidly expanding environment (requiring collaborative efforts of faculty, instructional designers, and programmers), changing institutional culture, and developing new procedures and policies. All stakeholders will need help and support to address changes in technology and learning/teaching roles (Bower \& Hardy, 2004).

Stella and Gnanam (2004) takes a global stance when discussing impacts and challenges of distance education stating "it has caused a serious concern to the government and the quality assurance agencies all over the world about the safety of the national systems, legitimacy of the providers, protecting the public from fake providers, quality of the offerings etc. the common element being concern for quality" (p. 143). This serious concern for quality has many quality assurance agencies debating if practices for distance education are basically the same as in the traditional classroom or if distance education tests conventional assumptions and present 
mechanisms that are not adequate for distance education quality to be ensured (Stella \& Gnanam, 2004).

Li (2008) discussed challenges in terms of translating a traditional face-to-face course to an online environment. It requires organization, dedication, and commitment to modify materials and adjust to the online environment. Servonsky, Daniels, and Davis (2005) reported more precise planning and preparation time were needed for distance education instructional materials. Additionally, it was stated that it takes much more time to prepare a lecture for an online course than it does to prepare a lecture of a traditional face-to-face course (Servonsky et al., 2005). According to Karber (2003), both teachers and students spent more time and effort in online courses in comparison to their face-to-face classroom counterparts.

Li (2008) also pointed there are many challenges revolving around students. Students who struggle with motivation and self-discipline may have problems committing to the online format and feeling connected with peers and instructors. Swindell and Thompson (2000) discussed technical problems as a recurring source of frustration of online students (especially those without higher technical and computer skills). Githens (2007) discussed the readiness of the learner in needing an acceptable reading level, technical expertise, and computer expertise. Without those competencies, less educated individuals may not feel safe or comfortable. In most current forms of e-learning, written text is relied on heavily (Githens, 2007). It has been suggested that (older adult) students may experience a decline in reading comprehension due to vision problems and not because of cognitive decline (VanBiervliet, 2004).

Ceraulo (2005) reported results of a survey of consumer attitudes towards on-line education and found concern about the quality of online education. Thirty-eight percent of those surveyed were unsure of the quality of online education relative to classroom instruction, and 
$29 \%$ believed online education is inferior to classroom instruction. Additional findings revealed some students surveyed were worried that an online degree would not be as acceptable to potential employers as a more traditional campus-based degree - that these degrees would be perceived as different with the campus-based degree as more acceptable (Ceraulo, 2005).

\section{Concluding Thoughts}

The growth of distance education courses via the Internet prompted educational research focusing on learners' characteristics and learning differences during the past twenty years (Hills, 2003; Khan, 2005). Approaches to learning emphasized the importance of taking learners into consideration when designing instruction. Learners' characteristics have always been an important concern for educators, designers, and researchers (Khan, 2005; Laurillard, 2001; Moore \& Kearsly, 2005; Schwitzer, Ancis, \& Brown, 2001). Knowledge of learners’ characteristics is important when deciding on the type of media by which the content will be delivered and the structure of courses by which diverse students will be accommodated (Khan, 2005; Laulliard, 2001).

Distance education and web-based courses have been shown to be mainstream in colleges and universities in the United States and growing (U.S. Department of Education, 2008). The magnitude and impact of distance education in higher education can be easily shown through the current distance education statistics. Sixty-six percent of the 4,160 2-year and 4-year Title IV degree granting postsecondary institutions in the nation offered college-level distance education course in the 2206-07 academic year. This included and overall percentage of 97 percent of public 2-year institutions, 18 percent of private for-profit 2-year institutions, 89 percent of public 4-year institutions, 53 percent of private not-for-profit institutions, and 70 percent of private f0rprofit 4-year institutions. Sixty-five percent of the institutions reported college-level credit- 
granting distance education courses while 23 percent reported noncredit distance education courses. In 2006-07, enrollments or registrations in college-level credit-granting distance education courses totaled an estimated 12.2 million (77 percent reported as online courses, 12 percent reported as hybrid/blended online courses, and 10 percent reported in other types of distance education courses). During this 2006-07 academic year, approximately 11,200 collegelevel programs were designed to be completed totally through distance education (66 percent as degree programs and 34 percent as certificate programs) (U.S. Department of Education, 2008). As online education grows much current research focuses on learner's achievement and course evaluations as related to online learning (Moore \& Kearsley, 2005; Khan, 2005), but there is not much attention paid to the effects of online instruction on learners' psychological characteristics such as learning styles. Researchers believe that learning style is a good predictor of an individual's preferred learning behavior (Bostrom, Olfman, \& Sein, 1993).

The educational shift to the student-centered approach has led to researchers exploring learning styles to greater depths in both traditional face-to-face and online web-based classroom settings. As people learn and process information in many different ways, it has long been supported by educators that individual differences play an important role in learning and instruction (Moallem, 2007-2008). As unique as every student is, so are the learning styles and techniques they prefer. It has also been suggested by educational researchers a need to understand the distance learning student population (Vafa, 2002) and comparison of variables which might impact distance learning effectiveness such as learning styles (Zhang, 2005). Diaz and Cartnal (1999) emphasized research was sparse on the area of distance learning and learning styles. Learning style preferences play a role in success in distance learning and in the educational process in general (Diaz \& Bontenbal, 2001). 
Bailey (2002) believed colleges must move to the point where student-learning styles are matched with the delivery medium. Diaz (2002) believed that locus of control in addition to learning styles, should serve as the roadmap for potential online students. Beldarrain (2006) stated, "Today's learners demand more control of the learning experience when they need it; how they need it" (p. 142). If institutions of higher education can accommodate the needs of the 21 st century learner, satisfaction levels should theoretically remain high.

Learning styles can be used to create awareness and identify differences in how students take in and process information and can also help balance instruction. Students with different learning styles learned better in certain teaching environments than in others (Diaz \& Cartnal, 1999). The awareness gained by instructor of their students' learning styles could assist in choosing appropriate delivery methods. Moller, Foshay, and Huett (2008) suggested that "as web-based instruction evolves and learners become for adept at maneuvering within the environment, they will come to demand greater customization of the learning process to cater to their individual interaction needs - whatever those needs might be" (p. 75). By utilizing learning styles within the classroom (traditional and online), those needs can better be defined.

Distance education has been affected by, and help effect, higher education's response to the shifting currents of American society. Distance education environment "has the potential to be as unique and engaging as the individuals that become part of it in pursuit of their educational degrees" (Wickersham, Espinoz, \& Davis, 2007, p. 209). Research in the area of student learning styles can help programs better understand the needs of their students and better develop/structure teaching methods in both on-campus and via web-based instruction. Colleges and universities will need to change to meet the advancement of the technological revolution at hand. By recognizing differing student learning styles faculty may seek to employ different 
pedagogical approaches. As educators (virtual and live) faced with an increasingly diverse population of learners with a wide range of expectations, there is a need to continually seek to understand what factors add up to excellent delivery to promote effective learning. By recognizing differing student learning styles faculty may seek to employ different pedagogical approaches and better facilitate learning. By matching (or mismatching in some cases) learning and teaching styles in our classrooms, faculty may be able to create and enhance the learning experience. 


\section{Key Terms and Concepts}

For the purposes of this study, the following definitions will be used.

Asynchronous: two-way communication involving a time delay between transmission and receipt (Bower \& Hardy, 2004).

Distance Education (DE): teacher and student are separated by space and/or time (Moore \& Kearsley, 2005; Kearsley 2000; Perraton, 1988).

Experiential Learning: a four-stage cycle involving four adaptive learning modes-concrete experience, reflective observation, abstract conceptualization, and active experimentation. The structural bases of the learning process lie in the transactions among these four adaptive modes and the way in which the adaptive dialectics get resolved (Kolb, 1984, p. 40-41).

Experiential Learning Model (ELM): people learn in a two-step process of inputting information and processing information (Kolb, 1984).

Experiential Learning Theory (ELT): stresses the role experience plays in learning and emphasizes the link with Dewey, Lewin, and Piaget while distancing itself from other cognitive theories of the learning process. ELT contains six main characteristics: 1) Learning is best conceived as a process, not in terms of outcomes, 2) Learning is a continuous process grounded in experience, 3) Learning requires the resolution of conflicts between dialectically opposed modes of adaptation to the world, 4) Learning is a holistic process of adaptation to the world, 5) Learning involves transactions between the person and the environment, 6) Learning is the process of creating knowledge that is the result of the transaction between social knowledge and personal knowledge (Kolb, 1984).

Learning: the process whereby knowledge is created through the transformation of experience (Kolb, 1984, p. 38).

Learning Styles: a preferred way of learning (HayGroup/A shortguide, 2009); combinations of observations, experience, thinking, and action (HayGroup/A shortguide, 2009, p. 4); conceived not as fixed personality traits but as possibility-processing structures resulting from unique individual programming of the basic but flexible structure of human learning (Kolb, 1984, p. 95, 97).

Synchronous: communication without extended time delay - with activities such as chat sessions and discussions (Bower \& Hardy, 2004). 


\section{Chapter Three: Research Design and Method}

This chapter of the dissertation contains information pertaining to the research design, questionnaire/survey research, limitations of the study, research method, site selection/college profile, population, strategy for attaining institutional approval and participant cooperation, data collection procedures, and analysis. In addition, an overview of the pilot study, ethics, and researcher's background are included.

The purpose of this study was to identify and compare the prevalence of learning styles among undergraduate Sport Management Studies students at California University of Pennsylvania. Learning styles were assessed utilizing Kolb’s Learning Style Inventory, $3^{\text {rd }}$ Edition (LSI - 3.1). Learning style prevalence was determined for traditional face-to-face students and online web-based students. Differences in learning style prevalence between these two groups were explored. Finally, differences in student satisfaction between program delivery methods were examined by using an online questionnaire designed by the researcher.

\section{Quantitative Research Design}

The researcher used quantitative research methods throughout this study to provide information about the relative standing of people on a construct and about the magnitude of the difference between groups. Weimer (1993) defined quantitative data as "numerical information, such as how much or how many" (p. 17) measured on a numerical scale. According to Sansone, Morf, and Panter (2004), quantitative measures "typically represent in numerical form the standing of people or objects on some construct of interest” (p. 146). These measures are "intended to produce scores that at least approximate an interval level of measurement" (Sansone, et al, 2004, p. 146). Dunn (1999) suggested the chief advantage of the quantitative approach is "that numbers are easy to work with - data are readily collected, coded, summarized, and analyzed" (p. 37). Furthermore, a strength of quantification is that "dependent measures 
within the context of an experiment usually allow the researcher to use one set of data to infer the characteristics of other, similar populations" (Dunn, 1999, p. 37). Since Kolb's Learning Style instrument has been validated and subjected to numerous rigorous tests of reliability, it was appropriate to use in this dissertation research study.

The choice of quantitative methods was based upon the premise that it allowed the researcher to use one set of data to infer the characteristics of other, similar populations. The research problem and questions posed in Chapter One were best addressed through quantitative inquiry. The quantitative design allowed the researcher to identify and compare the prevalence of learning styles among traditional face-to-face students and online web-based students enrolled in the undergraduate Sport Management Studies programs at California University of Pennsylvania. This design was also used to examine differences in student satisfaction between the two delivery methods.

\section{Questionnaire/Survey Research}

This study utilized three sections on a questionnaire to gather information. The first section contained demographic questions (Appendix A), the second section consisted of the Learning Style Inventory (this cannot be included in the appendices due to copyright), and the third included satisfaction items (Appendix B). Dunn (1999) stated, “Questionnaires are comprised of a series of questions that usually pertain to the same issue or set of issues" (p. 47). Questionnaires are described by Dunn (1999) as having two goals. The goals include "finding out people's reactions to some person, place, or thing" and are "usually conducted to determine the beliefs of a population, or all members of a particular group" (Dunn, 1999, p. 47).

Kolb's LSI - 3.1 utilized a rating scale. Student respondents ranked a "4" for the sentence endings that described how they learn best, down to a " 1 " for the sentence ending that 
seemed least like the way they learn $(4=$ most like you, $3=$ second most like you, $2=$ third most like you, 1 = least like you). Rating scales "seek to obtain an evaluation or quantitative judgment of personality, group, or institutional characteristics based upon personal judgments" (Miller, 1977, p. 91). The rater placed their rating at some point along a continuum or in an ordered series of categories and a numerical value is attached to the category. The utility of rating scales can be to assess attitudes, values, norms, social activities, and social structural features (Miller, 1977).

The researcher utilized the Likert-type scale when developing the "Satisfaction" portion of the questionnaire since this scale was described as "highly reliable when it comes to a rough ordering of people with regard to a particular attitude or attitude complex" (Miller, 1977, p. 89). The score included a measure of intensity as expressed on each statement. This researcher utilized the following intensity dimensions: Very Satisfied (5), Satisfied (4), Neutral (3), Dissatisfied (2), and Very Dissatisfied (1). Suskie (1996) described advantages of using Likerttype rating scales as "easy to complete," "efficient," and "successfully used to measure attitudes or opinions" (p. 33). It is for these reasons the researcher used a Likert-type rating scale for the student satisfaction portion of the online survey.

\section{Limitations of the Study}

The primary limitation of this study is external validity, specifically, the inability to generalize results to other institutions and/or other student populations. For that reason, the following limitations of the study are articulated:

1. This study was limited to a sample of convenience at a single institution and consequently student responses may not have been representative of other institutions. 
2. Data were collected from the fall 2009 cohort of students. As a result, the participants in this sample may not have been representative of the entire student body.

3. This study was limited to students with access to a computer and the Internet.

4. Student learning styles are measured at one time, but may change over the course of the program or specific class.

\section{Research Method}

This section presents the characteristics of the selected site, strategy for attaining institutional approval and participant cooperation, data collection procedures: instrument, data coding and analysis, pilot study, ethics, researcher's background, and summary.

\section{Site selection / college profile.}

California University of Pennsylvania (Cal U) is one of the 14 universities within the Pennsylvania State System of Higher Education (PASSHE). It is located in California, Pennsylvania having a population of approximately 6,000 Borough of California residents. Cal U has a total enrollment of 9,024 students (7,211 undergraduate students and 1,813 graduate students). Most of the students are in-state students and there is a small percentage of international students. Females comprise approximately $54 \%$ of the entire student body while the student body is also predominantly white (CUP Factsheet, 2005). There are approximately 383 full-time and part-time faculty members and the university boasts 73 undergraduate degree programs and 28 graduate degree programs (PASSHE, 2009).

California University of Pennsylvania is accredited by the Commission on Higher Education of the Middle States Association of Colleges and Schools, the National Council for Accreditation of Teacher Education, and various program-based agencies (Cal U Global Online, 2009). 
Table 1

California University of Pennsylvania - Carnegie Classification

Level: 4-year or above Control: Public

$\begin{array}{ll}\text { Classification }^{\mathrm{a}} & \text { Category }\end{array}$

Undergraduate Instructional Program

Prof+A\&S/SGC: Professions plus arts \&

sciences, some graduate coexistence

Graduate Instructional Program

Postbac-Comp: Postbaccalaureate

comprehensive

Enrollment Profile

HU: High undergraduate

Undergraduate Profile

FT4/S/HTI: Full-time four-year, selective, higher transfer-in

Size and Setting

M4/R: Medium four-year, primarily

residential

Basic

Master's L: Master's Colleges and

Universities (larger programs)

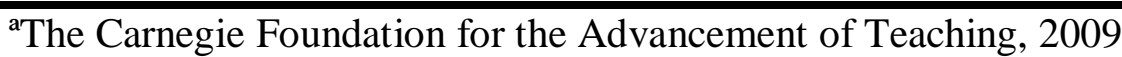

As part of the PASSHE, Cal U serves a broad range of students from diverse educational backgrounds and, often, limited financial resources for higher education. As an institution that traces its roots in the region to 1852 , California State was an academy and then a normal school. It became state owned in 1914, and 1928 it was renamed California State Teachers' College. This change reflected the fact that a variety of liberal arts curricula had been introduced.

Master's degree programs were introduced in the 1960s and in the 1970s a broader mission in 
science and technology was adopted. In 1983 the State System of Higher Education implemented Act 188. This law transformed state colleges into universities whereby California College became California University and a part of the State System of Higher Education. Administration shifted to a chancellor and a board of trustees. Currently, Cal $\mathrm{U}$ has the following four university colleges: The College of Education and Human Services, The College of Liberal Arts, The Eberly College of Science and Technology, and The School of Graduate Studies and Research (CUP About Us, 2005).

This site was chosen for not only for convenience, but a number of other reasons. Cal U has a well-established reputation for online education and a large online student population. Additionally, the majority of the faculty involved in the online program has five or more years of online teaching experience. Through $\mathrm{Cal} \mathrm{U}$, the researcher was able to gain access to the types of students necessary for the study. A balanced number of students in each sample of students (primarily traditional face-to-face or primarily online web-based) was available.

\section{Population.}

The participants in this research were undergraduate students enrolled in the Sports Management Studies (SMS) major within the Department of Exercise Science and Sport Studies (ESSS) at California University of Pennsylvania (Cal U) during the fall 2009 semester. Students may take classes on-campus in the traditional face-to-face classroom environment or take their coursework via online delivery utilizing the eCollege learning platform. eCollege is a system designed specifically for fully-online distance learning programs (eCollege, 2008).

The selection of this population was a sample of convenience. There are several reasons for the selection of this department and the students enrolled in this major. Sport Management Studies has a large population of both traditional and online students. Both groups have over 
350 students and include freshmen, sophomores, juniors, and seniors. The utilization of the students in this major as participants allowed for a significant number of students in both online and traditional delivery methods. Since they are all in one department and major, contact was made easier and the primary researcher was better able to enlist the assistance of instructional faculty. Students self-reported if they identify themselves as "primarily traditional face-to-face" or "primarily online web-based" within the demographic section of the survey instrument.

All students enrolled in SMS were invited to participate in the study following approval from theWest Virginia University (WVU) Institutional Review Board for the Protection of Human Subjects (IRB). Faculty teaching in this major were asked to participate by making an announcement of the study in their online and/or traditional classes. These announcements were provided to the faculty and written by the primary researcher to maintain consistency. The researcher emailed participants in regards to the study and encouraged participation. The approximately 713 participants were recruited via electronic mail addresses supplied by the institution. Participants were directed to an online site (SurveyMonkey ${ }^{\mathrm{TM}}$ ) for completion of the survey. Electronic mail requests for participation were made initially and then included two follow-up participation invitations in a two week period.

Student participation was voluntary and individual responses were anonymous. SMS students were enticed to complete the survey by being offered chances to win prizes in a raffle. Prizes were determined by results of the pilot study and included items equal or similar to an iPod nano (approximate value $\$ 50$ - \$100) or iTouch (approximate value $\$ 150$ - \$250) and several gift certificates (for example iTunes or Wal-Mart in various denominations ranging from $\$ 20$ to $\$ 50)$. Students completing the survey were given the opportunity to enter their email address to be eligible for the raffle. Subjects could choose to not participate in the raffle. 
Winners were selected randomly. Subjects' email addresses were not attached to data collection and study results. Emails were properly discarded immediately after winners are determined; hence, anonymity was preserved.

\section{Strategy for Attaining Institutional and Participant Cooperation.}

The researcher obtained written permission to conduct the study from the program director of the traditional face-to-face delivery Sport Management Studies Program and the program director of the online web-based Sport Management Studies Program within the Department of ESSS at Cal U. A cover letter including a brief statement regarding the purpose and procedure of the research, the benefits, and the confidentiality concern was sent to the directors (Appendix C).

The researcher followed the following steps in securing institutional approval:

1. The researcher sent a cover letter to the directors of on-campus traditional and online web-based SMS programs in the Department of ESSS at Cal U. The e-mail asked for them to volunteer to participate in a study of their students (including approximately 380 traditional face-to-face students and approximately 380 online web-based students) during the fall 2009 semester. This letter continued with a brief statement regarding the purpose and procedure of the research, the benefits, and the confidentiality concern. The letter also asked if they would be willing to provide a program listing (including emails) of their students.

2. Both program directors volunteered to allow student participation in the study during the fall 2009 semester and agreed to supply the email addresses for the students (Appendix D). 
3. The researcher applied for exempt review by the West Virginia University Institutional Review Board for the Protection of Human Subjects (IRB). The mission of the Human Subjects Protection Program is to protect the rights, dignity, welfare, and privacy of human research subjects at the University and at any of the sites covered under the provisions of the Federalwide Assurance of West Virginia University (WVU IRB, 2009). The researcher participated in the CITI Training Program required by the IRB at WVU for all individuals involved in human subject research.

4. After IRB approval, a pilot study was conducted and survey instruments distributed to four to eight Cal $\mathrm{U}$ students. All student participants were informed that their participation was completely voluntary and their level of participation or nonparticipation did not affect their grades or their employment status with the college. Participants were informed of the confidential nature of individual and institutional results. A pilot study served as a review to make sure questions are clear and understandable, checked technology and the survey instrument process, familiarized the researcher with the survey software (including creation and downloading of data into a statistical analysis program). There was a cover letter to students participating in the pilot study (Appendix E).

5. After pilot study review, the researcher sent participation letters to program directors (Appendix F).

6. The researcher sent invitation letters to the sample population via email addresses (Appendix G). 


\section{Data Collection Procedures/Instrument.}

The researcher's electronic survey instrument included three main sections. The categories included the following: 1) demographic data questions, 2) learning style questions (Kolb's Learning Style Inventory in its entirety), 3) and student satisfaction questions based on the National Survey of Student Engagement (NSSE) benchmarks. Students completed each portion of the survey before being redirected to the next portion by clicking a link.

The researcher created eight demographic questions (Appendix A). The first question asked the participant's academic program. If the student was not a SMS student, they did not meet the subject criteria and the survey and did not participate in the study. Students selfidentified as primarily on-campus face-to-face students or primarily online web-based student. The study indicated their gender. Students were asked their age category as traditional (18-24 years of age) or nontraditional (25 year or older), residence status (on-campus or off-campus), and student status (full-time for 12 credits or more, part-time for less than 12 credits). Students were asked ethnic affiliation via a drop-down menu of the following choices: African American/Black, Asian American/Pacific Islander, Hispanic American/Latino/Chicano, Native American/Tribal Affiliation, White/Caucasian/European American, Multi-Racial, other, don't know, or prefer not to answer. A second drop-down menu allowed students to indicate their level of academic standing in the following groups: Freshman (0-29 total credits), Sophomore (30-59 total credits), Junior (60-89 total credits), and Senior (90+ total credits). Levels of academic standing were verified by the $\mathrm{Cal} \mathrm{U}$ undergraduate catalog (Cal U Undergraduate Catalog, 2009).

The second section of the survey instrument was the completion of the LSI -3.1 . This instrument has been widely used and has generated a very considerable body of research 
(Coffield, 2004). Kayes (2005) stated it "remains one of the most influential and widely distributed instruments used to measure individual learning preference” (p. 249). Kolb’s Experiential Learning Theory and the Learning Style Inventory was discussed in greater depth in Chapter Two. The researcher made application and received permission from HayGroup (Hay Group Transforming Learning) to utilize the LSI - 3.1 for this study (Appendix H).

Normative percentile scores for the LSI 3.1 were based on LSI scores from several groups of users (online, research university freshmen/MBA students, liberal arts college students, art college undergraduates, and distance e-learning adult undergraduates). The sample totals were 6,977 valid LSI scores. The norm group consisted of $50.4 \%$ women and $49.4 \%$ men with ages ranging from 17 to 75 . The norms were used to convert LSI raw scale scores to percentile scores to achieve scale comparability and to define cut-points for defining the learning style types (Kolb \& Kolb, 2005).

Arnold, Gansneder, and Perrin (2005) discussed "two major criteria for judging the quality of the measures" (p. 115) as reliability and validity. They stated a goal is to have measures having "very little error (reliability) and that produce scores that are valid for your purposes" (Arnold et al., 2005, p. 115). Furthermore, Arnold et al. (2005) defined reliability as "the extent to which a measurement remains constant as it is repeated under conditions taken to be constant," while validity "traditionally has dealt with the degree to which there is evidence that a measure actually measures what it purports to measure" (p. 116). Reliability is important to this researcher as unreliable measures would produce inaccurate estimates of variables and could also cause inappropriate conclusions to be drawn.

A number of researchers have examined reliability of LSI, most recently Kayes (2005). When Kayes (2005) examined CE, RO, AC, and AE, a range of Chronbach's alpha coefficients 
from .78 to .84 were found which demonstrates the learning orientations exhibit high internal consistency. Kayes' (2005) combined score of preference also showed high internal consistencies with Chronbach's alpha coefficients of .77 (AC-CE) and .84 (AE-RO). Internal reliability of the LSI-2 scales has generally been supported by prior research demonstrating Cronbach's alphas in the .80 to .87 range (Loo, 1996).

Verdes, Sims, and Locklear (1991) published a test-retest reliability study and found the Kappa coefficient to be between .95 and .97 for the learning style orientations (CE, RO, AC, and AE). Even on the third testing, all subjects had a Kappa coefficient of .91 or higher indicating very few students changed their learning style type from administration to administration (Verdes et al., 1991).

Kayes (2005) stated "internal construct validity is used to describe how accurately instrument scale constructs can be distinguished from one another and to what degree the constructs account for the variance found in the sample" (p. 251). Moderate support for two bipolar factors along the dimensions were found by Loo (1996) although these two factors accounted for only $30 \%$ of the total model variance (Kayes, 2005). Other researchers have found support for a two-factor structure along hypothesized dimensions in some groups of students, but not in others (Kayes, 2005). Kayes (2005) stated "research generally supports a two-factor structure along hypothesized dimensions when analyzing aggregated scale scores on prior versions of the LSI” (p. 252). Kolb and Kolb (2005) reported 17 published studies that used factor analysis to examine the internal structure of the LSI (most focusing on the LSI 2). Of the 17 studies identified, seven supported the predicted internal structure of the LSI, four found mixed support, and six found no support (Kolb \& Kolb, 2005). 
From the LSI, the learning orientations (CE, RO, AC, and $\mathrm{AE}$ ) and corresponding learning style question are shown in Table 2.

Table 2

Sport Management Studies Learning Style Inventory - Page 3: KLSI- 3.1

Learning Orientations: Modes of Grasping Corresponding Learning Style Question

Experience $^{\mathrm{a}}$

Concrete Experience (CE)

9A, 10C, 11D, 12A, 13A, 14C, 15B, 16D,

17B, 18B, 19A, 20B

Reflective Observation (RO)

9D, 10A, 11C, 12C, 13B, 14A, 15A, 16C,

17A, 18A, 19B, 20C

Abstract Conceptualization (AC)

9B, 10B, 11A, 12D, 13C, 14D, 15C, 16B, 17D, 18D, 19C, 20A

Active Experimentation (AE)

9C, 10D, 11B, 12B, 13D, 14B, 15D, 16A,

17C, 18C, 19D, 20D

The third portion of the online survey was completion of ten questions of student satisfaction (Appendix B). The researcher designed the satisfaction questionnaire based on the five benchmarks of effective education practice as delineated by the National Survey of Student Engagement (NSSE). Two student satisfaction questions were created by the researcher for each benchmark (ten total questions). The benchmarks are "based on 42 key questions from the NSSE survey that capture many vital aspects of the student experience" (NSSE, 2009, p. 1) and include the following: 
1. Level of Academic Challenge (LAC) - challenging of intellectual and creative works is central to student learning and collegiate quality created by emphasizing high levels of academic effort and setting high expectations for student performance.

2. Active and Collaborative Learning (ACL) - students learn more when intensely involved in their education and when they are asked to think about and apply what they are learning in different situations.

3. Student-Faculty Interaction (SFI) - students see first-hand how experts think about and solve practical problems by interacting with faculty inside and outside the classroom whereby teachers become role models, mentors, and guides for continuous, life-long learning.

4. Enriching Educational Experiences (EEE) - students experience diversity learning important things about other cultures and themselves. Complementary learning opportunities inside and outside the classroom augment the academic program.

5. Supportive Campus Environment (SCE) - students perform better and are more satisfied at colleges that are committed to their success and cultivate positive working and social relations among different groups on campus. 
Table 3

Sport Management Studies Learning Style Inventory - Student Satisfaction

Five Benchmarks of Effective Education Corresponding Satisfaction Question

Practice (NSSE) $)^{\mathrm{a}}$

Level of Academic Challenge

21,22

Active and Collaborative Learning

23,24

Student-Faculty Interaction

25,26

Enriching Educational Experience

27,28

Supportive Campus Environment

29,30

${ }^{\mathrm{a}}$ Note: The National Survey of Student Engagement five benchmarks of effective education practice. From: NSSE (2009) http://nsse.iub.edu/pdf/nsse_benchmarks.pdf

\section{Data coding and analysis of data.}

Descriptive statistics were used to describe the demographic data on the survey as well as data from specific survey items that address the two research questions listed below.

1. What is the prevalence of the Diverging, Assimilating, Converging, and Accommodating learning styles of the traditional face-to-face Sport Management Studies undergraduate student based on the Kolb's Learning Style Inventory, $3^{\text {rd }}$ Edition (LSI-3.1) (survey items \# 9 through 20)?

2. What is the prevalence of the Diverging, Assimilating, Converging, and Accommodating learning styles of the online web-based Sport Management Studies undergraduate student based on the Kolb's Learning Style Inventory, $3^{\text {rd }}$ Edition (LSI-3.1) (survey items \# 9 through 20)? 
Descriptive statistics "are used to classify and summarize numerical data; that is, to describe data" (Hinkle, Wiersma, \& Jurs, 2003, p. 12). Blalock (1979) stated descriptive statistics are "especially useful in instances where the investigator finds it necessary to handle interrelationships among more than two variables" (p. 5). The prevalence of Kolb's four learning style groups (Diverging, Assimilating, Converging, and Accommodating) in the traditional face-to-face and the online web-based groups will be reported as percentages. Information gathered from these undergraduates will allow the researcher to make inferences about the learning style characteristics of the two samples (traditional face-to-face and online web-based). Hinkle et al. (2003) stated, "Descriptive statistics is a collection of methods for classifying and summarizing numerical data" (p. 13). Descriptive statistics will appropriately report the prevalence of learning styles in the two samples for the first two research questions.

The third research question will utilize data collected from the learning style inventory and a series of chi-square $\left(\chi^{2}\right)$ test for frequencies will be used to analyze the data.

3. Is there a statistically significant difference in prevalence of learning styles between the traditional face-to-face Sport Management Studies undergraduate students to the online web-based Sport Management Studies undergraduate students?

This statistical decision is appropriate due to the analysis of nominal (categorical) data in which observed frequencies of occurrence will be compared with theoretical or expected frequencies. Hinkle et al. (2003) stated, "nonparametric tests can be used when the parametric assumptions of normality and homogeneity of variance are not met” (p. 546). Blalock (1979) stated the chi-square test "is a very general test that can be used whenever we wish to evaluate whether or not frequencies which have been empirically obtained differ significantly from those which would be expected under a certain set of theoretical assumptions" (p. 279). The 
researcher used a $2 \times 4$ chi-square $\left(\chi^{2}\right)$ goodness-of-fit test to explore whether or not the observed frequencies are a good fit to the expected frequencies. In regards to fit, Hinkle et al. (2003) stated the fit is considered good "when the observed frequencies are within random fluctuation of the expected frequencies and the computed $\chi^{2}$ value is relatively small, or less than the critical value of $\chi^{2}$ for the appropriate degrees of freedom" (p. 551). The independent variable in this analysis was program delivery method. This variable was self-reported by the participant and had two levels, traditional and online delivery. The dependent variable was learning style as determined by Kolb's Learning Style Inventory, $3^{\text {rd }}$ Edition with four learning style preferences: Diverging, Assimilating, Converging, and Accommodating. Research question three findings were presented with the results of significance testing utilizing the chi-square.

When exploring satisfaction in research question four, a $t$-test was used to compare the difference between mean satisfaction of two different groups of students to determine whether that difference is statistically significant.

4. Is there a statistically significant difference in satisfaction between the traditional face-toface Sport Management Studies undergraduate students and the online web-based Sport Management Studies undergraduate students?

According to Hinkle et al. (2003), "t distributions are a family of symmetrical, bell-shaped distributions that change as the sample size changes" (p. 190). The $t$ distribution provides the distribution of the differences between the samples. The $t$-test was used to help determine inferences about the larger group it represents. For this research question, the program delivery method was utilized as independent variables and satisfaction was the dependent variable. Satisfaction score was calculated by summing the total of satisfaction scores (each score per subject ranged from ten to fifty). 
The researcher organized the data from the study into datasets. The researcher removed any student identifiable information from the datasets during the data coding process to ensure the anonymity of participants. The following data was collected and coded:

Demographic Characteristics

1. Academic Program: Sport Management Studies or Other (results of subjects answering "Other" in this section will be dismissed from the study)

2. How would you best be classified: Primarily on-campus face-to-face student or Primarily online web-based student

3. Gender: Male or Female

4. Age Category: traditional (18-24 years of age) or nontraditional (25 years or older)

5. Residence Status: On-campus or Off-campus

6. Ethnic Affiliation: African American/Black, Asian American/Pacific Islander, Hispanic American/Latino/Chicano, Native American/Tribal Affiliation, White/Caucasian/European American, Multi-Racial, Other, or Prefer not to answer

7. Student Status: Full-time (12 credits or more) or Part-time (less than 12 credits); (Cal U Undergraduate Catalog, 2009)

8. Student Level: Freshman (0-29 total credits), Sophomore (30-59 total credits), Junior (60-89 total credits), Senior (90+ total credits); (Cal U Undergraduate Catalog, 2009) Kolb Learning Style Inventory Variables

1. Diverging

2. Assimilating

3. Converging

4. Accommodating 
Satisfaction Variables - a ten-item scale measuring degrees of satisfaction in five clusters of effective education practice (based on the NSSE Benchmarks previously discussed):

1. Level of academic challenge

2. Active and collaborative learning

3. Student-faculty interaction

4. Enriching educational experience

5. Supportive campus environment

The study's four research questions are shown in Table 4 and the survey items technique.

Table 4

Learning Style Inventory Cal U SMS Survey Item Techniques

$\begin{array}{ll}\text { Research Question } & \text { Corresponding Question }\end{array}$

1. What is the prevalence of the Diverging,

Assimilating, Converging, and Accommodating

learning styles of the traditional face-to-face Sport

Management Studies undergraduate student based

on the Kolb's Learning Style Inventory, $3^{\text {rd }}$ Edition

\section{(LSI-3.1)?}

2. What is the prevalence of the Diverging,

Assimilating, Converging, and Accommodating

learning styles of the online web-based Sport

Management Studies undergraduate student based

on the Kolb's Learning Style Inventory, $3^{\text {rd }}$ Edition 
(LSI-3.1)?

3. Is there a statistically significant difference in

prevalence of learning styles between the

traditional face-to-face Sport Management Studies

undergraduate students to the online web-based

Sport Management Studies undergraduate

students?

4. Is there a statistically significant difference in satisfaction between the traditional face-to-face Sport Management Studies undergraduate students

to the online web-based Sport Management

Studies undergraduate students?

\section{Pilot study.}

The researcher conducted a pilot study in order to increase the quality of the online survey instrument and the study's data collection administration process. The pilot subjects were four to six undergraduate students in the Departments of Health Sciences and Exercise and Sport Studies at California University of Pennsylvania based upon convenience, access, subject similarity, and geographic proximity. Arnold et al. (2005) described pilot testing as "essentially rehearsing the data collection procedures you will use in your study" (p. 171) to identify unknowns and problem areas uncovered through the actual testing of human subjects. 
Pilot subjects were supplied with the participation invitation letter having the web address to the study (Appendix I). Upon completion of the online survey instrument, pilot subjects were asked the following open-ended questions:

1. Approximately how long did it take you to complete the survey?

2. Did you have any problems entering the survey or completing the survey? Please explain.

3. Were any items not clear or difficult to answer? Please explain.

4. Do you have any suggestions of how to make the process easier or survey better?

5. Would you be motivated to take this survey?

6. If a prize drawing or give-away were available to those completing the survey, what "prize" might you recommend (within the price range of \$10 - \$200)?

The pilot study was used to make sure questions are clear to subjects. The researcher was committed to using the framework established for the seven principles for good practice in undergraduate education and the Kolb Learning Style Inventory. Subjects that participated in the pilot study were not population members in the actual study.

\section{Ethics.}

Tuckman (1972) stated, "the matter of ethics is an important one for educational researchers" (p. 15). Therefore, the researcher deliberated and followed ethical considerations as discussed by the literature to take into account designing the research in order to not invade human rights. Tuckman (1972) presented four main characteristics: the right to remain anonymous, the right to privacy, the right to confidentiality, and the right to expect experimenter responsibility. The researcher took the following steps to assure ethical practice. First, the researcher designed the research tool through SurveyMonkey, an Internet based survey tool, to ensure student respondents' identities would remain anonymous. In the participant cover letter 
(Appendix I) the researcher explained to subjects that their individual identities would remain anonymous. Second, the researcher attempted to avoid asking unnecessary questions and allowed participants to not report any information they chose. Third, the researcher treated data with confidentiality. Finally, the researcher was sensitive to human dignity and reassured potential participants they would not be harmed (academically or otherwise) by their participation or lack of participation.

The American Psychological Association (2001) discussed ethical practices to be applied to Internet research. The guidelines suggested that the researchers should identify themselves, ensure confidential treatment of personal information, obtain consent from those providing data whenever possible, and provide participants with information about the study. The researcher conducted herself in this manner and designed the student questionnaire based on the aforementioned principles guiding survey research. Additionally, the researcher followed the ethical standards for the reporting and publishing of scientific information as outline by the APA (American Psychological Association, 2001).

\section{Researcher's background.}

The researcher earned a Bachelor of Science degree dual majoring in athletic training and elementary education from California University of Pennsylvania. The researcher also earned a Master of Science degree in physical education (athletic training emphasis) from West Virginia University. Currently, the researcher is a doctoral candidate in educational leadership studies at West Virginia University. In addition, she is a full-time associate professor of exercise science and sport studies at California University of Pennsylvania. She has 18 years of experience as faculty member and athletic trainer in the Pennsylvania State System of Higher Education (PASSHE). The researcher holds state and national teaching certifications as well as state and 
national certified athletic trainer credentials. She has a certificate in chemical dependency counselor education from the Pennsylvania State University.

\section{Summary.}

This chapter discussed the quantitative research design used to address the four research questions identified in Chapter One. The researcher presented information about the survey as well as limitations of the study, population of students, and data collection and analysis. This research study was performed at California University of Pennsylvania, identified as a four-year degree granting Pennsylvania public university. The university offers over one hundred degree programs to approximately 9,024 undergraduate and graduate students. The population for this study was identified as the approximately 713 Sport Management Studies traditional face-to-face students and online web-based students. The researcher conducted the pilot study in fall 2009 surveyed the population of students later in the semester. 


\section{Chapter Four: Results}

\section{Introduction}

This dissertation study examined the prevalence of learning styles among undergraduate Sport Management Studies (SMS) students at California University of Pennsylvania (Cal U). Learning style prevalence was determined for traditional face-to-face students and online webbased students utilizing Kolb's Learning Style Inventory, $3^{\text {rd }}$ Edition (LSI 3.1) (2005). Differences in learning style prevalence between these two groups were identified. Finally, differences in student satisfaction between program delivery methods were examined by using an online questionnaire designed by the researcher.

This chapter initially presents the results from the pilot study and then discusses the demographic and academic characteristics of the students in the sample. Next, the results of each research question will be reported. The research questions were:

1. What is the prevalence of the Diverging, Assimilating, Converging, and Accommodating learning styles of the traditional face-to-face Sport Management Studies undergraduate student based on the Kolb's Learning Style Inventory, $3^{\text {rd }}$ Edition (LSI-3.1)?

2. What is the prevalence of the Diverging, Assimilating, Converging, and Accommodating learning styles of the online web-based Sport Management Studies undergraduate student based on the Kolb's Learning Style Inventory, $3^{\text {rd }}$ Edition (LSI-3.1)?

3. Is there a statistically significant difference in prevalence of learning styles between the traditional face-to-face Sport Management Studies undergraduate students to the online webbased Sport Management Studies undergraduate students? 
4. Is there a statistically significant difference in satisfaction between the traditional face-to-

face Sport Management Studies undergraduate students to the online web-based Sport

Management Studies undergraduate students?

\section{Pilot Study Results}

SurveyMonkey ${ }^{\mathrm{TM}}$ was used for each of the two survey instruments that were administered on-line in a pilot study. The researcher gained permission from the HayGroup (Kolb's Learning Style Inventory, 3.1, 2005) to change the learning styles paper survey into an on-line survey. In addition, the researcher developed a satisfaction survey that was administered on-line. The purpose of the pilot study was twofold. First the pilot was necessary in order to determine if there were any system issues with using an on-line survey. Second, the pilot was used for developing and testing adequacy of the research instrument, assessing the feasibility of the research study survey, assessing whether the research protocol was realistic and workable, assessing the likely success of the proposed recruitment approach, and identifying logistical problems which might occur using the proposed methods.

In this phase of the pilot, the researcher solicited 19 undergraduate (eleven male and eight female) Exercise Science and Sport Studies students to participate in the pilot. All were not members of the sample population, but were similar and within the same department.

Eight students completed the pilot survey. Six pilot subjects were male and two were female. Four pilot subjects $(50 \%)$ were 18 to 24 years old, while four (50\%) were nontraditional (25 years old or older). Four were considered primarily on-campus face-to-face undergraduate students (50\%) and four were online web-based students (50\%). Three lived on-campus (37.5\%) while five had off-campus residence status (62.5\%). One subject was of African American/Black (12.5\%) ethnic affiliation and seven were of White/Caucasian/European 
American (87.5\%) ethnic affiliation. All students were enrolled full-time (12 credits or more). Two students were freshmen (25\%), one was a sophomore (12.5\%), four were juniors (50\%), and one was a senior $(12.5 \%)$.

The Learning Style Inventory (2005) was coded properly according to the inventory scale. Through SurveyMonkey ${ }^{\mathrm{TM}}$, the researcher could successfully download a spreadsheet which could be imported into SPSS for the data analysis. Through the pilot study, the researcher was able to determine the 12 -items were appropriately rank ordered and numbered. The researcher was successfully able to determine a learning style for each pilot participant and translate that finding into an aggregate learning style preference for the group. Therefore, the ability to establish prevalence of the Diverging, Assimilating, Converging, and Accommodating learning styles of the traditional face-to-face and online web-based Sport Management Studies undergraduate student (research questions one and two) was confirmed. It was determined that the statistically significant difference in prevalence of learning styles between the traditional face-to-face Sport Management Studies undergraduate students to the online web-based Sport Management Studies undergraduate students could appropriately be determined by use of the instrument and appropriate methodology (research question three).

The researcher found the satisfaction questions to be coded properly. Each subject received a satisfaction score between 10 and 50 (50 being the best, or most satisfied, 10 being very dissatisfied). From the satisfaction score, the researcher was able to calculate a mean satisfaction score for the satisfaction portion of the survey (instrument questions 21 through30). Additionally, the researcher was able to analyze the data by question since there are only ten items. The researcher could successfully analyze satisfaction between the two groups (FTF and OL) per survey item (instrument questions 21 through 30). The researcher determined that it 
could be found if a statistically significant difference in satisfaction, as a whole and per survey item, existed between the traditional face-to-face Sport Management Studies undergraduate students to the online web-based Sport Management Studies undergraduate students was present (research question four).

For the researcher's follow-up questions, students indicated it took them between three and fifteen minutes to complete the survey (one pilot subject skipped this question). All respondents indicated that they had no problems entering the survey or completing the survey (one pilot subject skipped this question). When asked if any items were not clear or difficult to answer, three responded by saying "no," one thought the sentence structure instructions were confusing at first glance (this referred the LSI which cannot be changed), one indicated there was a typo on one word, and one said "Everything was clear and easy to understand." One pilot study subject skipped this question. Seven students responded when asked if they had any suggestions of how to make the process easier or survey better. Three wrote "no" or "none," one said "it was good," while one reported "everything was perfect." Additionally, one student stated, "one thing i do not like is 15 minute quizes, thats not enough time and students who are just begginning in the sports management program will not like that very much." (sic) This comment did not seem directly related to the survey, but rather to a course. Four pilot subjects indicated they would be motivated to take the survey, one said it depended on their major and future. One respondent indicated they would not be motivated to take the survey, and two skipped this question. Students were asked about what rewards could be given to them for their participation in this study. Answers from the five remaining pilot study subjects varied from an $\mathrm{iPod}^{\mathrm{TM}}$, to cash $(\$ 15-\$ 100)$, or a gift card. 


\section{Demographics}

The population for this study was the 713 undergraduate Sport Management Studies students at California University of Pennsylvania (Cal U) who were enrolled in the Fall 2009 term. Two hundred forty-seven (35\%) was the overall response rate for survey completion (30\% face-to-face and $38 \%$ on-line). To address the research questions in the study, respondents were divided into two groups: traditional face-to-face Sport Management Studies undergraduate students and online web-based Sport Management Studies undergraduate students. Face-to-face students $(n=101)$ comprised $41 \%$ of the total respondents and on-line students $(n=146)$ comprised 59\% of the total respondents (see Table 5). Both the face-to-face and on-line response rates were between thirty and forty percent.

Table 5

Cal U Sport Management Studies Undergraduate Student Population and Respondents

\begin{tabular}{|c|c|c|c|c|c|c|}
\hline & \multicolumn{2}{|c|}{ Face-to-Face } & \multicolumn{2}{|c|}{ On-line } & \multicolumn{2}{|c|}{ Total } \\
\hline & $\mathrm{N}$ & & $\mathrm{N}$ & $\%$ & $\mathrm{~N}$ & $\%$ \\
\hline Population & 333 & 47 & 380 & 53 & 713 & 100 \\
\hline Respondents & 101 & 41 & 146 & 59 & 247 & 100 \\
\hline
\end{tabular}

Respondents were asked eight demographic questions. Of the 247 total respondents, 125 were male and 122 were female. One hundred one students were face-to-face while 146 students were on-line. As shown in Table 6, $62(61.4 \%)$ of the face-to-face students were male and 39 $(38.6 \%)$ were female while $83(56.8 \%)$ of the on-line students were female and $63(43.2 \%)$ were male; therefore, the majority of the face-to-face participants were male and the majority of the on-line participants were female. As a whole, male and female participants were balanced. 
Table 6

Participating Students by Gender

\begin{tabular}{lcccc}
\hline Delivery & \multicolumn{2}{c}{ Male } & \multicolumn{2}{c}{ Female } \\
& $\mathrm{N}$ & $\%$ & $\mathrm{~N}$ & $\%$ \\
\hline Face-to-Face & 62 & 61.4 & 39 & 38.6 \\
On-line & 63 & 43.2 & 83 & 56.8 \\
Total & 125 & 50.1 & & \\
\hline
\end{tabular}

The majority (97\%) of the face-to-face respondents were of traditional age (18 to 24 years) and the majority (79.5\%) of the on-line respondents were of non-traditional age (25 years or older). Overall, the respondents were fairly balanced with approximately half being traditional and approximately half being non-traditional (see Table 7).

Table 7

Participating Students by Age Group

\begin{tabular}{lcccc}
\hline Delivery & \multicolumn{2}{c}{ Traditional } & \multicolumn{2}{c}{ Non-traditional } \\
& $\mathrm{N}$ & $\%$ & $\mathrm{~N}$ & $\%$ \\
\hline Face-to-Face & 98 & 97 & 3 & 3 \\
On-line & 30 & 20.5 & 116 & 79.5 \\
Total & & & & \\
& 128 & 51.8 & 119 & 48.1 \\
\hline
\end{tabular}

Note. Traditional is 18 to 24 years of age and non-traditional is 25 years of age or older. From Cal U Undergraduate Catalog. (2009). Undergraduate catalog. Retrieved August 21, 2009 from http://www.cup.edu/universitycatalogs/undergraduate/ugcatalog.htm

Eighty-three percent of all respondents resided off-campus. As shown in Table 8, 61 $(60.4 \%)$ of the face-to-face respondents lived off-campus while 40 (39.6\%) lived on-campus. An overwhelming majority (98.6\%) of the on-line respondents lived off campus. 
Table 8

Participating Students by Residence Status

\begin{tabular}{lccccc}
\hline Delivery & \multicolumn{2}{c}{ On-Campus } & \multicolumn{2}{c}{ Off-campus } \\
& $\mathrm{N}$ & $\%$ & $\mathrm{~N}$ & $\%$ \\
\hline Face-to-Face & 40 & 39.6 & 61 & 60.4 \\
On-line & 2 & 1.4 & 144 & 98.6 \\
Total & 42 & 17 & & & \\
& & & 205 & 83 \\
\hline
\end{tabular}

Respondents were asked to identify their ethnicity. The majority (81\%) of both the faceto-face and online respondents was White/Caucasian/European American and they were similar in their makeup (see Table 9). For face-to-face instruction twelve students (12\%) were African American/Black, Hispanic American/Latino/Chicano or Multi-Racial. For on-line instruction twenty-three students (16\%) were African American/Black, Hispanic American/Latino/Chicano or Multi-Racial. 
Table 9

Ethnic Affiliation by Participant Delivery Method

Participant Delivery Method

Ethnic Affiliation Face-to-Face On-line

African American/Black

\begin{tabular}{rrrr}
$\mathrm{N}$ & $\%$ & $\mathrm{~N}$ & $\%$ \\
\hline 8 & 7.9 & 14 & 9.6
\end{tabular}

$(n=22)$

Asian American/Pacific Islander

$(n=3)$

Hispanic American/Latino/Chicano

$(n=6)$

Native American/Tribal Affiliation

$(n=3)$

White/Caucasian/European American

$(n=200)$

Multi-Racial

$(n=7)$

Other

$(n=1)$

Don't Know

$(n=0)$

Prefer not to answer

$(n=5)$

Total

$\begin{array}{cccc}0 & 0 & 3 & 2.1 \\ 2 & 2 & 4 & 2.7 \\ 0 & 0 & 3 & 2.1 \\ 88 & 87 & 112 & 76.7 \\ 2 & 2 & 5 & 3.4 \\ 0 & 0 & 1 & 0.7 \\ 0 & 0 & 0 & 0 \\ 1 & 1 & 4 & 2.7 \\ 101 & 100 & 146 & 100\end{array}$

As shown in Table 10, $226(91.5 \%)$ of respondents reported being full-time students (12 credits or more) and 21 (8.5\%) reported being part-time students (less than 12 credits). Nearly all $(99 \%)$ face-to-face respondents were full-time. One hundred twenty-six $(86.3 \%)$ on-line respondents were full-time and $20(13.7 \%)$ were part-time. 
Table 10

Number of Respondents by Student Status

\begin{tabular}{lcccc}
\hline Delivery & \multicolumn{2}{c}{ Full-time } & \multicolumn{2}{c}{ Part-time } \\
& $\mathrm{N}$ & $\%$ & $\mathrm{~N}$ & $\%$ \\
\hline Face-to-Face & 100 & 99 & 1 & 1 \\
On-line & 126 & 86.3 & 20 & 13.7 \\
Total & & & & \\
& 226 & 91.5 & 21 & 8.5 \\
\hline
\end{tabular}

Note. Status defined by Cal U Undergraduate Catalog. (2009). Undergraduate catalog. Retrieved August 21, 2009 from http://www.cup.edu/universitycatalogs/undergraduate/ugcatalog.htm

As shown in Table 11, nearly two-thirds of face-to-face respondents reported being senior $(31.7 \%)$ or sophomore $(30.7 \%)$. By contrast, the majority $(70.2 \%)$ of on-line respondents were senior $(40.3 \%)$ or junior $(29.9 \%)$. Most $(36.7 \%)$ of the overall respondents were seniors.

Table 11

Number of Respondents by Academic Status

\begin{tabular}{|c|c|c|c|c|c|c|c|c|}
\hline \multirow[t]{2}{*}{ Delivery } & \multicolumn{2}{|c|}{ Freshman } & \multicolumn{2}{|c|}{ Sophomore } & \multicolumn{2}{|c|}{ Junior } & \multicolumn{2}{|c|}{ Senior } \\
\hline & $\mathrm{N}$ & $\%$ & $\mathrm{~N}$ & $\%$ & $\mathrm{~N}$ & $\%$ & $\mathrm{~N}$ & $\%$ \\
\hline Face-to-Face & 18 & 17.8 & 31 & 30.7 & 20 & 19.8 & 32 & 31.7 \\
\hline On-line & 21 & 14.6 & 22 & 15.2 & 43 & 29.9 & 58 & 40.3 \\
\hline Total & 39 & 16 & 53 & 21.6 & 63 & 25.7 & 90 & 36.7 \\
\hline
\end{tabular}

Note. Two on-line respondents did not answer this question

\section{Prevalence of Learning Styles in Face-to-Face and On-Line Participants}

Using Kolb's (2005) Learning Style Inventory, there are four possible learning styles:

Diverging, Assimilating, Converging, and Accommodating. The first research question utilized descriptive statistics to appropriately report the prevalence of learning styles for the face-to-face 
student participants. One hundred one traditional face-to-face Sport Management Studies undergraduate students completed the survey. Forty-one (40.6\%) were found to be Diverging, $38(37.6 \%)$ were found to be Accommodating, $16(15.8 \%)$ were found to be Assimilating, and 6 (5.9\%) were found to be Converging (see Table 12). For the face-to-face Sport Management Studies undergraduate students Diverging is the most prevalent learning style.

The second research question utilized descriptive statistics to appropriately report the prevalence of learning styles for the on-line student participants. One hundred forty-six online web-based Sport Management Studies undergraduate students completed the survey. The Accommodating (33.6\%), Diverging (29.5\%), and Assimilating (28.1\%) learning style preferences were shown to be most prevalent for on-line students (see Table 12). Learning style preferences were shown to differ between delivery methods. Accommodating was shown to be most prevalent for on-line students while Diverging was shown to be most prevalent for face-toface students.

Table 12

Learning Style Preference by Delivery Method

\begin{tabular}{cccccc}
\hline $\begin{array}{c}\text { Delivery } \\
\text { Method }\end{array}$ & Accommodating & Diverging & Assimilating & Converging & Total \\
\hline Face-to-Face & $n=38$ & $n=41$ & $n=16$ & $n=6$ & $n=101$ \\
Row \% & 37.6 & 40.6 & 15.8 & 5.9 & 100 \\
Col \% & 43.7 & 48.8 & 28.1 & 31.6 & 40.9 \\
& & & & & $n=13$ \\
On-Line & $n=49$ & $n=43$ & $n=41$ & 8.9 & $n=146$ \\
Row \% & 33.6 & 29.5 & 28.1 & 68.4 & 59.1 \\
Col \% & 53.6 & 51.2 & 71.9 & & \\
& & & & $n=19$ & $\mathrm{~N}=247$ \\
Total & $n=87$ & $n=84$ & $n=57$ & 7.7 & 100 \\
Row \% & 35.2 & 34.0 & 23.1 & 100 & 100 \\
Col \% & 100 & 100 & 100 & & \\
\hline
\end{tabular}




\section{Differences in Learning Style Preference between Delivery Method}

The third research question utilized data collected from the learning style inventory and was analyzed using a $2 \times 4$ Pearson Chi-Square $\left(\chi^{2}\right)$ test for frequencies with a significance level of $p \leq .05$. Research question three is as follows:

3. Is there a statistically significant difference in prevalence of learning styles between the traditional face-to-face Sport Management Studies undergraduate students and the online web-based Sport Management Studies undergraduate students?

By utilizing the frequencies for learning style preference by delivery method (see Table 12), significance in prevalence of learning styles between the traditional face-to-face Sport Management Studies undergraduate students to the online web-based Sport Management Studies undergraduate student were determined (see Table 13). The overall (omnibus) Chi Square yielded a trend toward significance, $\chi^{2}(3, \mathrm{~N}=247)=7.017, p=.071$. A statistical finding of greater than $\alpha=.05$ but less than $\alpha=.10$ is considered a "strong trend." Follow-up analyses were conducted to further explicate this trend.

Table 13

Pearson Chi Square for Learning Style Preference by Delivery Method

\begin{tabular}{lccc}
\hline & $\begin{array}{c}\text { Chi-Square } \\
\text { Value }\end{array}$ & df & $\begin{array}{c}\text { Significance } \\
(2 \text {-tail })\end{array}$ \\
\hline Pearson Chi Square & 7.017 & 3 & .071 \\
\hline
\end{tabular}

The first follow-up analysis consisted of comparison of the four learning styles for both the face-to-face students and the on-line students (see Table 14). The comparison of the four learning styles for the face-to-face participants yielded 
$\chi^{2}(3, \mathrm{~N}=101)=34.68, p<.01$, indicating a statistically significant difference. This analysis utilized the observed learning style preferences as 1) Diverging $(n=41), 2)$ Accommodating $(n=38), 3)$ Assimilating ( $n=16)$, and 4) Converging ( $n=6)$ and compared the observed distribution to the expected distribution for the face-to-face respondents. This analysis showed the four learning style preferences for face-to-face Sport Management Studies students were not equally distributed and a significant difference was present.

Table 14

Pearson Chi Square for Learning Style Preference for Each Delivery Method

\begin{tabular}{lccc}
\hline & $\begin{array}{c}\text { Chi-Square } \\
\text { Value }\end{array}$ & df & $\begin{array}{c}\text { Significance } \\
(2-\text { sided })\end{array}$ \\
\hline Face-to-Face Learners & 34.68 & 3 & $<.01$ \\
On-line Learners & 21.43 & 3 & $<.01$ \\
\hline
\end{tabular}

The comparison of the four learning styles for the on-line participants yielded $\chi^{2}(3$, $\mathrm{N}=146)=21.43, p<.01$, indicating a statistically significant difference. This analysis utilized the observed learning style preferences as 1) Accommodating ( $n=49), 2)$ Diverging $(n=43), 3)$ Assimilating ( $n=41)$, and 4) Converging ( $n=13)$ and compared the observed distribution to the expected distribution. This analysis showed the four learning style preferences for on-line Sport Management Studies students were not equally distributed and a significant difference was present.

The second set of follow-up analyses consisted of comparison of each of the four learning styles separately by delivery method: 1) the Accommodating learning style for the face-to-face versus on-line delivery methods, 2) the Diverging learning style for the face-to-face versus on- 
line delivery methods, 3) the Assimilating learning style for the face-to-face versus on-line delivery methods, and 4) the Converging learning style for the face-to-face versus on-line delivery methods (see Table 15$)$. For Accommodating, $\chi^{2}(1, \mathrm{~N}=87)=.022, p>.05$, indicating no statistical significance. For Diverging, $\chi^{2}(1, \mathrm{~N}=84)=1.42, p>.05$, indicating no statistical significance. For Assimilating, $\chi^{2}(1, \mathrm{~N}=57)=3.28, p>.05$, indicating no statistical significance. For Converging, $\chi^{2}(1, \mathrm{~N}=19)=.6, p>.05$, indicating no statistical significance. The analyses compared the percentage of learners in each learning style preference per delivery method to an equal and expected distribution percentage.

Table 15

Pearson Chi Square for Each Learning Style Preference

\begin{tabular}{lccc}
\hline & $\begin{array}{c}\text { Chi-Square } \\
\text { Value }\end{array}$ & df & $\begin{array}{c}\text { Significance } \\
\text { (2-sided) }\end{array}$ \\
\hline Accommodating & .22 & 1 & $>.05$ \\
Diverging & 1.42 & 1 & $>.05$ \\
Assimilating & 3.28 & 1 & $>.05$ \\
Converging & .6 & 1 & $>.05$ \\
\hline
\end{tabular}

\section{Differences in Student Satisfaction by Delivery Method}

The researcher explored student satisfaction in research question four. Research question four is as follows:

4. Is there a statistically significant difference in satisfaction between the traditional face-toface Sport Management Studies undergraduate students and the online web-based Sport Management Studies undergraduate students? 
An independent-samples t-test was conducted to compare mean overall satisfaction scores of respondents in face-to-face Sport Management Studies undergraduate students to the on-line Sport Management Studies undergraduate students. Satisfaction was calculated by summing the responses of ten satisfaction questions. There was no statistically significant difference between the face-to-face respondents' mean satisfaction scores $(M=42.05, S D=5.567)$ and on-line respondents' mean satisfaction scores $(M=42.77, S D=5.583) ; t(245)=.994, p=0.321($ see Table 16).

Table 16

Student's t-Test for Mean Satisfaction Score between Delivery Methods

\begin{tabular}{cccc}
\hline & $\mathrm{t}$ & $\mathrm{df}$ & $\begin{array}{c}\text { Significance } \\
\text { (2-tailed) }\end{array}$ \\
\hline T Test & .994 & 245 & .321 \\
\hline
\end{tabular}

In an effort to further examine student satisfaction, a MANOVA was calculated to examine the association between mean scores of each individual satisfaction question (see Table 17) as dependent variables and methods of delivery (face-to-face and on-line) as the independent variables. The MANOVA allowed the researcher to examine the simultaneous effects of the independent variable on multiple dependent variables. The major benefit of the researcher using a MANOVA was controlling experiment-wise level of Type I error rate.

Table 17 presents the means and standard deviations of the dependent variables for the ten satisfaction questions (Q21 to Q30). A score of five indicated the highest level of satisfaction (very satisfied) and a score of one indicated the lowest level of satisfaction (very dissatisfied). 
Table 17

Means and Standard Deviations for each Dependent Variable by Delivery Method

\begin{tabular}{lrrrrr}
\hline & \multicolumn{2}{c}{ FTF } & \multicolumn{2}{c}{ OL } & \\
& $\mathrm{M}$ & $\mathrm{SD}$ & $\mathrm{M}$ & $\mathrm{SD}$ & $\mathrm{P}$ \\
\hline Satisfaction Question & 4.15 & .841 & 4.45 & .622 & .002 \\
Challenge and demand of courses (Q21) & 4.14 & .837 & 4.42 & .672 & .004 \\
High expectations for student performance (Q22) & 4.36 & .715 & 4.34 & .745 & .827 \\
Variety of learning experiences and group interactions & & & & & \\
promoting critical thinking and analysis (Q23) & 4.19 & .880 & 4.39 & .699 & .046 \\
$\begin{array}{l}\text { Connection of classroom learning to past experiences and } \\
\text { daily life application (Q24) }\end{array}$ & & & & & \\
Accessibility of instructors (Q25) & 4.38 & .798 & 4.29 & .864 & .452 \\
Interaction and rapport between faculty and students (Q26) & 4.29 & .779 & 4.14 & .868 & .165 \\
Quality of academic experience within program (Q27) & 4.12 & .864 & 4.33 & .789 & .049 \\
$\begin{array}{l}\text { Opportunities to learn multicultural and global perspectives } \\
\text { (Q28) }\end{array}$ & 3.8 & .928 & 3.84 & .887 & .774 \\
$\begin{array}{l}\text { Program being warm, friendly, and supportive of students } \\
\text { (Q29) }\end{array}$ & 4.41 & .695 & 4.39 & .755 & .870 \\
Sense of belonging (Q30) & & & & & \\
\hline
\end{tabular}

Note. $\mathrm{FTF}$ = face-to-face students; $\mathrm{OL}=$ on-line students.

Result of the overall MANOVA showed a significant difference in the dependent variable upon the delivery method as $F(10,236)=2.928, \mathrm{p}=.002$. Four individual satisfaction questions had significant mean differences between the two delivery method groups. Student satisfaction with the challenge and demand of course, had a statistically significant MANOVA sub-test of $F$ $(1,245)=10.151, p \leq .002$. On-line respondents $(\bar{X}=4.45)$ were more satisfied with the challenge and demand of Sport Management Studies courses than the face-to-face students $(\bar{X}=$ 4.15). Student satisfaction for high expectations for student performance had a statistically significant MANOVA sub-test of $F(1,245)=8.410, p \leq .004$. On-line Sport Management Studies respondents ( $\bar{X}=4.42$ ) were significantly more satisfied with the Sport Management 
Studies major setting high expectations for student performance than the face-to-face students ( $\bar{X}=4.14$ ). Student satisfaction in finding connection of classroom learning to past experiences and daily life application had a statistically significant MANOVA sub-test of $F(1,245)=4.040$, $p \leq .046$. On-line Sport Management Studies respondents $(\bar{X}=4.39)$ were significantly more satisfied with the program finding connections between what students were learning in the classroom, relating it to their past experiences, and applying it to their daily lives than the faceto-face students $(\bar{X}=4.19)$. Student satisfaction in the quality of academic experience within a program had a statistically significant MANOVA sub-test of $F(1,245)=3.913, p \leq .049$. Online Sport Management Studies respondents $(\bar{X}=4.33)$ were significantly more satisfied with the quality of their academic experience within the program compared to the face-to-face students $(\bar{X}=4.12)$.

The remaining six questions $(23,25,26,28,29$, and 30) were not found to be statistically significant. Question 23, variety of learning experiences and group interactions promoting critical thinking and analysis had an $F(1,245)=4.040, p>.05$. Accessibility of instructors $(\mathrm{Q} 25)$ had an $F(1,245)=.568, p>.05$. Interaction and rapport between faculty and students (Q26) had an $F(1,245)=1.940, p>.05$. Opportunities to learn multicultural and global perspectives (Q28) had an $F(1,245)=.083, p>.05$. Program being warm, friendly, and supportive of students (Q29) had an $F(1,245)=.027, p>.05$. Sense of belonging $(\mathrm{Q} 30)$ had an $F(1,245)=.118, p$ $>.05$.

\section{Summary of Key Findings}

The purpose of this study was to identify and compare the prevalence of learning styles among undergraduate Sport Management Studies (SMS) students at California University of Pennsylvania (Cal U) by utilizing Kolb's Learning Style Inventory, $3^{\text {rd }}$ Edition (LSI 3.1) (2005). 
Learning style prevalence was determined for traditional face-to-face students and online webbased students, and differences in learning style prevalence between these two groups were explored. Finally, differences in student satisfaction between program delivery methods were examined by using an online questionnaire designed by the researcher.

In this research study, 247 Sport Management Studies undergraduate students completed an on-line survey during the end of the fall 2009 semester. One hundred one were face-to-face students and 146 were on-line students. The majority of the face-to-face respondents were male (61\%), and $97 \%$ were in the "traditional" age grouping. The majority of the on-line respondents were female (57\%), and $80 \%$ were in the "non-traditional" age grouping. Eighty-three percent of all respondents resided off-campus. The majority (81\%) of both the face-to-face and on-line groups were White/Caucasian/European American although African American/Black, Asian American/Pacific Islander, Hispanic American/Latino/Chicano, Native American/Tribal Affiliation, and Multi-Racial ethnic affiliations were all represented by the respondents. Ninetytwo percent of all respondents indicated full-time status with $36 \%$ being seniors, $26 \%$ juniors, $22 \%$ sophomores, and $16 \%$ freshman.

Of the 101 face-to-face Sport Management Studies undergraduate students who completed the survey, $41(40.6 \%)$ were found to be Diverging, $38(37.6 \%)$ were found to be Accommodating, and $16(15.8 \%)$ were found to be Assimilating. Diverging was the most prevalent learning style preference for face-to-face respondents.

Of the 146 on-line Sport Management Studies undergraduate students who completed the survey, 49 (33.6\%) were found to be Accommodating, 43 (29.5\%) were found to be Diverging, and $41(28.1 \%)$ were found to be Assimilating. Accommodating was the most prevalent learning style preference for on-line respondents. 
The overall (omnibus) Chi Square for learning style preference by delivery method yielded a trend toward significance. The comparison of the four learning styles for the face-toface participants indicated a statistically significant difference. The comparison of the four learning styles for the on-line participants indicated a statistically significant difference. The follow-up analysis consisted of comparison of each of the four learning styles separately by delivery method (face-to-face and on-line) yielded no statistical significant difference.

Four satisfaction questions were found to have statistical significance in ratings between face-to-face and on-line students. On-line respondents were significantly more satisfied with the challenge and demand of Sport Management Studies courses, significantly more satisfied with the Sport Management Studies major setting high expectations for student performance, significantly more satisfied with the program finding connections between what students are learning in the classroom, relating it to their past experiences, and applying it to their daily lives, and significantly more satisfied with the quality of their academic experience within the program when compared to the face-to-face respondents. 
Learning Styles Traditional and Online 112

\section{Chapter Five: Conclusions and Implications}

\section{Introduction}

This chapter discusses the results of this study and presents the conclusions and implications. First, findings related to the literature are presented. The researcher discusses demographic implications, learning styles of face-to-face and on-line learners, learning style comparisons, and satisfaction of face-to-face and on-line learners of the study. Second, recommendations for practice are offered. Third, recommendations for future research are presented.

The growth of distance education courses via the Internet prompted educational research focused on learners' characteristics and learning differences during the past twenty years (Hills, 2003; Khan, 2005). Approaches to learning emphasized the importance of taking learners into consideration when designing instruction. Learners' characteristics have always been an important concern for educators, designers, and researchers (Khan, 2005; Laurillard, 2001; Moore \& Kearsley, 2005; Schwitzer, Ancis, \& Brown, 2001). Knowledge of learners’ characteristics is important when deciding on the type of media by which the content will be delivered and the structure of courses by which diverse students will be accommodated (Khan, 2005; Laulliard, 2001).

Distance education and web-based courses are mainstream in colleges and universities in the United States and growing (U.S. Department of Education, 2008). The 2007 Distance Education Survey concluded the distance education market outlook is "strong," and will continue to "be heavily utilized" and "grow for many years" (Distance Education and Training Council, 2007, p. 7). Additionally, as public acceptance of distance education is increasing and competition in distance education is growing, higher education will be turning to distance 
education as a mainstream delivery medium. This may encourage diversity of students and an expansion to more and various markets (Distance Education and Training Council, 2007). Beldarrain (2006) speculated student interaction will be "at the heart of learner-centered constructivist environments" (p. 139) as pedagogical perspectives and theoretical frameworks shift to accommodate current trends in distance education.

Current research focuses on learners' achievement and course evaluations as related to online learning (Moore \& Kearsley, 2005; Khan, 2005), but there is not much attention paid to the effects of online instruction on learners' psychological characteristics such as learning styles. Researchers believe that learning style is a good predictor of an individual's preferred learning behavior (Bostrom, Olfman, \& Sein, 1993).

The educational shift to the student-centered approach has led researchers to explore learning styles in greater depth in both traditional face-to-face and online web-based classroom settings. Because people learn and process information in many different ways, it has long been supported by educators that individual differences play an important role in learning and instruction (Moallem, 2007). As unique as every student is, so are the learning styles and techniques they prefer. Educational researchers suggest there is a need to understand the distance learning student population (Vafa, 2002) and comparisons of variables which might impact distance learning effectiveness such as learning styles (Zhang, 2005). Diaz and Cartnal (1999) emphasized that very little research examines distance learning and learning styles.

\section{Findings Related to the Literature}

\section{Demographic implications.}

As reported in Chapter 4, the majority of the face-to-face respondents were male $(61 \%)$ and $97 \%$ were in the "traditional" age grouping. The majority of the on-line respondents were 
female $(57 \%)$ and $80 \%$ were in the "non-traditional" age grouping. This is similar to the demographics reported by Diaz and Cartnal (1999), who in a similar study found their distance group had a higher percentage of females (59\% which is parallel to this researcher's findings) and higher percentage of students above 26 years of age (i.e., comparable to the non-traditional grouping). As discussed by Thompson (1998), these characteristics align with the general profile of distance students. Diaz and Carnal (1999) suggested distance education instructors "should continually monitor students' characteristics" since it seems "the dynamic nature of distance education in general will keep student characteristics fluid" (p. 135).

Beqiri, Chase, and Bishka, (2010) investigated factors impacting business students’ satisfaction with online course delivery. Their findings suggested a student having the profile of graduate, married, resides more than 1 mile away from campus, and male would be more satisfied with the delivery of online courses (Beqiri, Chase, \& Bishka, 2010). Eighty-three percent of all respondents in this study resided off-campus and half were male. This study did not make the comparison between satisfaction and gender or other demographic areas.

Similar to this study's sample population, many studies (Diaz \& Cartnal, 1999; Manochehri \& Young, 2006; Mupinga et al., 2006; Neuhauser, 2002; Rabe-Hemp, Woollen, \& Humiston, 2009; Rassool \& Rawaf, 2007; Tucker, 2001) have utilized undergraduate student populations when exploring prevalent learning styles. Neuhauser (2002) found similar gender demographics to this study with more of the face-to-face students being male and more of the online students being female. Additionally, similar to this study's findings, more of the on-line students were categorized as non-traditional (Neuhauser, 2002). 


\section{Learning styles of face-to-face learners.}

Using Kolb’s (2005) Learning Style Inventory, potentially there are four learning styles: Diverging, Assimilating, Converging, and Accommodating. Of the 101 traditional face-to-face Sport Management Studies undergraduate students who completed the survey for this study, Diverging $(41 \%)$ was found to be the most prevalent learning style (38\% were found to be Accommodating, 16\% were found to be Assimilating, and 6\% Converging).

Two research studies (Rassool \& Rawaf, 2007; Cavanagh, Hogan, \& Ramgopal, 1995) were found to have similar results to this dissertation study and one study (Manochehri \& Young, 2006) supported the Diverging and Accommodating learning styles within the traditional setting. While other research studies (Buerck et al., 2003; Diaz \& Cartnal, 1999; Rabe-Hemp, Woollen, \& Humiston, 2009; Aragon et al; 2002; Neuhauser, 2002; Tucker, 2001) had contradictory findings, it must be noted that a wide range of results may be reported due to variations of survey instruments and sample populations.

After conducting a review of literature, Rassool and Rawaf (2007) indicated that the predominant learning style preference among nursing students is Kolb's Concrete Experience (CE) dimension, the Accommodator and Diverger learning styles. The research finding of undergraduate nursing students based on Honey and Mumford's (1992) learning styles categories found Reflector to be the predominate learning style followed by Activist (Rassool \& Rawaf, 2007). Reflector and Activist would correspond to Diverger and Accommodator using Kolb's (1994) learning style categories.

Cavanagh, Hogan, and Ramgopal (1995) in a study of undergraduate nursing students, found by using Kolb's learning styles inventory that $54 \%$ of the students had a predominantly Accommodating (concrete) learning style while $46 \%$ were predominantly Diverging (reflective). 
These numbers relate well to the learning styles of the on-line SMS students (predominantly Accommodating followed by Diverging) and were not dissimilar from the group as a whole (both the on-line and face-to-face learners preferred the Accommodating and Diverging learning style). Because nursing students were found to have fairly evenly distributed learning styles, Cavanagh et al. (1995) stressed the need to use a variety of delivery styles with students while focusing on participation and experiential learning was emphasized.

Many studies' (Buerck et al., 2003; Aragon et al., 2002, 1995; Diaz \& Cartnal, 1999; Neuhauser, 2002; Tucker, 2001; Rabe-Hemp, Woollen, \& Humiston, 2009) results were different from the findings of this dissertation research study. In Buerck, Malmstrom, and Peppers' (2003) study directed at determining if there was a relationship between students' preferred learning environment (face-to-face or on-line) and also if there was a difference in the academic success of the students majors in the two learning environments, face-to-face students (nontraditional students in a computer science course) were found more likely to have the Assimilator learning-style. Aragon, Johnson, and Shaik's (2002) study compared two sections of a graduatelevel instructional design course for human resource development professionals. Aragon et al. (2002) reported face-to-face learners were found to report a greater use of learning by doing, or active experimentation, scale. Seemingly, this would be on the opposite end of the processing continuum when compared to this study.

The Grasha-Reichmann Student Learning Style Scale (GRSLSS) was used in a study by Diaz and Cartnal (1999) comparing students' learning styles in online distance and an equivalent on-campus health education class. Results indicated on-campus students were more dependent in their styles as learners while online students were more independent. The collaborative on- 
campus students tended to be competitive and participatory in the classroom and preferred structure and guidance (Diaz \& Cartnal, 1999).

In Neuhauser's (2002) study of undergraduate students, it was found that approximately two-thirds of face-to-face learners were considered visual or kinesthetic learners. Tucker (2001) classified the majority of the learners within her study as inanimate and iconic. Rabe-Hemp et al. (2009) found most face-to-face undergraduate students preferred a more collaborative learning environment while on-line students preferred a more reflective learning environment.

The results of this dissertation research study support Kolb's (1984) claim that no single learning environment is oriented towards just one of the learning modes. The divergence of learning styles in both delivery methods provided more evidence that a variety of modes of teaching and learning should be used in meeting the diverse learning needs of students. Although this dissertation research found the most prevalent face-to-face learners to be Divergers, all learning styles were represented within the group reinforcing the need for using a variety of pedagogical approaches with students.

\section{Learning styles of on-line learners.}

In this dissertation research study, the Accommodating (34\%) learning style was shown to be most prevalent for on-line students followed by Diverging (29\%), Assimilating (28\%) and Converging (9\%). After examining previous literature, a wide array of prevalent learning styles were reported for on-line learners but none with results the same as this dissertation research study.

Wang, Wang, Wang, and Huang (2006) conducted a study investigating the effects of formative assessment and learning style on student achievement in a web-based learning environment. Students were tested using Kolb's Learning Style Inventory and consisted of 455 
seventh-grade students and were found to perform best when they had a Divergent learning style (Wang et al., 2006). Wang et al. (2006) concluded two main points from their findings: 1) awareness of student learning styles may increase student performance when considered in elearning design, and 2) because of the great diversity in students, utilizing various teaching strategies may be more effective than utilizing a single teaching strategy.

In contrast to this study's findings, Buerck et al., (2003) found on-line students were found to more likely have a Converger learning style. In fact, the Converging learning style was represented least in both the face-to-face and on-line students in this research study.

Aragon, Johnson, and Shaik's (2002) study which questioned whether there were distinguishable differences between the learning style preferences of students enrolled in an online course and those enrolled in an equivalent face-to-face course found significant differences in the area of cognitive processing habits (cognitive controls). Online students were found to be more reflective and have a higher reported preference for abstract conceptualization in comparison to face-to-face students (Aragon et al., 2002). Diaz and Cartnal (1999) indicated on-line students with independent learning styles tended to be less collaborative and dependent and appeared more driven by intrinsic motives and not by the reward structure of the class than their face-to-face counterparts.

A study of online students' needs by Butler and Pinto-Zipp (2006) looked for a dominant learning style, a preferred method of online instruction, and a relationship between learning styles and the preferred method of online instruction. The Gregorc Learning Styles Delineator (GSD) along with a demographic and Likert scale questionnaires were utilized. Varied learning styles with dual learning styles (56.2 percent) represented the greatest number of students. The 
students preferred asynchronous log-ons and high course interaction and also noted a high degree of satisfaction within their online programs (Butler \& Pinto-Zipp, 2006).

In a study designed to determine the learning styles, expectations, and needs of online industrial education undergraduate college students, Mupinga, Nora, and Yaw (2006) did not identify a predominant learning style among the online students; however, about half of the survey population were categorized as introverts, sensors, and judgers. Because there was not a predominant style, Mupinga et al. (2006) reported "the design of online learning activities should strive to accommodate multiple learning styles" (p. 188). Web-based environments were identified as not addressing student diversity. Instructors need to understand the online learning environment, and be able to meet the learners' diverse learning styles, need, and expectations to maximize the learning experiences (Mupinga et al., 2006).

Moallem, 2007-2008 in a study of web-based undergraduate university courses discovered web-based courses appear more appropriate for Abstract Conceptualization (AC) learners (in perception of authentic and active learning). Moallem (2007-2008) suggested webbased courses could better accommodate learners with the preferences for Concrete Experience (CE) and (Active Experimentation) AE if the courses include more collaborative and real life activities. This result is consistent with the researcher's findings for on-line students since the Accommodating learning style is a combination of both the $\mathrm{CE}$ and $\mathrm{AE}$ preferences. Moallem (2007-2008) recommended "course activities be designed to address a range of learning styles with instructional activities" (p. 134). When considering the high emphasis social interaction, collaboration, and problem solving have in the online environment, Moallem (2007-2008) stated, “it is likely that students' perceptions of their positive learning experience influence their motivation and willingness to adjust their preferred learning styles" (p. 238). 
Tucker (2001) found undergraduate on-line learners preferred people and direct experiences while Neuhauser's (2002) study reported undergraduate on-line learners as predominately visual and kinesthetic. Rabe-Hemp et al. (2009) found on-line students to be more reflective (tendencies towards the Diverger and Assimilator learning styles). When reporting performance results, Manochehri and Young (2006) stated Assimilators and Convergers did better in an on-line learning environment. Graduate students in moderated online conferences in two courses were found by Fahy and Ally (2005) to be predominately Assimilators and Convergers. Less than one third of participants were Accommodators or Divergers (Fahy \& Ally, 2005). In contrast, this study found most on-line learners were Accommodators and Divergers while Assimilators and Convergers represented lowest learning style preferences.

\section{Comparing learning styles.}

For this dissertation study's third question, the overall (omnibus) Chi Square for learning style preference by delivery method yielded a trend toward significance. The comparison of the four learning styles for the face-to-face participants indicated a statistically significant difference. The comparison of the four learning styles for the on-line participants indicated a statistically significant difference. The follow-up analysis consisted of comparison of each of the four learning styles separately by delivery method (face-to-face and on-line) yielded no statistical significant difference.

When comparing learning styles between the face-to-face and on-line learning environments, several researchers' (Neuhauser, 2002; Tucker, 2001; Liu, 2007; Keri, 2002-2003; Mahoney, 2006) results were similar to this study’s results finding no significant overall differences in learning style preferences. Neuhauser (2002) utilized learning styles in her 
research but focused primarily on effectiveness and compared two sections of a course (one was asynchronous and online while the other was face-to-face). Neuhauser (2002) concluded there were no significant differences between learning preferences. Results showed most students (greater than 60 percent in each) were visual learners whereas only three students (of the total population) chose auditory as their preferred style. The most successful students, identified by Neuhauser (2002) as "A" students, had preferred learning styles of kinesthetic (66 percent) and visual (40 percent) for the online learner and had preferred learning styles of kinesthetic (43 percent) and visual (43 percent) for the face-to-face learner.

Mahoney (2006) utilized the Sensory Modality Checklist and assessed strengths in nineteen graduate nursing students in the auditory, visual, and kinesthetic domains. No significant differences were found between visual or kinesthetic learners in the online versus traditional students. Auditory and visual learners were strongest between groups and both used mixed sensory modality styles. It was suggested that faculty need to be aware of their own learning styles and the varying needs of students to incorporate various learning modalities (Mahoney, 2006). Both groups of students by delivery method in this dissertation study used a combination of different manners in which students input and process information (learning style). The two most prevalent learning styles for both the face-to-face and on-line students were Divergers and Accommodators. These findings would support notions of auditory, visual, and kinesthetic domains with learners feeling and sensing (Concrete Experience) and watching and reviewing (Reflective Observation) for the Divergers and learners feeling and sensing in the perceiving continuum and doing and planning (Active Experimentation) in the processing continuum for the Accommodators. 
In contrast to this dissertation research study's findings, several researchers (Buerck et al., 2003; Aragon et al., 2002; Diaz \& Cartnal, 1999; Manochehri \& Young, 2006; Moallem, 2007-2008) found significant differences when comparing prevalent learning styles in face-toface versus on-line delivery methods. In a study conducted by Buerck et al. (2003), a significant difference was found in learning styles between the two learning environments. Online students were found to more likely have a Converger learning style while face-to-face students were more likely to have the Assimilator learning-style. These findings supported the hypothesis that there is a relationship between students' preferred learning style and their learning environment.

Aragon, Johnson, and Shaik's (2002) study found there were significant differences between the learning style preferences of the students enrolled in different learning environments (but these differences were not significant when success factors were controlled). No significant differences in the social and environmental preferences between the students of the two delivery formats were found and both the face-to-face and online students were found to have similar learning and study strategies. The two groups showed significant differences in the area of cognitive processing habits (cognitive controls). Online students were found to be more reflective and have a higher reported preference for abstract conceptualization in comparison to face-to-face students. Face-to-face learners were found to report a greater use of learning by doing, or active experimentation, scale (Aragon et al., 2002).

Results in a study by Diaz and Cartnal (1999) comparing students' learning styles in online distance and an equivalent on-campus health education class, indicated on-campus students were more dependent in their styles as learners while online students were more independent. The online students with independent learning styles tended to be less collaborative and dependent and appeared more driven by intrinsic motives and not by the 
reward structure of the class. Significant positive correlations were also found between the collaborative learning style and the competitive and participant learning styles. The collaborative on-campus students tended to be competitive and participatory in the classroom. The on-campus students preferred structure and guidance (Diaz \& Cartnal, 1999).

Manochehri and Young (2006) conducted a study which compared the effects student learning styles (web-based learning and traditional instructor-based learning) had on student knowledge and satisfaction utilizing university students enrolled in the Math 1100 (college algebra) course. The following results were found: 1) there was no significant difference in student satisfaction based on their learning styles, but there was a significant difference in satisfaction based on teaching methodology (instructor-led were more satisfied than web-based); 2) students' learning styles were statistically significant for knowledge performance (Assimilator and Converger did better with web-based methodology, while Diverger and Accommodator received better results with instructor-based learning); 3) there was not a significant difference in performance between instructor-based and web-based subjects.

Moallem's (2007-2008) study showed the majority of the students were equally divided in different categories of learning styles with visual learners being the highest in frequency. Additionally, all active learners were also visual learners while only half of reflective learners were visual. Reflective and active learners were equally divided between sequential and global learning styles. Eighty percent of active learners were intuitive and 80 percent of reflective learners were sensing learners. Regarding online learning, Moallem (2007-2008) offered several conclusions of his study. First, students' perceptions of their positive learning experience influence their motivation and willingness to adjust their preferred learning styles (in online environments where social interaction, collaboration, and problem solving were highly 
emphasized). Second, learning styles can be integrated into online learning environments instruction without compromising the appropriateness of instructional strategies for specific content and learning outcomes. Third, integrating learning styles in the design of instructional materials seemed to encourage learners to spend more time interaction with content and exploring various instructional materials to achieve learning outcomes. Fourth, higher learning outcomes may result if multiple learning styles are addressed in a variety of instructional strategies (Moallem, 2007-2008).

\section{Satisfaction with face-to-face and on-line programs.}

The researcher in this dissertation study concluded there was no significant difference between the face-to-face respondents' means satisfaction scores and on-line respondents' mean satisfaction scores; however, four satisfaction questions were found to have statistical significance. Both groups were highly satisfied. Face-to-face and on-line students reported the program was warm, friendly, and supportive of them and the students perceived a sense of belonging. On-line respondents were significantly more satisfied with the challenge and demand of Sport Management Studies courses, significantly more satisfied with the Sport Management Studies major setting high expectations for student performance, significantly more satisfied with the program finding connections between what students are learning in the classroom, relating it to their past experiences, and applying it to their daily lives, and significantly more satisfied with the quality of their academic experience within the program when compared to the face-to-face respondents.

While there is a substantial amount of evidence linking distance education and face-toface classroom instruction and results, Walker and Kelly (2007) stated student satisfaction has been found to be generally good. Walker and Kelly (2007) when surveying online students in 
the College of Liberal Studies at the University of Oklahoma found overall that the students were very satisfied.

Although Bollinger and Wasilik (2009) focused their research on factors influencing faculty satisfaction with online teaching and learning in higher education, they also discussed key points within student satisfaction. Students can be influenced depending on their perceptions about their learning experiences and with levels of satisfaction with overall online learning experiences to continue with a course (Bollinger \& Wasilik, 2009).

Mason and Weller (2000) showed students' satisfaction was affected most by instructor support, the amount of time devoted to study, and the extent to which the course content and presentation fit students' expectations and learning styles. According to this study, this could be a positive effect since both face-to-face and on-line students scored high in interaction and rapport between faculty and students.

In a study by Downing and Chim (2004), students enrolled in two online courses were compared with students enrolled in equivalent classroom-based courses. The relationship between learning style and mode of delivery was investigated as well as student satisfaction measures. It was found that students of a Reflector learning style demonstrated higher satisfaction with online instructional delivery than those in the classroom-based courses. Students classified with the Reflector learning style exhibited Extrovert behavior while in the online courses while in the traditional setting they might be considered Introverts (Downing \& Chim, 2004).

A study examining the influence of learning styles on student satisfaction in conventional and web-based environment was conducted by Manochehri and Young (2006). The population for this study was university students enrolled in the college algebra course (both an on-campus 
instructor-led course and a web-based course) having the same instructor. Based on a student's learning styles, a series of two-way analysis of variance (ANOVA) techniques and independent variable tests were used for the dependent variable - satisfaction. This study had four major conclusions. First, there was no significant difference in student satisfaction based on their learning styles, but there was a significant difference in satisfaction, based on teaching methodology. Second, there is a significant difference in student satisfaction between learning on the web versus instructor-based learning, with the instructor-led methodology being more satisfying. Third, there was a slight trend in an increase of satisfaction among the learning styles of Assimilator and Converger compared to Diverger and Accommodator. Fourth, there was greater satisfaction of the instructor-based students, regardless of their learning styles, compared to the web-based students (Manochehri \& Young, 2006). The fourth result finding was not congruent with the results of this dissertation study in which both delivery groups were found to be satisfied and the on-line students were found to be more satisfied in four of the ten areas.

Allen, Bourhis, Burrell, and Mabry (2002) conducted a meta-analysis summarizing and evaluating empirical literature comparing student satisfaction with distance education to traditional classrooms in higher education. Overall, analysis indicated students have a slightly higher level of satisfaction with live course settings than distance education formats; however, after removal of three outliers and reanalysis, the results indicated there is homogeneity. In general, there was little decline in student satisfaction with the quality of the educational experience between the two methodologies. The meta-analysis supported researchers arguing that when compared to traditional face-to-face instruction, distance education does not diminish the levels of student satisfaction (Allen et al., 2002). It was shown, "students find distance education as satisfactory as traditional classroom learning formats" (Allen et al., 2007, p. 93). 
Moallem (2007-2008) examined what effects students' learning styles and the design of instruction have on attitude and satisfaction. The course used in the study was a foundation course for all students in a graduate instructional technology program using the Vista platform and was a blend of asynchronous and synchronous instruction. No significant differences in satisfaction were shown (Moallem, 2007-2008).

Student satisfaction with e-learning was investigated in a study by Levy (2007) which compared dropouts and persistence in e-learning courses. Results indicated students' lack of satisfaction with e-learning was a key indicator in students' decision to dropout from e-learning courses (Levy, 2007). Studies such as Chyung, Winiecki, and Fenner (1998) reported satisfaction as a major factor in a student's decision to dropout of a distance education course. Sachs and Hale (2003) proposed major emphasis should be placed on students' satisfaction in measuring success of college and university e-learning courses and also retention. Keeping students' satisfaction levels with e-learning high should be goal of college distance education programs (Sachs \& Hale, 2003).

\section{Recommendations for Practice}

Based upon the results of this dissertation research study, there are five major recommendations for practice.

First, as educators plan and design their pedagogical approaches, they should consider students' learning styles and use that information to create a more learner-centered constructivist approach. This researcher believes there is no "cookie-cutter" approach to pedagogy and the individual needs of students must be realized. As Huebner (2010) pointed, “today's classrooms are filled with diverse learners who differ...in their cognitive abilities, background knowledge, and learning preferences" (p. 79). Many experts recommend responding 
to individual student differences such as learning style (Huebner, 2010; Anderson, 2007; Rock, et al., 2008). A general one-size-fits-all approach does not take in account the needs of all the different learners (Janicki \& Liegle, 2001) and it is proposed that a more effective system to adapt to the relationship of the material presentation mode and learning style of the users could be implemented (Liegle \& Janicki, 2006).

In order to give students an opportunity to learn in an environment more conducive to their preferences, Suskie (2003) suggests that instructors should attempt to alter their teaching methods. By focusing on students' unique needs and learning styles, instructors can better facilitate the learning process whereby creating a more learner-centered constructivist approach. To help students become more effective learners, Cooper (2007) suggests knowing the learning style of students is a valuable skill that can help educators identify and solve learning problems among students. Information about learning styles allows faculty to be sensitive to the multitude of differences students bring to the classroom.

By matching or mismatching students' learning styles, educators can thoughtfully and systematically design learning experiences depending on the teacher's purpose (Acharya, 2002). Because of the dialectic relationships among the learning modes, Yeganeh and Kolb (2007) also discussed inhibiting and developing dominating modes as being effective. The attention to students' needs will assist instructors in becoming a "guide on the side" instead of a "sage on the stage" perpetuating a learner-centered environment. By recognizing students' learning styles, Kazu (2009) suggests matching teaching styles and learning tasks by providing input and learning tasks preferred by students and also mismatching styles so learners can improve. By being concrete and practical, and supporting students' imagination, creativity, and exploration of new possibilities, teachers help students quickly reach their goals (Kazu, 2009). "Overall 
learning effectiveness is improved when individuals are highly skilled in engaging all four modes of the learning cycle at contextually appropriate times" (Yeganeh \& Kolb, 2007, p. 16).

When planning and designing pedagogical approaches, educators should consider students' learning styles and use that information to create a more learner-centered constructivist approach. Yeganeh and Kolb (2007) offered four suggestions to improve experiential learning through mindfulness. Experiential learning can be improved 1) by developing the capacity for experiencing, 2) by developing the capacity for reflecting, 3) by developing the capacity for thinking, and 4) by developing the capacity for action (Yeganeh \& Kolb, 2007). Learners should be allowed to engage in experiences, reflect upon them, and then further synthesize and analyze information.

Learning styles can impact education in the areas of curriculum, instruction, and assessment. In addition to traditional skills of analysis, reason, and sequential problem solving, learning style informed educators can additionally place importance on intuition, feeling, sensing, imagination, watching, reviewing, thinking, concluding, doing, and planning. Instructional methods should connect with all four learning styles (or provide means that all are utilized), using various combinations of experience, reflection, conceptualizations, and experimentations. A wide variety of experiential elements such as sound, media, music, visuals, and movement should be introduced and utilized in the classroom through lectures, discussions, projects, collaborations, research, role-playing scenarios, laboratories, etc. By immersing students in these various elements, optimal learning environments can be achieved. As Confucius once said "Tell me, and I will forget. Show me, and I may remember. Involve me, and I will understand" (Chin, 2007). 
Educators should utilize a variety of alternate assessment techniques focusing on strengths and weaknesses of each of the four learning styles. Approaches utilizing simulations, case study, homework, problem solving, group work, peer feedback, logs, journals, brainstorming, papers, analogies, theory readings, laboratories, field work, observations, activities, performance checklists, tests with open-ended questions, collaborations, student portfolios (paper-based or ePortfolios), etc. may be employed.

Second, based on the results of this study student satisfaction was higher for online learners; therefore, during curricular development and revisions, it is recommended that universities support the utilization of effective online instruction to increase satisfaction. In this research study both the face-to-face and on-line students were highly satisfied. The students reported the program was warm, friendly, and supportive of them and the students perceived a sense of belonging. The on-line students were however significantly more satisfied in four areas.

When comparing on-line respondents to face-to-face respondents, on-line students were significantly more satisfied with the challenge and demand of Sport Management Studies courses. Mean scores were reported in this study between 42 and 43 (with 50 indicating the highest possible score for satisfaction). This research showed on-line students were significantly more satisfied with the Sport Management Studies major setting high expectations for student performance. Additionally, on-line respondents were significantly more satisfied with the program finding connections between what students are learning in the classroom, relating it to their past experiences, and applying it to their daily lives. Finally, the on-line respondents were significantly more satisfied with the quality of their academic experience within the program when compared to the face-to-face respondents. In general, the on-line students provided positive ratings for satisfaction. 
All of these findings demonstrate greater satisfaction for the on-line students. Therefore, when classes are created, and programs are implemented, faculty and administration should embrace on-line delivery methods and techniques. While researcher such as Moallem (20072008) have found no significant differences between delivery methods and satisfaction levels, and Manochehri and Young (2006) reported greater satisfaction levels with instructor-based programming, Walker and Kelly (2007) have found on-line learners overall to be very satisfied. Allen et al. (2002) stated, "in general, the replacement of traditional face-to-face education with distance education technology should demonstrate little decline in student satisfaction with the quality of the educational process" (p. 91).

The reason we might see a difference here, based on the researcher's experience and data, is possibly because the on-line program at $\mathrm{Cal} \mathrm{U}$ utilizes teaching techniques and suggestions like those offered by Chickering and Gamson (1987) and Gould and Padavano (2006) therefore increasing student satisfaction. Chickering and Gamson's (1987) Seven Principles for Good Practice in Undergraduate Education mapped out fundamental principles of effective teaching which have remained timeless even after decades of research. Good practice in undergraduate education focus on encouraging contact between students and faculty, developing reciprocity and cooperation among students, encouraging active learning, giving prompt feedback, emphasizing time on task, communicating high expectations, and respecting diverse talents and ways of learning.

Gould and Padavano (2006) offered seven suggestions to improve student satisfaction in on-line courses. They suggest 1) managing organization and course expectations by posting the syllabus, 2) administering and sharing the results of a learning style inventory, 3) explaining the importance of group work, 4) using team contracts that outline how and when the group will 
work together (options include e-mail, threaded discussion, text-based chat, document sharing, and audio bridging), 5) using a variety of assessments, 6) encouraging flexibility (facilitating based on student participation in the course), and 7) providing frequent interaction for students between instructors and fellow students (Gould \& Padavano, 2006).

Third, it is recommended that educators realize the technological revolution at hand and utilize the latest technological advancements when designing instruction and creating pedagogical approaches to provide learning conditions suitable for the various students' learning styles. Because higher education is beginning to change in response to providing education and increasing student diversity, opportunities to restructure the educational system utilizing technology and e-learning will initiate new pedagogical change (Desai, Hart, \& Richards, 2008).

As distance education programs have been increasing in the United States, Internet-based distance education now could be described as mainstream education (Scagnoli, 2001). The 2007 Distance Education Survey concluded the distance education market outlook is "strong," and will continue to "be heavily utilized" and "grow for many years" (Distance Education and Training Council, 2007, p. 7). Additionally, as public acceptance of distance education is growing and competition in distance education is growing, higher education will be turning to distance education as a mainstream delivery medium. Baldwin and Baumann (2005) described education "in a time of rapid change" contending academic fields "must adapt to accommodate changing student interest, new approaches to teaching and learning" and also be "dynamic" (p. 89). Higher education is encouraged to "think outside the box" and apply new options to encourage programs to become more flexible and adaptive to serve a diverse society effectively 
(Baldwin \& Baumann, 2005, p. 90). Utilizing learning styles and creative pedagogical approaches can help academic programs to achieve these goals.

According to Davis (2001), the world is starting a new age of learning where technology is the driving force to reaching an "increasingly diverse audience with a variety of flexible, compelling, and more effective learning opportunities" (ף2). Davis (2001) suggested the key to delivering effective instruction that meets the needs of the diverse population of learners is recognizing DE learning requires different pedagogical approaches from classroom learning. Zhao (2003) agreed that teaching online is not the same as teaching in a traditional classroom in terms of pedagogical approaches and use of technology.

The researcher suggests educators embrace this technological revolution when designing instruction. By utilizing the latest technological advancements while creating pedagogical approaches, educators can provide learning conditions suitable for the various students' learning styles. Technology provides infinite possibilities within both the face-to-face and on-line delivery methods.

Klopfer, Osterweil, Groff, and Haas (2009) suggested utilizing social networking, digital gaming, and simulations to connect with students through technology. Brady (2004) advocated multimedia education to improve both student comprehension and interest in the subject material. Technologies are "safe" and "valuable tools" (Klopfer et al., 2009, p. 2) that help shape new ways of communication, collaboration, and formation of social constructs. Technologies "afford us the ability to convey concepts in new ways that would otherwise not be possible, efficient, or effective, with other instructional methods" (Klopfer et al., 2009, p. 4). There are endless possibilities and potential in the ways technology can enhance the classroom. Delivery methods can include both synchronous and asynchronous activities. 
Various media, such as text, audio, graphics, video and animation, narration and PowerPoint, can help enhance instruction. Additionally, instructors can augment the course content by linking students with other Internet sources (Lu \& Chiou, 2010). The use of the Web in learning can open infinite possibilities and sources of information. Courses can integrate cooperative learning communities through the use of Web technology tools such as instant messaging, discussion boards, blogs, wikis, twitter, forums, and chats.

Learning management systems (LMS) such as Blackboard, eCollege, Desire2Learn, WebCT, Moodle and many others can provide means for tutoring systems, virtual laboratories, simulations, and frequent opportunity for assessment and feedback. LMS can provide media libraries, webliography, document sharing, linked library, and live chat opportunities for students.

PCs, Macs, Wireless laptops, and hand-held devices such as iPads ${ }^{\mathrm{TM}}$, iPods ${ }^{\mathrm{TM}}$, and Blackberries $^{\mathrm{TM}}$ provide students learning opportunities on the go and from locations around the world. Through electronic means, students can engage in lectures, presentations, podcasts, video chat, discussions, journals/logs, e-portfolios, chats, assignments, activities, laboratories, simulations, etc. Even digital textbooks could replace the traditional textbooks students have become accustomed to buying. Major textbook companies have struck deals with software companies such as ScrollMotion, Inc and Inkling to adapt textbooks for the electronic page (Trachtenberg \& Kane, 2010). Software companies such as ScrollMotion and Inkling are developing digital versions of texts and end-to-end platforms for mobile learning content for use on iPhone ${ }^{\mathrm{TM}}$ and $\mathrm{iPad}^{\mathrm{TM}}$ while Desire2Learn $2 \mathrm{Go}$ has produced a mobile learning application for Blackberry ${ }^{\mathrm{TM}}$ Smartphone products. Applications such as iTunes $U$ are currently being utilized in colleges and universities worldwide. Through applications such as this, educators can use 
audio and video content from museums, universities, cultural institutions, and public television stations to supplement their lectures. Digital content created or curated by educators can be available to only members of a certain educational community (internal) or world-wide through the iTunes Store (public) and then be downloaded and viewed on any Mac ${ }^{\mathrm{TM}}, \mathrm{PC}$, iPod ${ }^{\mathrm{TM}}$, or iPhone ${ }^{\mathrm{TM}}$ (iTunes U, 2010).

Cooperative pedagogical and technological approaches can take into account differing student learning styles and allow for learner-centered methodology. Through the use of technology in the classroom there are endless possibilities for learning. Therefore, it is recommended that educators realize the technological revolution at hand and utilize the latest technological advancements when designing instruction and creating pedagogical approaches to provide learning conditions suitable for the various students' learning styles.

Fourth, when developing and designing on-line courses, based on this study educators need to take into account the majority of the students are non-traditional (25 years or older) and more likely to be female. This study found eighty percent of the on-line respondents were nontraditional and fifty-seven percent were female. This is similar to the demographics reported by Diaz and Cartnal (1999), who in a similar study found their distance group had a higher percentage of females (59\%) and a higher percentage of non-traditional students. As discussed by Thompson (1998), these characteristics align with the general profile of distance students. Neuhauser (2002) found similar gender demographics to this study with more on-line students being female and categorized as non-traditional. It has been reported that more women than men now enroll in college (57\% female) and parallels the fact that more women are entering the workforce (Lifelong, 2002). Huebner (2010) suggested the importance of responding to individual student differences. Not only might this include demographics, but also learning 
style, prior knowledge, interests, and level of engagement. Although this study did not specifically examine interactions between gender and learning styles, previous studies indicate that there is a correlation between gender and the preferred styles of learning.

Besides age, academic achievement, brain processing, culture, and creative thinking, according to Honigsfeld (2001), gender is among a number of factors found to influence student learning style. In Raymayha's (2009) study, gender was found to play a significant role in influencing students learning style preferences. It was found that females preferred visual and aural learning styles more than males. Visual learning shows preference of graphical and symbolic ways of representing information such as the depiction of information in maps, spider diagrams, charts, graphs, labeled diagrams, flow charts, and other symbolic representations to what could have been presented in words. Preference for aural information is that which is heard or spoken (Raymayha, 2009). Therefore, educators should present information visually through pictures, diagrams, charts, films, and demonstrations or aurally through lectures and narrated presentations, tutorials, tapes, group discussions, web chats, and talking/speaking experiences. Again, technology can play an important part in delivering quality education to a varying student population with unique learning styles and needs.

While focusing on the online student, Ackoff and Greenberg (2008) pointed how equitable and fair education can be in online learning. Age, gender, religion, race, ethnic origin and almost any other factor that has played a major role in determining a person's relationship with those around them is irrelevant. In cyberspace, "everyone is a person" and "treated in the same manner as the communication of any other person" (Ackoff \& Greenberg, 2008, p. 15). Students can be linked directly to the most up-to-date sources of information on virtually any topic through the Internet, CDs, DVDs, and storage media making an infinite diversity of 
activities and interests accessible. Ackoff and Greenberg (2008) stated these endless possibilities as a "stark contrast to the narrowly limited field of view presented by the handful of subjects selected by anonymous pedagogues as the proper focus for all students" while the world of traditional education seems "hopelessly sterile, arcane, and irrelevant" (p. 15).

Aslanian (2001) reports approximately " 42 percent of all students at both private and public institutions are age 25 or older" (p. 4). Adult learners are the fastest-growing population in higher education. Between 1970 and 2000, the number of adult students increased 170\% (Aslanian, 2001; Lifelong, 2002). Bishop (2003) offered possible influences to include the growth of continuing education programs, economic necessity, the rapidly changing job market, changes in the economy, and the simple aging of student populations.

Betts, Harman, and Oxholm (2009) stated, “demographics have always had profound effects on higher education, and the impending shifts will undoubtedly change higher education in many significant ways" (p. 11). For higher education to remain competitive and sustainable it must adjust to the influx of non-traditional learners. There is a greater demand for education by the non-traditional learner because of the demand for higher education degrees by employers. On-line education has become a viable option for non-traditional students who are working fulltime, unemployed and seeking employment, displaced or dislocated, have family responsibilities, or are unable to afford additional costs related to enrollment in traditional residential campuses (Betts et al., 2009).

Karber (2003) suggested many opportunities for non-traditional education are accessible and available through the Internet and World Wide Web. Li (2008) contended similar thoughts adding that the flexibility of online education has helped working self-motivated and mature students to complete their education while still supporting themselves or their families. Online 
education is "a catalyst to enable the paradigm shift to take place in education, making educators/academics think about and study how such programs are best delivered" (Li, 2008, n.p.) Online education and e-learning has become an essential part of teaching in higher education.

When designing on-line courses, Bovell and Ansalone (2001) suggested providing adult learners with opportunities in which to control their own learning by selecting from suggested resources, choosing some of their own assignments (including ways to complete and present them), and choosing with whom they work. Truluck and Courtenay (1999) in a study of learning style preferences of older adults, utilized Kolb's (1985) Learning Style Inventory and found older adults fairly evenly distributed across the four learning style preferences. Fewer preferred the Converger style (similar to this research study) which involves thinking and doing while learning. As the adult age ranges were older, they preferred the Accomodator, Diverger, and then Assimilator learning styles. Therefore, it was suggested that with age there is a tendency to become more reflective and observational in the learning environment (Truluck \& Courtenay, 1999). Howell, Williams, and Lindsay (2003) suggested non-traditional preferred doing to knowing, trial-and-error to logic, and typing to handwriting. Adult learners differ from traditional learners by tending to be practical problem solvers. They want to know the rationale for what they are learning (Howell et al., 2003).

Miller (2001) considered DE to be a "lifeline" between higher education and lifelong learners (p. 321). Learning communities can now be created at a scale not previously practical by bringing together students outside of the traditional campus classroom (Miller, 2001). Miller (2001) concluded, "the scalability offered by distance education technology may prove, ultimately, to be its most practical benefit to general education" (p. 322). The most common 
factors cited as affecting distance education decisions to a major extent were meeting student demand for flexible schedules (68 percent), providing access to college for students who would otherwise not have access (67 percent), making more courses available (46 percent), and seeking to increase student enrollment (45 percent) (U.S. Department of Education, 2008).

Diaz and Carnal (1999) suggested distance education instructors "should continually monitor students' characteristics" since it seems "the dynamic nature of distance education in general will keep student characteristics fluid" (p. 135). By getting a good academic pulse on students' learning styles and characteristics, educators can develop and design on-line courses better suited to the needs of their students.

Fifth, based on the findings of this study, the researcher recommends pedagogical approaches including observations, brainstorming, journals, lecture, and cooperative groups for the face-to-face learner (Diverging preference) and recommends simulations, case study, homework, problem solving, small group discussions, and hands-on approaches for the on-line learner (Accommodating preference). In this dissertation research study, the most prevalent learning style for face-to-face students was Diverger, or divergent learning style, which emphasizes concrete experience and reflective observation and falls into the upper right-hand quadrant of the graph. Kolb (1984) stated the greatest strength of this orientation "lies in the imaginative ability and awareness of meaning and values" (p. 77).

The Diverger emphasizes an innovative and imaginative approach to doing things. Little (2004) stated these individuals like to ask "why?" of a situation and reason from concrete, specific information exploring what the system has to offer (p. 8). For example, those with this style view concrete situations from many perspectives and adapt by observation rather than by action. They relate to "brainstorming" idea sessions and focus on people, imagination, and 
feeling oriented (Kolb, 1984, p. 78). Along with the use of cooperative groups and brainstorming, Little (2004) identified instructional methods aligning with the Diverger to include the lecture method. Lectures should focus on specifics like strengths, weaknesses, and uses of a system. Kazu (2009) states main characteristics as "thinking, being aware of values and meanings, concrete experience and learning through reflective observation" as well as constructing their ideas "patiently, objectively, and carefully in the learning process" (p. 88).

Considering these findings, within the traditional face-to-face Sport Management Studies courses it would be advantageous for instructors to use examples, questioning, and reflective time for students to answer (Little, 2004) honing in on sensitive and imaginative strengths (Rassool \& Rawaf, 2007). As Divergers prefer to watch rather than do (observe), and gather information in situations requiring ideas-generation, brainstorming, logs, and journals could be very useful in classroom activities. In conjunction with lectures, group work where students are able to listen with an open mind and receive personal feedback may be employed. It is for these reasons the researcher recommends pedagogical approaches including observations, brainstorming, journals, lecture, and cooperative groups for the face-to-face learner (Diverging preference).

In this dissertation research study the Accommodator, or accommodative learning style, was found to be the most prevalent for on-line students. The Accommodating learning style emphasizes concrete experience and active experimentation and falls into the upper left-hand quadrant of the graph. Kolb (1984) stated the greatest strength of this orientation "lies in doing things, carrying out plans and tasks and getting involved in new experiences” (p. 78). Individuals in this grouping focus on opportunity seeking, risk taking, and action (Kolb, 1984). Kolb (1984) described this style as "accommodation" because it is "best suited for those 
situations where one must adapt oneself to changing immediate circumstances" (p. 78). Little (2004) stated these individuals like to ask "What would happen if I did this?" (p. 8) because they learn by doing and feeling through hands-on experience. Those within the accommodative learning style solve problems in an intuitive trial-and-error manner and rely on other people for information. Accommodators tend to be at ease with people, yet they can be seen as impatient or pushy with others (Kolb, 1984). Little (2004) identified instructional methods aligning with the Accommodator as anything encouraging independent discovery and active learning.

This study suggests allowing on-line students to take a practical or experiential approach in learning experiences. Carriuolo (2002) stated, "advocates of electronic learning often point out that the learning styles of most students are accommodated not by lectures, but by engaging students in active learning accompanied by continuous feedback and review" (p. 60). This would correlate to the researcher's findings of online students. Accommodating learners are attracted to new challenges and experiences and are active learners (Rassool \& Rawaf, 2007; Kazu, 2009).

Since Accommodators perform well when they need to adapt to new situations and have strength in their ability to carry out plans of actions that may be made by others (Cavanagh et al., 1995; Kolb, 1984), the researcher recommends pedagogical approaches including simulations, case study, homework, problem-solving, small group discussions, and hands-on approaches to cater to the needs of these active learners. Villaverde, Godoy, and Amandi (2006) stated, "Elearning environments can take advantage of these different forms of learning by recognizing the style each individual student using the system and adapting the content of courses to match this style" (p. 197). 


\section{Recommendations for Future Research}

Based on the findings of this dissertation research study, five major recommendations for future research are presented. For the first recommendation, the researcher suggests addressing the limitations of the current study. Because this study was limited to a sample of convenience at a single institution and consequently student responses may not have been representative of other institutions, the researcher suggests utilizing a population from multiple institutions and/or from different Carnegie classifications. Data were collected from the fall 2009 cohort. As a result, the participants in this sample may not have been representative of the entire student body.

Therefore, the researcher suggests a larger sample using multiple groupings of students from multiple years. For these reasons, the researcher suggests studying different sample populations including utilization of multiple institutions and/or from different Carnegie classifications and utilization of a larger sample using multiple groupings (programs) of students from multiple academic levels.

Second, student learning styles are usually measured at one time, but may change over the course of the program or specific class. Because student learning styles may change, the second recommendation is to utilize learning style inventories or preference guides at different points within the class or program. Henry (2008) recommended measuring learning styles at the beginning of a course in order to "get acquainted" with students and to get them "more engaged and reflective in their learning" (p. 413). The researcher advocates initial learning style measurement and then subsequent re-evaluation and reflection within and after the course completion.

Due to the uniqueness of the undergraduate online program within this study, the third recommendation is for further demographic study to include active military or veteran 
participants. Cal U Global Online offers seven approved programs of study through

GOArmyEd, a virtual gateway that enables soldiers on active duty, along with their spouses and dependents, to request Tuition Assistance (TA) and apply and register online for approved classroom and online courses (Go Army Ed, 2010). The researcher proposes further research of Go Army (and all military members) in regards to learning styles and student satisfaction within the online programs.

The researcher's fourth recommendation suggests further exploration of the relationship between each individual learning style and student satisfaction depending upon delivery method. By successfully linking particular learning styles to satisfaction based on delivery methods, educators could both mentor and advise students to making more informed choices when selecting courses, and better create and design course to meet the needs of their students.

Wang, Hinn, and Kanfer (2001) investigated links between students' learning styles and computer-supported collaborative learning environments. It was found that learning style does not affect student satisfaction with online students and Convergers who combined active experimentation and abstract conceptualization preformed better in the online learning environment than students with other learning styles (Wang et al., 2001). Student satisfaction with e-learning was investigated in a study by Levy (2007) which compared dropouts and persistence in e-learning courses. Results indicated students' lack of satisfaction with e-learning was a key indicator in students' decision to dropout from e-learning courses (Levy, 2007). Studies such as Chyung, Winiecki, and Fenner (1998) reported satisfaction as a major factor in a student's decision to dropout of a distance education course. Sachs and Hale (2003) proposed major emphasis should be placed on students' satisfaction in measuring success of college and 
university e-learning courses and also retention. Keeping students' satisfaction levels with elearning high should be goal of college distance education programs (Sachs \& Hale, 2003).

Liu (2007) described online education as growing "exponentially every year all over the world" (p. 41). Damoense (2003) believed "E-learning is increasingly forming an integral part of course delivery and instruction, and is reshaping traditional learning world wide" (p. 25). Even though research studies recommended considering online students' learning styles in both course design and online course delivery (Grasha \& Yangarber-Hicks, 2000; Kirkwood \& Price, 2005; Mupinga, et al., 2006), there seems to be paucity in the research supporting distance learners' unique needs and learning styles. Harris, Dwyer, and Leeming (2003) also found the relationship between individual learning styles and Web-based instruction has received very little attention. Concerning online instruction on learner's psychological characteristics such as learning styles, Liu (2007) stated "there is not much attention paid to the effects" (p. 42). Liu (2007) asserted there is a need to investigate the similarities and differences in learning styles between online and traditional students to "make the online option more attractive and viable for different groups of learners" (p. 44).

Lastly, the researcher's fifth recommendation suggests further exploration of learning style preference and student satisfaction in regards to different demographic variables such as gender, age, residence status, ethnic affiliation, student status, and academic standing. As educators, it is important to realize student profiles are continually changing resulting in different abilities, skills, beliefs, and experiences. With changes in demographic variables and a growing diversity of students, a more flexible approach is needed to optimize learning activities and meet learning needs of students. 
It has been concluded by many researchers that people learn and process information in many different ways (Villaverde, Godoy, \& Amandi, 2006; Coffield, 2004; Lawrence, 1982; Diaz \& Cartnal, 1999; Diaz \& Bontenbal, 2001; Fizzell, 1984; Speth, Lee, \& Hain, 2006). Moallem (2007) suggested it has been long supported by educators "that individual differences play an important role in learning and instruction" (p. 217). As unique as every student is, so are the learning styles and techniques they prefer. Ackoff and Greenberg (2008) encouraged faculty of offer students "a wide variety of ways to learn, among which they could choose or with which they could experiment. They do not have to learn different things the same way" (p. 5). Educators must remember that "the objective of education is learning, not teaching" (Ackoff \& Greenberg, 2008, p. 5).

By understanding and gauging students' preferred learning styles and unique demographic characteristics and qualities, educators can move toward a constructivist approach and act as a guide (rather than a dispenser of knowledge) to help the learner construct new knowledge based on their prior knowledge and experience. If differences are realized and addressed in instructional programming, educators can create greater opportunities to make courses challenging, rewarding, and meaningful whereby every individual learner will benefit. 


\section{References}

Acharya, C. (2002). Students learning styles and their implications for teachers. Minneapolis, MN: Center for the Development of Technological Leadership.

Ackoff, R.L., \& Greenberg, D. (2008). Turning learning right side up: Putting education back on track. Upper Saddle River, NJ: Pearson Education.

Allen, M., Bourhis, J., Burrell, N., \& Mabry, E. (2002). Comparing student satisfaction of distance education to traditional classrooms in higher education: A meta-analysis. American Journal of Distance Education, 16(2), 83-97.

Anderson, K.M. (2007). Differentiating instruction to include all students. Preventing School Failure, 51(3), 49-54.

American Psychological Association. (2001). Publication Manual of the American Psychological Association, $5^{\text {th }}$ edition. Washington, DC: American Psychological Association.

Aragon, S.R., Johnson, S.D., \& Shaik, N. (2002). The influence of learning style preferences on student success in online versus face-to-face environments. The American Journal of Distance Education, 16(4), 227-244.

Arnold, B.L, Gansneder, B.M., \& Perrin, D.H. (2005). Research methods in athletic training. Philadelphia, PA: F.A. Davis Company.

Aslanian, C B. (2001). Adult Students Today. New York: The College Board.

Astin, A.W. (1985). Achieving educational excellence. San Francisco: Jossey-Bass.

Bailey, M. (2002). A new perception on the construct of distance learning. New York: Miller \& Associates Publishing.

Baker, A. C., Jensen, P. J., \& Kolb, D. A. (2002). Conversational learning: An experiential approach to knowledge creation. Westport, $\mathrm{CN}$ : Quorum Books.

Baldwin, R.G., \& Baumann, M.J. (2005). Options for change: A flexible vehicle for curriculum evolution and reform. Innovative Higher Education 30(2), 89-98.

Barr, R.B., \& Tagg, J. (1995, November/December). From teaching to learning: A new paradigm for undergraduate education. Change 27(6), 12-26.

Beldarrain, Y. (2006, August). Distance education trends: Integrating new technologies to foster student interactions and collaboration. Distance Education, 27(2), 139-153. 
Bovell, C. \& Ansalone, G. (2001, Fall). An exploration of adult learning styles: Doesn't everyone learn similarly? Michigan Community College Journal: Research \& Practice, 7 (2), 41-59.

Bernard, R.M., Abrami, P.C., Lou, Y., Borokhovski, E., Wade, A., Wozney, L., Wallet, P.A., Fiset, M., \& Huang, B. (2004, Fall). How does distance education compare with classroom instruction? A meta-analysis of empirical literature. Review of Educational Research, 74(3), 379-439.

Betts, K., Hartman, K., \& Oxholm, C. (2009). Re-examining \& repositioning higher education: 20 economic and demographic factors driving online and blended program enrollments. Journal of Asynchronous Learning Networks, 13(4). Retrieved from http://www.aln.org/publications/jaln/index.asp

Beqiri, M.S., Chase, N.M., \& Bishka, A. (2010). Online course delivery: An empirical investigation of factors affecting student satisfaction. Journal of Education for Business, 85, 95-100.

Blakemore, T. McCray, P. \& Coker, C. (Eds.). (1984). A guide to learning style assessment. Stout Vocational Rehabilitation Institute: Monomonie, WI: University of Wisconsin Stout.

Blalock, H.M. (1979). Social statistics (Rev. $2^{\text {nd }}$ ed.). New York: McGraw Hill, Inc.

Bollinger, D.U. \& Wasilik. (2009). Factors influencing faculty satisfaction with online teaching and learning in higher education. Distance Education, 30(1), 103-116.

Bonstingl, J.J. (1996) Schools of quality. Alexandria, VA: Association for Supervision and Curriculum Development.

Bostrom, R. P., Olfman, L., \& Sein, M. K. (1993). Learning styles and end-user training: A first step. MIS Quarterly, 17(3), 118-120.

Bower, B.L., \& Hardy, K.P. (2004). From correspondence to cyberspace: Changes and challenges in distance education. In B.L. Bower \& K.P. Hardy (Eds.) From distance education to e-learning: lessons along the way (p. 5-12). San Francisco: Jossey-Bass.

Brady, J. (2004, November). More than just fun and games? Applied Clinical Trials. Retrieved July 16, 2007 at http://www.actmagazine.com/appliedclinicaltrials/article/articleDetail.jsp?id=131503

Britzman, D.P. (2003). Practice makes practice: A critical study of learning to teach (Rev. ed.). Albany, NY: Albany State University of NY Press.

Brown, K.L. (2003, Fall). From teacher-centered to learner-centered curriculum: Improving learning in diverse classrooms. Education, 124(1), 49-54. 
Buerck, J.P., Malmstrom, T., \& Peppers, E. (2003). Learning environments and learning styles: Non-traditional student enrollment and success in an internet-based versus a lecture-based computer science course. Learning Environments Research, 6, 137-155.

Butler, K. (1987). Learning and teaching style in theory and practice. Columbia, CT: The Learner's Dimension.

Butler, T.J., \& Pinto-Zipp, G. (2006). Students' learning styles and their preferences for online instructional methods. Journal of Educational Technology Systems, 34(2), 199221.

Cal U Global Online. (2009). Cal U global online. Retrieved August 21, 2009 from http://www.cup.edu/go/index.jsp

Cal U Undergraduate Catalog. (2009). Undergraduate catalog. Retrieved August 21, 2009 from http://www.cup.edu/universitycatalogs/undergraduate/ugcatalog.htm

Canfield, A., \& Canfield, J. (1988). Canfield instructional styles inventory (ISI) manual. Los Angeles, CA: Western Psychological Services.

Canfield, A.A. (1992). Canfield learning styles inventory manual. Los Angeles, CA: Western Psychological Services.

Carnegie Foundation for the Advancement of Teaching. (2009). Retrieved on August 23, 2009 from http://www.carnegiefoundation.org

Carriuolo, N. (2002, November/December). The nontraditional undergraduate and distance learning: Is higher education providing a portal or just a keyhole to social and economic mobility? Change, 56-61.

Carvin, A. (2008, October). Campus technology and the expectations game. Learning Now. Retrieved June 7, 2009 from http://www.pbs.org/teachers/learning.now/2008/10/campus_technology_and_the_expe.ht $\mathrm{ml}$

Cavanagh, S.J., Hogan, K., \& Ramgopal, T. (1995). The assessment of student nurse learning styles using the Kolb Learning Styles Inventory. Nurse Education Today, 15(3). 177-183.

Ceraulo, S.C. (2005, July 1). Defense Department fosters "common language" for DE. Distance Education Report, 3-7.

Chen, C.C. (2001). Construction and evaluation of a web-based learning portfolio system: An electronic assessment tool. Innovation in Educations \& Training International, 38(2), 144-145. 
Chickering, A.W. \& Gamson, Z.F. (1987, March). Seven principles for good practice. AAHE Bulletin, 39(7) 2-6.

Chin, A. (2007). The Authentic Confucius: A Life of Thought and Politics. New York: Scribner.

Chyung, Y., Winiecki, D.J., \& Fenner, J.A. (1998). A case study: Increase enrollment by reducing dropout rates in adult distance education. In Proceedings of the annual conference on distance teaching \& learning, Madison, WI. Retrieved on May 1, 2009 from http://www.eric.ed.gov/ERICDocs/data/ericdocs2sq1/content_storage_01/0000019b/80/1 5/bf/a9.pdf

Claxton, C.S., \& Ralston, Y. (1978). Learning styles. In C. S. Claxton and Y. Ralston (Eds.), Learning styles: their impact on teaching and administration. Washington: American Association for Higher Education.

Coffield, F., Moseley, D., Hall, E., \& Ecclestone, K. (2004). Learning styles and pedagogy in post-16 learning: a systematic and critical review of learning style models. London: Learning and Skills Research Centre. Retrieved on September 15, 2008 from http://www.lsda.org.uk/files/PDF/1543.pdf

Cook, R.G., Ley, K., Crawford, C., \& Warner, A. (2009). Motivators and inhibitors for university faculty in distance and e-learning. British Journal of Educational Technology, 40(1), 149-163.

Cooper, S. S. (2007). Life circles, Inc. Learning styles (Online). Retrieved from http://www.lifecircles-inc.com/learningstyles.htm

Cooze, M. \& Barbour, M. (2005). Learning styles: A focus upon e-learning practices and pedagogy and their implications for designing e-learning for secondary school students in Newfoundland and Labrador. Malaysian Online Journal of Instructional Technology, 2(1), 1-9. Retreived on June 2, 2008 from http://pppjj.usm.my/mojit/articles/pdf/April05/02-Michael\%20Barbour.pdf

Cross, K.P. (1993, February-March). Involving faculty in TQM. AACC Journal, 15-20.

CUP About Us (2005). Retrieved February 27, 2006 from http://www.cup.edu/aboutus/index.jsp?pageId=1580830010421122038136786

CUP Factsheet (2005). Retrieved September 28, 2005 from http://www.cup.edu/nu_upload/CALU_Fact_Sheet_copy1.pdf

Dabbagh, N. (2004). Distance learning: Emerging pedagogical issues and learning designs. The Quarterly Review of Distance Education, 5(1), 37-49. 
Damoense, M.Y. (2003). Online learning: Implications for effective learning for higher education in South Africa. Australian Journal of Educational Technology, 19(1), 25-45.

Daniel, J., Kanwar, A., \& Uvalić-Trumbić, S. (2009, Mar/Apr). Breaking higher education's iron triangle: Access, cost, and quality. Change, 41(2), 30-35.

Davidman, L. (1981, May). Learning styles: The myth, the panacea, the wisdom. Phi Delta Kappan, 641-646.

Davis, S.M. (2001, October). What e-learning can learn from history. USDLA Journal, 15(10). Retrieved February 18, 2009 from http://www.usdla.org/html/journal/OCT01_Issue/article01.html

De Jesus, H., Almeida, P., Teixeira-Dias, J., \& Watts, M. (2007, November). Where learners' questions meet modes of teaching: A study of cases. Research in Education, Retrieved September 19, 2008, from Academic Search Complete Database.

Della-Dora, D., \& Blanchard, J.L. (Eds.). (1979). Moving toward self-directed learning: Highlights of relevant research and promising practice. Alexandria, VA: Association for Supervision and Curricular Development.

Desai, M.S., Hart, J., \& Richards, T.C. (2008, December). E-learning: Paradigm shift in education. Education, 129(2), 327-334.

Diaz, D.P. (2000, March/April 2000). Carving a new path for distance education research. The Technology Source. Retrieved July 30, 2008 from http://horizon.unc.edu/TS/default.asp?show=article\&id=648

Diaz, D.P., \& Bontenbal, K.F. (2001, August). Learner Preferences: Developing a learner-centered environment in the online or mediated classroom. Education at a Distance, 15(8), Retrieved September 20, 2007, from http://www.usdla.org/html/journal/AUG01_Issue/article03.html

Diaz, D. P., \& Cartnal, R.B. (1999, Fall). Students' learning styles in two classes: Online distance learning and equivalent on-campus. College Teaching, 47(4), 130-135.

Distance Education and Training Council. (2007, June). 2007 Distance education survey: A report on course structure and educational services in distance education and training council member institutions. Fort Collins, CO: Weston Distance Learning.

Downing, K., \& Chim, T.M. (2004, September). Reflectors as online extraverts. Educational Studies, 30(3), 265-276.

Duffy, T.M., \& Jonassen, D.H. (1991). Constructivism: New implications for instructional technology? Educational Technology, 31(5), 7-11. 
Dunn, R., DeBello, T., Brennan, P., Krimsky, J., \& Murrain, P. (1981). Learning style researchers design differences differently. Educational Leadership, 38, 372-374.

Dunn, R. (2000). Capitalizing on college students' learning styles: Theory, practice, and research, in Practical Approaches to Using Learning Styles in Higher Education. Westport, CT: Bergin \& Garvey.

Dunn, R. (2003). Practical applications of the research. In R. Dunn and S. Griggs (eds). Synthesis of the Dunn and Dunn learning styles model research: who, what, when, where and so what - the Dunn and Dunn learning styles model and its theoretical cornerstone, 1-10. New York: St. John's University.

Dunn, R., \& Dunn, K.J. (1979). Learning styles/teaching styles: should they, can they, be matched? Educational Leadership, 36(4), 238-244.

Dunn, R., \& Dunn, K.J. (1992a). Teaching elementary students through their individual learning styles: Practical approaches for grades 3-6. Boston, MA: Allyn \& Bacon.

Dunn R., \& Dunn K.J. (1992b). Teaching secondary students through their individual learning styles. Needham Heights, MA: Allyn and Bacon.

Dunn, R.S., \& Griggs, S.A. (2000). Practical approaches to using learning styles in higher education. Westport, CT: Bergin \& Garvey.

Eaton, J.S. (2001). Distance Learning: Academic and Political Challenges for Higher Education Accreditation. CHEA Monograph Series, Number 1, online www.chea.org.

eCollege. (2008). Retrieved February 11, 2008 from http://www.ecollege.com/index.learn.

Entwistle, N. (1981). Styles of learning and teaching: an integrated outline of educational psychology. New York, NY: John Wiley \& Sons.

Fahy, P., \& Ally, M. (2005). Student learning style and asynchronous computer-mediated conferencing (CMC) interaction. The American Journal of Distance Education, 19, 5-23.

Falvo, D.A., \& Johnson, B.F. (2007, March/April). The use of learning management systems in the United States. Tech Trends, 51(2), 40-45.

Felder, R.M., \& Soloman, B.A. (n.d.). Learning styles and strategies. Retrieved on February 20, 2008 from http://www4.ncsu.edu/unity/lockers/users/f/felder/public/ILSdir/styles.htm

Ferrell, B.G. (1983). A factor analytic comparison of four learning-styles instruments. Journal of Educational Psychology, 75(1), 33-39. 
Fizzell, R. (1984, Spring). The status of learning styles. The Educational Forum, 48(3), 303312.

Ford, N., \& Chen, S. (2000) Individual differences, hypermedia navigation and learning: An empirical study. Journal of Educational Multimedia and Hypermedia, 9(4), 281-312.

Fuhrmann, B.S., \& Grasha, A.F. (1983). A practical handbook for college teachers. Boston: Little, Brown and Company.

Fuller, D., Rena, F.N., Pearce, K., \& Strand, S. (2000). Internet teaching by style: Profiling the online professor. Educational Technology \& Society, 3(2). Retrieved January 15, 2009 from http://www.ifets.info/journals/3_2/pearce.html

Gardiner, L.F. (1998). Why must we change: The research evidence. The NEA Higher Education Journal, 71-88.

Geiger, M.A., \& Pinto, J.K. (1991). Changes in learning style preferences during a three-year longitudinal study. Psychological Reports, 69, 755-762.

Githens, R.P., (2007, Winter). Older Adults and E-Learning: Opportunities and barriers. Quarterly Review of Distance Education, 8(4). 329-338.

Go Army Ed. (2010). Go Army Applicants. Retrieved February 20, 2010 from https://www.goarmyed.com/public/facility_pages/California_Univ_of_Pennsylvani/defau lt.asp

Gould, M., Padavano, D. (2006). 7 Ways to Improve Student Satisfaction in Online Courses. Distance Education Report, 10(11). 7.

Grasha, A.F. (1996). Teaching with style. Pittsburgh, PA: Alliance.

Grasha, A.F., \&Yangarber-Hicks, N. (2000). Integrating teaching styles and learning styles with instructional technology. College Teaching, 48(1), 2-10.

Gregorc, A. F., \& Ward, H. B. (1977, February). A new definition for individual. NASSP Bulletin, 61(406). 20-26.

Gregorc, A.F. (1979a). Learning/teaching styles: Potent forces behind them. Educational Leadership, 36(4), 234-236.

Gregorc, A. (1979b). Learning/teaching styles: Their nature and effects. In J. W. Keefe (Ed.) Student learning styles: diagnosing and prescribing programs. Reston, VA: National Association of Secondary School Principals.

Gregorc, A.F. (1982). Mind Styles Model: Theory, Principles, and Applications. Maynard, MA: Gabriel Systems 
Gregorc, A.F. (2009). Frequently asked questions on style. Retrieved July 2, 2009 from www.gregorc.com/faq.html

Guskin, A.E. (1994, September/October). Restructuring Faculty Work. Change, 16-25.

Harris, R.N., Dwyer, W.O., \& Leeming, F.C. (2003). Are learning styles relevant in web-based instruction? Journal of Educational Computing Research, 29(1), 13-28.

Haycock, K. (2003). Toward a fair distribution of teacher talent. Educational Leadership, $60(4), 11-15$.

HayGroup (n.d.). A shortguide to the way people learn and why it matters. Retrieved July 11, 2009 from http://www.haygroup.com/tl/Downloads/Why_People_Learn.pdf

HayGroup. (n.d.) FAQ/Help. Retrieved November 3, 2008 from http://www.haygroup.com/tl/Downloads/LSI_FAQs.pdf

HayGroup (n.d.). Kolb Learning Style Inventory 3.1. Retrieved December 8, 2008 from http://www.haygroup.com/t1/Questionnaires_Workbooks/Kolb_Learning_Style_Inventor y.aspx

Henry, P.D. (2008). Learning style and learner satisfaction in a course delivery context. Proceedings of World Academy of Science, Engineering and Technology, 28, 410-413.

Herrington, J. \& Standen, P. (2000). Moving from an instructivist to a constructivist multimedia learning environment. Journal of Educational Multimedia and Hypermedia, 9(3), 195-205.

Hills, H. (2003). Individual preferences in e-learning. Burlington, VT: Gower.

Hillstock, L.G. (2005). Innovative use of technology for online learning. Proceedings of the 2005 ASCUE Conference, June 12-16, 2005, Myrtle Beach, SC, 139-145. Retrieved June 9, 2009 from www.ascue.org

Hinkle, D.E., Wiersma, W., \& Jurs, S.G. (2003). Applied statistics for the behavioral science $\left(5^{\text {th }}\right.$ ed.). Boston: Houghton Mifflin Company.

Honey, P. \& Mumford, A. (1992). The manual of learning styles. Maidenhead, Berkshire, UK: Peter Honey Publications.

Honey, P. \& Mumford, A. (2000). Using your learning styles: 80 item version. Maidenhead, Berkshire, UK: Peter Honey Publications.

Honigsfeld, A. M. (2001). A comparative analysis of the learning styles of adolescents from diverse nations by age, gender, academic achievement level and nationality. Doctoral dissertation, Dissert Abstr Int, 62, 969. 
Honigsfeld, A., \& Dunn, R. (2006, Winter). Learning-style characteristics of adult learners. Delta Kappa Gamma Bulletin, 72(2), 14-31.

Horton, W. (2000). Designing web-based training: How to teach anyone anything anywhere anytime. New York: Wiley \& Sons.

Howell, S., Williams, P., \& Lindsay, N. (2003). Thirty-two trends affecting distance education: An informed foundation for strategic planning. Online Journal of Distance Learning Administration, 6(3), 1-18.

Howles, L., \& Jeong, A. (2009, April). Learning styles: What the research says and how to apply it to designing e-learning. Online Cl@ssroom, 1-4. Retrieved on May 2, 2009 from http://isg.urv.es/library/papers/learning\%20styles_overview.pdf

Huba, M.E., \& Freed, J.E. (2000). Learner-centered assessment on college campuses: shifting the focus from teaching to learning. Boston, MA: Allyn and Bacon.

Huebner, T.A. (2010, February). Differentiated instruction. Educational Leadership, 67(5), 7981.

Hunt, D.E. (1979). Learning style and student needs: An introduction to conceptual level. In Student learning styles: diagnosing and prescribing programs. Reston, VA: National Association of Secondary School Principals, 27-38.

Hussar. W.J. (2005). Projections of education statistics to 2014 (NCES 2005-074). U.S. Department of Education, National Center for Education Statistics. Washington, DC: U.S. Government Printing Office.

iTunes U. (2010). What is iTunes U? Retrieved March 15, 2010 from http://www.apple.com/education/itunes-u/what-is.html

Jackson, S.H. (2005, June 15). Lost in translation: Turning on-ground courses into effective web-based learning. Distance Education Report, p. 4, 7

James, W.B., \& Gardner, D.L. (1995, Fall). Learning styles: Implications for distance learning. New Directions for Adult and Continuing Education, 67, 20.

Janicki, T., \& Liegle, J.O. (2001). Development and evaluation of a framework for creating web-based learning modules: A pedagogical and systems perspective. Journal of Asynchronous Learning Networks, 5(1), 58-84.

Joint Task Force on Student Learning. (1998). Learning principles and collaborative action. Washington, DC: American Association for Higher Education.

Jonassen, D.H. \& Grabowski, B.L. (1993). Handbook of individual differences, learning, and instruction. Hillsdale, NJ: Lawrence Erlbaum Associates. 
Kain, D.J. (2003, Winter). Teacher-centered versus student-centered: Balancing constraint and theory in the composition classroom. Pedagogy, 3(1), 104-108.

Kanuka, H. (2002). Guiding principles for facilitating higher levels of web-based distance teaching and learning in post-secondary settings. Distance Education, 23(2), 163-182.

Karber, D.J. (2003). Comparisons and contrasts in traditional versus on-line teaching in management. Higher Education in Europe, 26, 533-536.

Kayes, D.C. (2005, Winter). Internal validity and reliability of Kolb's Learning Style Inventory Version 3 (1999). Journal of Business and Psychology, 20(2), 249-257.

Kazu, I.Y. (2009). The effect of learning styles on education and the teaching process. Journal of Social Sciences, 5(2). 85-94.

Kearsley, G. (2000). Online education: Learning and teaching in cyberspace. Toronto: Wadsworth.

Keefe, J.W. (1982). Assessing student learning styles: An overview. In Student learning styles and brain behavior. Reston, VA: National Association of Secondary School Principals, 43-53.

Keri, G. (2002-2003). Traditional and nontraditional students' learning styles: Using Canfield's Learning Style Inventory. Perspectives: The New Your Journal of Adult Learning, 1(2), 29-38.

Khan, B. H. (2005). Managing e-learning: Design, delivery, implementation and evaluation. Hershey: Information Science.

King, F.B., Young, M.F., Drivere-Richmond, K., \& Schrader, P.G. (2001). Defining distance learning and distance education. Educational Technology Review, 9(1), 1-14. Norfolk, VA: AACE.

Kirby, P. (1979). Cognitive style, learning style, and transfer skill acquisition. Columbus, OH: National Center for Research in Vocational Education.

Kirkwood, A., \& Price, L. (2005). Learners and learning in the twenty-first century: What do we know about students' attitudes towards and experiences of information and communication technologies that will help us design courses? Studies in Higher Education, 30(3), 257-274. 
Klopfer, E., Osterweil, S., Groff, J., \& Haas, J. (2009). Using the technology of today, in the classroom of today: The instructional power of digital games, social networking, simulations and how teachers can leverage them. The Education Arcade: MIT. Retrieved March 15, 2010 from http://education.mit.edu/papers/GamesSimsSocNets_EdArcade.pdf

Kolb, D. A. (1971). Individual learning styles and the learning process. Working Paper \#535-71, Sloan School of Management, Massachusetts Institute of Technology.

Kolb, D. A., (1976). Learning style inventory. Boston: McBer and Company.

Kolb, D. A. (1981). Experiential learning theory and the learning style inventory: A reply to Feedman and Stumpf. Academy of Management Review, 6, 289-296.

Kolb, D.A. (1984). Experiential learning: experience as the source of learning and development. Englewood Cliffs, NJ: Prentice Hall.

Kolb, D. A. (1985). Learning Style Inventory: Technical Manual. Boston, MA: Hay Group, Hay Resources Direct.

Kolb, D. A. (1999). Learning Style Inventory, Version 3: Technical specifications. Boston, MA: Hay Group, Hay Resources Direct.

Kolb, D. (2000). Learning places: Building dwelling thinking online. Journal of Philosophy of Education Society of Great Britain, 34(1), 121-133.

Kolb, A.Y., \& Kolb, D. A. (2005). The Kolb Learning Style Inventory - version 3.12005 : Technical Specifications. Boston, MA: Hay Group, Hay Resources Direct.

Laurillard, D. (2001). Rethinking university teaching: A framework for the effective use of educational technology. London: Routledge.

Lawrence, G.D. (1993). People types and tiger stripes: A practical guide to learning styles. ( $3^{\text {rd }}$ ed.). Gainesville, Florida: Center for Application of Psychological Type, Inc.

Leigle, J.O., \& Janicki, T.N. (2006). The effect of learning styles on the navigation needs of web-based learners. Computers in Human Behavior, 22, 885-898.

Levy, Y. (2007). Comparing dropout and persistence in e-learning courses. Computers and Education, 48, 185-204.

Li, C. \& Irby, B. (2008, June). An overview of online education: Attractiveness, benefits, challenges, concerns and recommendations. College Student Journal, A42(2). Retrieved 
Academic Search Complete February 6, 2009.

Lifelong. (2002, April). Lifelong Learning Trends: A Profile of Continuing Higher Education. 7th Edition. Washington, DC: University Continuing Education Association.

Little, L. (2004, August). Kolb's learning styles for leaders. Administrator, 8.

Liu, Y. (2007). A comparative study of learning styles between online and traditional students. Journal of Educational Computing Research, 37(1), 41-63.

Loo, R. (1996). Construct validity and classification stability of the revised learning style inventory (LSI-1985). Educational and Psychological Measurement, 56, 529-536.

Lovelace, P. (1999). CUNA explores web-based learning. Credit Union Magazine, 65(2), 29-30.

Lu, H., \& Chiou, M. (2010). The impact of individual differences on e-learning system satisfaction: A contingency approach. British Journal of Educational Technology, 41(2). 307-323.

Lyons, J.F. (2004). Teaching U.S. history online: Problems and prospects. The History Teacher, 37, 447-456.

Mahoney, J. (2006). Do you feel like you belong? An on-line versus face-to-face pilot study. Visions: The Journal of Rogerian Nursing Science, 14(1), 16-26.

Manochehri, N., \& Young, J.I. (2006). The impact of student learning styles with webbased learning or instructor-based learning on student knowledge and satisfaction. The Quarterly Review of Distance Education, 7(3), 313-316.

Mason, R., \& Weller, M. (2000). Factors affecting students' satisfaction on a web course. Australian Journal of Educational Technology, 16(2), 173-200.

McCombs, B.L. (2001). What do we know about learners and learning? The learnercentered framework: Bringing the education system into balance. Educational Horizons, 79(4), 182-193.

McDermott, P. \& Beitman, B. (1984). Standardization of a scale for the study of children's learning styles: Structure, stability, and criterion validity. Psychology in the Schools, 21, 5-14.

Messick, S. (1987). Structural relationships across cognition, personality, and style. In N.J. Farr (Ed.), Aptitude, learning, and instruction (p. 35-75). Hillsdale, NJ: Lawrence Erlbaum Associates.

Miller, D.C. (1977). Handbook of research design and social measurement ( $3^{\text {rd }}$ ed.). New 
York: David McKay company, Inc.

Miller, G.E. (2001). General education and distance education: Two channels in the new mainstream. The Journal of General Education, 50(4), 314-322.

Miller, T.W., \& King, F.B. (2003, July-September). Distance education: Pedagogy and best practices in the new millennium. International Journal of Leadership in Education, 6(3), 283-297.

Moallem, M. (2007-2008, Winter). Accommodating individual differences in the design of online learning environments: A comparative study. Journal of Research on Technology in Education, 40(2), 217-245.

Moller, L., Forshay, W.R., \& Huett, J. (2008, May). The evolution of distance education: Implications for instructional design on the potential of the web. Tech Trends: Linking Research \& Practice to Improve Learning, 52(3), 70-75.

Moore, M.G., \& Kearsley, G. (2005). Distance education: A systems view, (2nd Ed.). Belmont, CA: Thomson Wadsworth.

Mupinga, D.M., Nora, R.T., \& Yaw, D.C. (2006). The learning styles, expectations, and needs of online students. College Teaching, 54 (1), 185-189.

Neuhauser, C. (2002). Learning style and effectiveness of online and face-to-face instruction. The American Journal of Distance Education, 16(2), 99-113.

Norman, D. T. (1993). Things that make us smart: Defending human attributes in the age of the machine. Reading, MA: Addison-Wesley.

NSSE. (2009). Benchmarks of effective educational practice. Retrieved September 5, 2009 from http://nsse.iub.edu/pdf/nsse_benchmarks.pdf

Olgren, C. H. (1998). Improving learning outcomes: The effects of learning strategies and motivation. In C. Gibson (Ed.) Distance learners in higher education: institutional responses for quality outcomes. Madison, WI: Atwood.

Parker, A. (2003, January). Identifying predictors of academic persistence in distance education. USDLA Journal, 17(1). Retrieved January 4, 2009 from http://www.usdla.org/html/journal/JAN03_Issue/article06.html

PASSHE (2005). Retrieved February 27, 2006 from http://www.passhe.edu http://www.passhe.edu/universities/Pages/UniversityDetails.aspx?q=California

Perraton, H. (1988). A theory for distance education. In D. Sewart, D. Keegan, \& B. Holmberg (Eds.), Distance education: International perspectives (pp. 34-45). New York: Routledge. 
Pinto, J.K., Marshall, A.G., \& Boyle, E.J. (1994). A three-year longitudinal study of changes in student learning styles. Journal of College Student Development, 35, 113 119.

Price, L. (2004, October). Individual differences in learning: Cognitive control, cognitive style, and learning style. Educational Psychology, 24(5), 681-698.

Rabe-Hemp, C., Woollen, S., \& Humiston, G.S. (2009, Summer). A comparative analysis of student engagement, learning, and satisfaction in lecture hall and online learning settings. Quarterly Review of Distance Education, 10(2). 207-218.

Rassool, G.H., \& Rawaf, S. (2007). Learning style preferences of undergraduate nursing students. Nursing Standard, 21(32), 35-41.

Raymayha, M., Sivanandan, P., Nasrijal, N.H., Letchumanan, T., \& Lim, C.L. (2009, August). Preferred learning style: Gender influence on preferred learning style among business students. Journal of US-China Public Administration, 6(4), 65-78.

Reeves, T.C. (1993). Interactive learning systems as mindtools. In P. Newhouse (Ed.), Viewpoints 2, 2-11. Perth: Educational Computing Association of Western Australia.

Ritter, M.E., \& Lemke, K.A. (2000). Addressing the 'seven principles for good practice in undergraduate education' with internet-enhanced education. Journal of Geography in Higher Education, 24(1), 100-108.

Rock, M., Gregg, M., Ellis, E., \& Gable, R.A. (2008). REACH: a framework for differentiating classroom instruction. Preventing School Failure, 52(2), 31-47.

Sachs, D., \& Hale, N. (2003). Pace university's focus on student satisfaction with student services in online education. Journal of Asynchronous Learning Networks, 7(2), 36-42.

Sahin, S. (2008, January). The relationship between student characteristics including learning styles, and their perceptions and satisfaction in web-based courses in higher education. Turkish Online Journal of Distance Education, 9(1), 123-138.

Salmi, J. (2000). Tertiary Education in the Twenty-First Century: Challenges and Opportunities. Washington DC: The World Bank.

Sansone, C., Morf, C.C., \& Panter, A.T. (2004). The Sage handbook of methods in social psychology. Thousand Oaks, CA: Sage.

Scagnoli, N. (2001) Student orientations for online programs. Journal of Research on Technology in Education, 34(1), 19-27. 
Schwitzer, A. M., Ancis, J. R., \& Brown, N. (2001). Promoting student learning and student development at a distance. Lanham, MD: American College Personnel Association.

Servonsky, E.J., Daniels, W.L., \& Davis, B.L. (2005, Nov/Dec). Evaluation of Blackboard"M as a platform for distance education delivery. ABNF Journal, 132-135.

Sherry, L. (1996). Issues in distance learning. International Journal of Educational Telcommunications, 1(4), 337-365.

Shieh, R.S., Gummer, E., \& Niess, M. (2008, November/December). The quality of a webbased course: Perspective of the instructor and the students. TechTrends, 52(6), 61-68.

Smith, D., \& Kolb, D.A. (1996). Users guide for the learning style inventory: A manual for teachers and trainers. Boston: McBer and Company.

Speth, C.A., Lee, D.J., \& Hain, P.M. (2006). Prioritizing improvements in internet instruction based on learning styles and strategies. Journal of Natural Resources \& Life Sciences Education, 35, 34-41.

Stella, A., \& Gnanam, A. (2004, March). Quality assurance in distance education: The challenges to be addressed. Higher Education, 47(2), 143-160.

Stroh, H.L. \& Sink, C.A. (2002). Applying APA's learning-centered principles to school-based group counseling. Professional School Counseling, 6(1), 71-78.

Squires, G. (1981). Cognitive styles and adult learning. Nottingham, UK: University of Nottingham.

Suskie, L.A. (1996). Questionnaire survey research: What works ( $2^{\text {nd }}$ ed.). Tallahassee, FL: Association for Institutional Research

Swindell, R., \& Thompson, J. (2000, September 14-16). Interactive online courses by and for older people. Paper presented at the XXth Congress of the International Association of Universities of the Third Age, Quebec, Canada.

Tagg, J. (2003). The learning paradigm college. Boston, MA: Anker Publishing Co.

Taylor, J.C. (2001, June). Fifth generation distance education. Higher Education Series, Report No. 40. Australia Department of Education, Training and Youth Affairs: Higher Education Division. Retrieved May 19, 2009, from http://www.dest.gov.au/archive/highered/hes/hes40/hes40.pdf

Thompson, M.M. (1998). Distance learners in higher education. In C. Gibson (Ed.), Distance learners in higher education: Institutional responses for quality outcomes (pp. 9-24). Madison, Wisconsin: Atwood. 
Trachtenberg, J.A., \& Kane, Y.I. (2010, February 2). Text book firms ink e-deals for iPad. The Wall Street Journal. Retrieved from http://online.wsj.com/article/SB10001424052748703338504575041630390346178.html

Truluck, J.E., \& Courtenay, B.C. (1999, Apr/May). Learning style preferences among older adults. Educational Gerontology, 25(3), 221-236.

Tucker, S. (2001). Distance education: Better, worse, or as good as traditional education? Journal of Distance Learning Administration, 4 (4). Retrieved from May 24, 2009 from http://www.westga.edu/ distance/ojdla/winter44/tucker44.html

Tuckman, B. W. (1972) Conducting Educational Research. New York: Holt, Rinehart \& Winston.

Tyler, R. W. (1986, December/1987, January). The five most significant curriculum events in the twentieth century. Educational Leadership, 44(4), 36-38.

U.S. Department of Education, National Center for Education Statistics. (2008). Distance Education at Degree-Granting Postsecondary Institutions: 2006-07.

Retrieved May, 5, 2009 from http://nces.ed.gov/pubsearch/pubsinfo.asp?pubid=2009044

Vafa, S. (2004). Learning style preferences among online university students. In C.

Crawford et al. (Eds.), Proceedings of Society for Information Technology and Teacher Education International Conference 2004 (pp. 736-739). Chesapeake, VA: AACE.

VanBiervliet, A. (2004). E-learning and an aging population: Research review and future directions. In proceedings of world conference on elearning in corporate, government, healthcare, and higher education (pp. 2200-2205). Norfolk,VA: Association for the Advancement of Computing in Education.

Veres, J.G., Sims, R.R., \& Locklear, T.S. (1991). Improving the reliability of Kolb's revised learning style inventory. Educational and Psychological Measurement, 51, 143-150.

Villaverde, J.E., Godoy, D. \& Amandi, A. (2006). Learning styles' recognition in elearning environments with feed-forward neural networks. Journal of Computer Assisted Learning, 22, 197-206.

Walker, S. L. (2005). Development of the Distance Education Learning Environments Survey (DELES) for higher education. The Texas Journal of Distance Learning, 2(1), 1-16.

Walker, C.E., \& Kelly, E. (2007). Online instruction: Student satisfaction, kudos, and pet peeves. The Quarterly Review of Distance Education, 8(4), 309-319.

Wang, X.C., Hinn, D.M., \& Kanfer, A.G. (2001). Potential of computer-supported collaborative learning for learners with different learning styles. Journal of Research on Technology in 
Education, 34(1), 75-85.

Wang, K.H., Wang, T.H., Wang, W.L., \& Huang, S.C. (2006). Learning styles and formative assessment strategy: Enhancing student achievement in web-based learning. Journal of Computer Assisted Learning, 22, 207-217.

Weimer, R.C. (1993). Statistics ( $2^{\text {nd }}$ ed.). Dubuque, IA: Wm. C. Brown Publishers.

Weinstein, C. E., Palmer, D. R., \& Schulte, A. C. (1987). LASSI: Learning and Study Strategies Inventory. Clearwater, FL: H\&H Publishing.

Wilson, B.G. (2002, Spring). Trends and futures of education: Implications for distance education. Quarterly Review of Distance Education, 3(1), 91-103.

Wickersham, L.E., Espinoza, S., \& Davis, J. (2007). Teaching online: Three perspectives, three approaches. AACE Journal, 15(2), 197-211.

Yeganeh, B., \& Kolb, D. (2009, Summer). Mindfulness and experiential learning. $O D$ Practitioner, 41(3), 13-18.

Zhang, Y. (2005). Distance learning receptivity: Are they ready yet? The Quarterly Review of Distance Education, 6(1) 45-53.

Zhao, F. (2003). Enhancing the quality of online higher education through measurement. Quarterly Assurance in Education, 11(4). 214-221. 


\section{APPENDIX A}

Demographic Questions

Please answer the following demographic questions to the best of your ability:

1. What is your academic program? Sport Management Studies or Other

2. How would you best be classified? Primarily on-campus face-to-face students or Primarily online web-based student

3. What is your gender? Male or Female

4. What is your age category? Traditional (18-24 years of age) or Nontraditional (25 year or older)

5. What is your residence status? On-campus or Off-campus

6. What is your ethnic affiliation? African American/Black, Asian American/Pacific Islander, Hispanic American/Latino/Chicano, Native American/Tribal Affiliation, White/Caucasian/European American, Multi-Racial, other, don't know, or prefer not to answer

7. What is your student status? Full-time ( 12 credits or more) or Part-time (less than 12 credits)

8. What is your level of academic standing? : Freshman (0-29 total credits), Sophomore (30-59 total credits), Junior (60-89 total credits), and Senior (90+ total credits). (Cal U Undergraduate Catalog, 2009) 


\section{APPENDIX B}

\section{Satisfaction Questions}

$(5=$ very satisfied, $4=$ satisfied, $3=$ neutral, $2=$ dissatisfied, $1=$ very dissatisfied $)$

21. How satisfied are you with the challenge and demand of your Sport Management Studies courses?

22. How satisfied are you with the Sport Management Studies major setting high expectations for student performance?

23. How satisfied are you with Sport Management Studies offering a variety of learning experiences and group interactions which promote critical thinking and analysis?

24. How satisfied are you in the program with finding connections between what you are learning in the classroom, relating it to your past experiences, and applying it to your daily life?

25. How satisfied are you with the accessibility of your instructor (ie., by email, phone, office hours, appointment, etc.)?

26. How satisfied are you with the interaction and rapport between Sport Management Studies faculty and students?

27. How satisfied are you with the quality of your academic experience within your program?

28. How satisfied are you with the opportunities to learn multicultural and global perspectives?

29. How satisfied are you with the program being warm, friendly, and supportive of students?

30. How satisfied are you with your sense of belonging within your program? 
Learning Styles Traditional and Online 165

\section{APPENDIX C}

Letter to request institutional site approval and pilot approval

(on WVU letterhead)

Prof. Jeffrey R. Hatton, MS, OTC

Department Chair, Exercise Science and Sport Studies

California University of Pennsylvania

California, PA 15419

Dear Prof. Hatton,

My name is Ellen J. West and I am a doctoral candidate in Educational Leadership Studies at West Virginia University. Thank you for your assistance in obtaining permission to conduct research at your institution as part of my dissertation study, Differences in Learning Styles Between Traditional Face-to-Face and Online Web-Based Sport Management Studies Students Based on Kolb's Learning Style Inventory, $3^{\text {rd }}$ Edition. The purpose of this letter is to inform you of the required steps involved in gaining written permission to conduct my research on your campus using Sport Management Studies undergraduate students as my population.

The purpose of my study is to identify and compare the prevalence of learning styles among undergraduate Sport Management Studies students at California University of Pennsylvania. Learning styles will be assessed utilizing Kolb's Learning Style Inventory, $3^{\text {rd }}$ Edition (KLSI 3.1). Learning style prevalence will be determined for traditional face-to-face students and online web-based students. Differences in learning style prevalence between these two groups will be explored. Finally, differences in student satisfaction between programs (online and faceto-face) will be examined.

Colleges and universities will need to implement changes to meet the advancement of the technological revolution at hand. By recognizing differing student learning styles, faculty may seek to employ different pedagogical approaches. As educators (virtual and live) are faced with an increasingly diverse population of learners with a wide range of expectations, there is a need to continually seek to understand what factors constitute excellent delivery to promote effective learning. Faculty may not always utilize the best delivery method attuned to students' differing learning styles. By understanding different students' learning styles, faculty may seek to employ different pedagogical approaches to better facilitate learning.

Specifically, I am writing to secure permission to solicit and conduct a pilot study with 4-6 of your department's students (other than Sport Management Studies). Students will be asked to participate in an online survey and then do a brief follow-up interview. Results of this pilot study will be important to assure the quality of my instrument and data collection. Additionally, I am writing to secure permission to solicit and conduct an online survey of all students within your Sport Management Studies undergraduate programs. Upon your approval, I am asking for you to supply a list of students, including email addresses, within the program. Additionally, I seek permission to use the name of the program and institution within my dissertation document. 
In order for me to conduct my research, I am required to gain approval from West Virginia University's Institutional Review Board and California University of Pennsylvania's Institutional Review Board. In order to gain such approval, I am required to submit a letter from you granting permission for me to solicit pilot-study participants from undergraduate students within your department, solicit participants from within your Sport Management Studies traditional and online programs, conduct research, identify the population by program, and identify the institution where the research will be conducted. It is important for me to emphasize that interview participation will be entirely voluntary. Also, I want to assure you that all responses will remain entirely anonymous, and confidentiality will be maintained throughout the collection and reporting process.

I am attaching a template letter of approval letter, which you may alter as you see fit, and then copy to your institution's letterhead. Upon your request, I can email the template to you as well. If you decide to allow your institution to participate, I ask that you forward me a letter of approval by October 18, 2009. For your convenience, I have enclosed a postage-paid envelope.

In closing, I want to reassure you that the results of this study will be used specifically for my dissertation and I will follow all IRB policies. I realize that study participation is entirely voluntary, and participants do not have to respond to every question. Additionally, I assure you that participant responses will remain entirely anonymous, and confidentiality will be maintained throughout the collection and reporting process.

Should you have any questions or concerns, please contact me via telephone at 724-938-4356 or via email at west_e@calu.edu.

Sincerely,

Ellen J. West, MS, ATC

Doctoral Student

West Virginia University 


\section{APPENDIX D}

Letter from institution granting permission for pilot and research

(On letterhead from case study institution)

Date:

Ms. Ellen J. West

646 Rosewood St.

Belle Vernon, PA 15012

Dear Ellen:

I am writing to offer my support for your pilot-study and dissertation research, Differences in Learning Styles Between Traditional Face-to-Face and Online Web-Based Sport Management Studies Students Based on Kolb's Learning Style Inventory, $3^{\text {rd }}$ Edition, at California University of Pennsylvania.

I am aware that you will need to solicit participation and conduct research for your pilot-study from 4-6 undergraduate students within my department. Additionally, you will solicit participation from my "official" Sport Management Studies students for your online survey, during the 2009 - 2010 academic year. I understand that you will be provided with program email addresses of the students. Each online survey will last for approximately 10-20 minutes. Furthermore, permission is granted to use the institution's name and program's title for identification and reference in the dissertation documentation.

Since you are seeking formal approval from West Virginia University's Institutional Review Board for the Protection of Human Subjects and California University of Pennsylvania's Institutional Review Board, I realize you will have agreed to emphasize that survey participation is entirely voluntary, and participants do not have to respond to every question. Additionally, please remind participants that their responses will remain entirely anonymous, confidentiality will be maintained throughout the collection and reporting process, and their academic status will not be affected by refusing to participate.

Thank you for seeking my approval for this dissertation project.

Sincerely,

Jeffrey R. Hatton, MS, OTR/L

Chair, Department of Exercise Science and Sport Studies 
Learning Styles Traditional and Online 168

\section{APPENDIX E}

Pilot Invitation Letter

Participant Invitation Letter (On WVU letterhead)

Date:

Dear Participant:

My name is Ellen West, and I am a West Virginia University doctoral student and Cal U professor who is exploring differences in learning styles between traditional face-to-face and online web-based Sport Management Studies students at California University of Pennsylvania. My intent is to pilot my dissertation study and I would like for you to participate in this study. This research is being conducted to fulfill the requirements for a doctoral dissertation in Educational Leadership Studies in the Department of Advanced Educational Studies at West Virginia University, under the supervision of Dr. Elizabeth A. Jones.

During the fall 2009 semester, I will pilot my survey with 4-6 Health Science and/or Exercise Science students at California University of Pennsylvania. I will be conducting an online survey accessed from your computer or the computer lab. The survey will take approximately 15 minutes of your time and will be comprised of the following three survey components (each with 12 questions or less): 1) Demographic information, 2) Learning Style Inventory, and 3) Student Satisfaction. I will then ask you a series of brief follow-up questions.

It is important to emphasize that this survey, its results, and your responses will remain anonymous. Your name or any other information that may identify you will not be released in the reported results and all responses will remain confidential. In any publications that result from this research, neither your name nor any information from which you might be identified will be published. Moreover, your participation is entirely voluntary, and you do not have to respond to every question I ask, and your academic status will not be affected by refusing to participate. Additionally, please note that there is no known or expected risks from participating in this study, except for the mild frustration possibly associated with answering the questions. You may not receive any direct benefit from this study and the knowledge gained from this study may eventually benefit others in their future research efforts.

If you agree to participate in this study, please contact me as soon as possible to make arrangements for a survey and interview time. Should you have any questions or concerns, please contact me via telephone at 724-938-4356 or via email at west_e@calu.edu.

Sincerely,

Ellen J. West, MS, ATC, Doctoral Student West Virginia University 


\section{APPENDIX F}

Cover letter for Program Directors participating in study

Date

Address

Dear Dr. Roy Yarborough or Professor Jeffrey Hatton:

Thank you very much for agreeing to serve as a liaison for my dissertation study project, Differences in learning styles between traditional face-to-face and online web-based Sport Management Studies students based on Kolb's Learning Style Inventory, $3^{\text {rd }}$ Edition. I really appreciate your willingness to assist me in the coordination of my surveys.

As a reminder, I have received approval from West Virginia University's Institutional Review Board (IRB) for the Protection of Human Subjects to conduct this study. Therefore, it is important for me to emphasize that interview participants will not be identified and results and all responses will remain confidential.

Included with this letter, you will find a copy of my cover letter asking your students for participation. Additionally, you will see the (insert motivation/rewards here) and the (link to the survey) necessary for participation in the study. Please share with those individuals you have identified as possible interview participants (all "official" Sport Management Studies students).

Also, by participating in the survey, your students will be eligible to win prizes in a free giveaway! Prizes will include an iTouch ${ }^{\mathrm{TM}}$ and two iPod ${ }^{\mathrm{TM}}$ shuffles.

I cannot stress to you how much I appreciate your institution's willingness to support my research and your eagerness to assist me with my survey. If you would like a copy of my research results, I will gladly provide them to you.

Should you have any questions or concerns, please contact me via telephone at 724-938-4356 or via email at west_e@calu.edu.

Sincerely,

Ellen J. West, MS, ATC

Doctoral Student

West Virginia University 
Learning Styles Traditional and Online 170

\section{APPENDIX G}

Student Participant Invitation Letter

Date:

Dear Sport Management Studies student,

This letter is a request for you to take part in a research project to explore differences in learning styles between traditional face-to-face and online web-based Sport Management Exercise Science and Sport Studies students at California University of Pennsylvania (Cal U). My intent is to conduct a study that discovers learning styles and satisfaction among students, and I would like for you to participate in my study. This project is being conducted by Ellen J. West, MS, ATC, a West Virginia University student and Cal U faculty member with supervision of Dr. Elizabeth A. Jones, a Professor in the College of Human Resources and Education, for a Doctoral degree in Educational Leadership Studies. I am also conducting this research with the approval of Mr. Jeffrey R. Hatton, MS, OTR, Chair of the Department of Exercise Science and Sport Studies at Cal U. Your participation in this project is greatly appreciated.

Your involvement in this project will be kept as confidential as legally possible. All data will be reported in the aggregate. You must be 18 years of age or older to participate. I will not ask any information that should lead back to your identity as a participant. Your participation is completely voluntary. You may skip any question that you do not wish to answer and you may discontinue at any time. Your class standing will not be affected if you decide either not to participate or to withdraw. West Virginia University's Institutional Review Board acknowledgement of this project is on file.

I will be conducting an online survey that can be taken at your convenience at any computer with an Internet connection. The survey will take approximately 10-20 minutes of your time and will be comprised of the following three survey components (each with 12 questions or less):

1. Demographic information

2. Learning Style Inventory, and

3. Student Satisfaction

It is important to emphasize that this is not a performance evaluation. Your name or any other information that may identify you will not be released in the reported results and all responses will remain confidential. In any publications that result from this research, neither your name nor any information from which you might be identified will be published.

Additionally, please note that there is no known or expected risks from participating in this study, except for the possible inconvenience of taking the online survey. You may not receive any direct benefit from this study and the knowledge gained from this study may eventually benefit others in their future research efforts. 
By completing the online survey, you can choose to be entered in a drawing for prizes. You may be a winner of an iPod Touch ${ }^{\mathrm{TM}}$ or one of two iPod Shuffles ${ }^{\mathrm{TM}}$. You could be a prize winner!!!

By clicking on the following link (insert link here), you will be agreeing to participate in this study and you will be automatically directed to the survey instrument.

I hope that you will participate in this research project, as it could be beneficial in understanding the learning styles and satisfaction of traditional face-to-face and online web-based Sport Management Students at Cal U. Thank you very much for your time. Should you have any questions about this letter or the research project, please feel free to contact Ellen West at 724-938-4356 or by email at west_e@calu.edu. Thank you for your time and help with this project.

Sincerely,

Ellen J. West, MS, ATC

Doctoral Student

West Virginia University 


\section{APPENDIX H}

\section{Approval for LSI Use}

-----Original Message--..-

From: Jessica Menendez [mailto:Jessica.Menendezẹaygroup.com]

Sent: Friday, September 04, 2009 12:59 PM

To: West, Ellen

Subject: Congratulations! LSI Research Approval

Congratulations! Your research-request regarding use of the Learning Style Inventory (LSI) has been approved. Attached you will find one document containing three pages (.pdf file--Adobe Acrobat 4.05):

* MCB200C - This is a copy of the LSI test. You may print or copy this document as needed for your research.

* MCB200D - The profile sheet contains the answer key for the test as well as the profiling graphs for plotting scores. This document may also be reproduced as necessary for your research. The AC-CE score on the Learning Style Type Grid is obtained by subtracting the CE score from the $A C$ score.

Similarly, the AE-RO score $=A E$ minus RO.

These files are for data collection only. This permission does not extend to including a copy of these files in your research paper. It should be sufficient to source it.

We wish you luck with your project and look forward to hearing about your results. Please email a copy of your completed research paper to Jessica MenendezaHaygroup.com or mail it to the following address:

LSI Research Contracts

c/o Jessica Menendez

HayGroup

116 Huntington Avenue, 4th floor

Boston, MA 02116

If you have any further questions, please let me know.

Regards,

Jessica L. Menendez

Hay Group Transforming Learning

116 Huntington Avenue

Boston, MA 02116

(617) 927-5026 (DD)

(617) 927-5008 (F)

WWw. haygroup. com/TL 


\section{APPENDIX I}

\section{Cover letter for SurveyMonkey}

Hello, my name is Ellen West and I am a doctoral student at West Virginia University, majoring in higher educational leadership. First, I want to thank you for agreeing to participate in my dissertation project which is exploring the prevalence of learning styles among undergraduate Sport Management Studies students at California University of Pennsylvania. Learning styles will be assessed utilizing Kolb's Learning Style Inventory, $3{ }^{\text {rd }}$ Edition (LSI-3.1). Learning style prevalence will be determined for traditional face-to-face students and online web-based students. Differences in learning style prevalence between these two groups will be explored. Finally, differences in student satisfaction between majors will be examined. Through the survey of students like you, I hope to help academic administrators better understand the needs of their students and better develop or structure teaching methods in both on-campus and webbased instruction.

I have received from both West Virginia University's Institutional Review Board for the Protection of Human Subjects and California University of Pennsylvania's Institutional Review Board, approval to conduct this dissertation study; hence, I want to point out a few things before we begin. First of all, your participation is entirely voluntary, and you do not have to respond to every question. I also want to assure you that your will responses will remain entirely anonymous, and confidentiality will be maintained throughout the collection and reporting process. Additionally, I want to assure you that your academic status will not be affected by refusing to participate.

By completing this study, you will be eligible to win iPod Touch ${ }^{\mathrm{TM}}$ or one of two iPod Shuffles ${ }^{\mathrm{TM}}$. You will be asked to enter your email address at the end of the survey for a freedrawing. Winners will be contacted by email. Your email address will not be connected to your survey in any way and will be discarded from the survey once the drawings have been completed.

Should you have any questions or concerns, please contact me via telephone at 724-9384356 or via email at west_e@calu.edu.

Sincerely,

Ellen J. West, MS, ATC

Doctoral Student, West Virginia University

Associate Professor, California University of Pennsylvania

\section{John H.

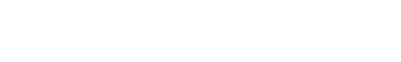

